JAHRESBERICHT 2003

DES ÖSTERREICHISCHEN ARCHÄOLGISCHEN INSTITUTS 
Für den Inhalt verantwortlich

Redaktion
Friedrich KRINZINGER

Maria Aurenhammer (Ephesos)

Barbara BRANDT

Gudrun WLACH 


\section{ZENTRALE WIEN}

\section{Personal}

Direktor: o. Univ.-Prof. Dr. Friedrich KRINZINGER

wissenschaftliches Personal im Bundesdienst

Dr. Maria Aurenhammer
Mag. Barbara Brandt (tlw. Elternkarenz)
Univ.-Doz. Dr. Stefan Groh
Dr. Karl Herold
Dr. Manfred KandLER (stv. Dir.)
tit. ao. Univ.-Prof. Dr. Stefan KARwiese

wissenschaftliches Personal mit Dienstverträgen
Dr. Michael Kerschner

Univ.-Doz. Dr. Ulrike Muss

Dr. Helga Sedlmayer

Dr. Peter SCHERrer

DI Gilbert WipLINGER

Dr. Heinrich ZabeHLICKY
Dr. Anita Giuliani
Dr. Andreas Pülz
Mag. Fabian Kanz
Dr. Martin STESKAL
Dr. Gudrun KLebinder-Gauss
Dr. Elisabeth TRINKL
DI Martino La TorRe
Mag. Klaus VondroveC
Mag. Volker Lindinger
Mag. Jasmine WAGNER
Univ.-Doz. Dr. Thomas Marksteiner
Dr. Michael WeIsSL
Dr. Şule Pfeiffer-TAş
Dr. Gudrun WLACH (auch Karenzvertretung)

allgemeine Bedienstete

Dr. Isabella BENDA-WeBer

Maria BODZENTA

Mag. Katharina HAsITZKA

Angela KLEES

Ulrike LANG
Gerlinde MAYER

Mag. Paul Pingitzer

Mag. Ronald RisY

Johanna SCHIELE

\section{FeldForschungsprojeKte}

Das Österreichische Archäologische Institut betreibt seit seiner Gründung archäologische Feldforschungen im In- und Ausland, die oftmals in Zusammenarbeit mit anderen Instituten der öffentlichen Hand organisiert sind.

\section{Bruckneudorf (Burgenland)}

Mit einer wieder durch eine Spende finanzierten Kampagne vom 30. Juni bis 29. August 2003 konnten die Grabungen im Inneren des Hauptgebäudes der Villa unter der Leitung von H. ZABEHLickY abgeschlossen werden. S. ZABEHLiCKY-SCHEFFENEGger hat wochenweise die Aufnahme der Kleinfunde fortgeführt. Als Praktikanten haben Student(inn)en der Universitäten Trnava (Z. HergoviTsová, K. Kytnarová, A. Lamprecht, Z. Majercíková, M. Putera, D. Ruman), Cluj (I. Chira, D. 
Inclezan, S. Lalu, M. Mihalachi, A. Varadi), Beograd (I. Nesic, G. Stojic), Sofia (D. Dobreva, I. Katsarkov) und Tirana (E. SheHI) teilgenommen.

Im Anschluß an die Arbeiten des Vorjahres (Jahresbericht 2002) wurden die Räume 3, 4, 9 und $10 \mathrm{im}$ Nordwestteil des Baus ergraben. In Raum 11 wurden noch zwei Pfosten der Holzbauperiode erfaßt.

Raum 3 hatte in der letzten Periode Mosaikenausstattung, die schon von B. SARIA nur im östlichsten Streifen angetroffen worden war. Dort liegt eine ältere Mauer darunter, die von einem Präfurnium durchbrochen wird, das eine Hypokaustheizung bediente. Da die Nordmauer von einem weiteren Präfurnium durchbrochen wird, dessen Unterkante aber höher liegt als der Hypokaustboden, ist für die letzte Periode eine Schlauchheizung anzunehmen, die aber schon vor der ersten Ausgrabung zerstört worden war. Alle Wände des Hypokaustums haben Mauervorsprünge, allerdings in unterschiedlicher Höhe; ein Befund, der sich auch in Raum 27 gezeigt hat. Die Sohle zeigt noch Rußspuren und die Haftmarken der Pfeilerchen, die Wände sind etwas wellig und sehr hart verputzt. Da einerseits eine Fortsetzung der Pfostenreihe des Holzbaus aus Raum 1 zu erwarten war und der Zusammenhang der Fundamente untersucht werden sollte, wurde die Hypokaustsohle teilweise entfernt und darunter vertieft. Unter einer Planierung aus Erde und Bauschutt konnten noch zwei der erwarteten Pfosten sowie ein schwaches Fundament angetroffen werden.

Der westlich anschließende Raum 4 erbrachte ebenfalls Mosaikreste, sein Unterbau ließ sich aber nicht mehr feststellen. Mörtel- und Verputzschutt liegt auf einem Kiesniveau, das wohl eher für einen nicht gedeckten Raum in der Zeit vor dem Fugenstrich spricht. Unmittelbar darunter folgt der dunkle antike Humus. Die Nordmauer der Fugenstrichperiode sitzt in ihrem westlichen Teil über einem älteren Fundament, in der Nordostecke ist sie aber einheitlich gebaut, und ihr Fundament sinkt ab. Dies ist wohl im Zusammenhang mit dem Hypokaustum des Raumes 3 zu verstehen, das einheitlich und sehr solide errichtet werden sollte. In dieser Periode läuft auch der Mauerabsatz nach West hin weiter durch bis nach Raum 10; die Westmauer gegen Raum 10 ist allerdings ohne Fundament auf den Kiesboden gesetzt.

Auch Raum 10 hatte in der letzten Periode Mosaikschmuck und eine T-förmige Schlauchheizung, die von der nördlichen Außenmauer her beheizt wurde. Die bekannte Inschrift des M. Cocceius Caupianus hatte als Spolie einen Schlauch dieser Heizung abgedeckt. Der oberste erhaltene Estrich liegt in der Westhälfte des Raumes 0,12 m tiefer als östlich des Heizkanals. Für die Zeit der Verwendung des ganzen Raumes muß also im Westen eine zusätzliche Bürste angenommen werden. Die östliche Wange des von Norden hereinziehenden Kanals zeigte sich dann auch als 0,60 m starke, gut gebaute Steinmauer. Diese hat in der dem Mosaik vorangehenden Fugenstrichperiode den Raum geteilt, wodurch die unterschiedlichen Niveaus erklärt werden können. Ein rot gefärbter Estrich der Periode der älteren Fundamente wurde nur im Ostteil des Raumes 0,50 m tiefer als die Mosaikunterlage angetroffen. Der Fundamentverlauf der erwähnten, als Kanalwange genutzten Mauer zeigt deutlich, daß diese in der Periode der älteren Fundamente die westliche Außenmauer war. Sie liegt in einer Flucht mit der weiter nach Süden verlaufenden Mauer zwischen den Räumen 13 und 15 einerseits und Raum 9 andererseits. Erst zusammen mit der Erhöhung des Bodenniveaus wurde der Bau nach Westen hin um eine Raumreihe erweitert. Dazu paßt, daß als tiefster Boden über dem gewachsenen Humus wie in den Räumen 13 und 15 eine sandige, nach Westen hin abfallende Schicht angetroffen wurde.

Der große Raum 9 zeigte eine einheitliche Schichtfolge. Unter der sorgfältig verlegten Bürste für das Mosaik mit dem Einschaltbild des Bellerophon folgte eine 0,10-0,20 m mächtige Lage aus Erde mit Sand vermengt. Diese Lage glich die Oberfläche einer Schuttschicht aus, die aus Verputz, Mörtel und Steinen bestand und bis zu 0,60 m hoch war. Sie lag auf einem Lehmboden, wie er im Hof des Baus auf weiten Flächen angetroffen wurde. Stellenweise ist dieser Lehm gebändert, aber nur in wenigen Lagen und nicht so dick wie an den Stellen des Hofes, die als Tenne angesprochen wurden. Darunter folgte eine maximal $0,10 \mathrm{~m}$ hohe Lage dunklen Humus, die nächste Lage war weniger einheitlich: sie enthielt stellenweise Lehmbrocken aber auch verbrannten Lehm und Kies, wieder in etwa 0,10 m Stärke unmittelbar über dem gewachsene Boden. Alle Mauern gehören im Aufgehenden zur Fugenstrichperiode, sie haben hier gut in den Boden vergossene Fundamente. Bei 
der Westmauer scheinen die älteren Fundamente ersetzt worden zu sein, die sonst durchweg vorhanden sind.

Zur Anhebung des Raumniveaus in dieser Periode gehört auch die Schwelle in der Südmauer, die in der Mosaikenperiode zugemauert war. Zu den älteren Fundamenten gehört der Lehmboden, auf dem in der Nordwestecke im Abstand von 1,50 m von der Nordmauer noch drei kleine Ziegellagen angetroffen wurden. Die Schicht mit teilweise verbranntem Lehm und Kies ist der ersten Periode zuzuweisen, von der auch an einer erwarteten Stelle an der Nordmauer eine der großen Pfostengruben angetroffen wurde.

Die Bereiche, in denen die Grabung abgeschlossenen ist, wurden wieder mit Frostschutzschotter und teilweise Bauvlies abgedeckt, teilweise mit Aushub verschüttet. Die Grabung im Inneren des Hauptgebäudes ist mit der Untersuchung dieser Räume beendet.

Eine Präsentation des Denkmals in Form einer Überbauung in mäßiger Höhe, Herstellung der spätesten Bodenniveaus und Andeutung der Mosaikrapporte ist in Vorbereitung. Diese Präsentation soll durch erläuternde Tafeln und eine Gestaltung des Geländes sowie durch Abgüsse von hier gefundenen Grabsteinen ergänzt werden.

\section{Carnuntum (Niederösterreich)}

Es entspricht der forschungsgeschichtlichen Situation der Archäologie von Carnuntum, daß in diesem Raum mehrere Institutionen wertvolle Forschungsarbeit leisten. Neben dem Land Niederösterreich, welches außer dem Museum Carnuntinum auch den Archäologischer Park Carnuntum betreibt, und dem Bundesdenkmalamt mit seiner Gesamtverantwortung bemüht sich auch das ÖAI mit einer Reihe von Projekten und in enger Zusammenarbeit mit dem Institut für Kulturgeschichte der Antike an der Österreichischen Akademie der Wissenschaften, seinen Beitrag zu leisten und wirkt darüber hinaus an den laufenden Koordinationsaufgaben und Planungen mit.

\section{Auxiliarkastell}

Die Feldarbeiten begannen Mitte April und dauerten bis Ende September 2003. Die Gesamtleitung lag in Händen von M. Kandler. Die Arbeiten auf den Parzellen 330/20 und 327/11 leitete U. Zimmermann. Ihr zur Seite standen R. SmischeK und J. Vavruš. Für die Fundaufnahme war wie immer Ch. KandLER-ZÖChMANn zuständig. Konservierung und Restaurierung des Fundmaterials lagen in den bewährten Händen von K. Herold und P. Pingitzer. An der Grabung und deren Dokumentation nahmen als Gastforscher(innen) von der Universität Bratislava M. FeNík, E. FILIpové und A. Majerová teil. W. Kopf, M. Nothnagel und G. Schmied, alle von der Universität Wien, halfen als studentische Praktikanten bei den Arbeiten mit. Wie jedes Jahr unterstützten dankenswerterweise mehrere Studenten und Absolventen des BG und BRG für Berufstätige, 1150 Wien, Henriettenplatz 6, als freiwillige Mitarbeiter die Grabungsarbeiten.

Im Bereich der Parzelle 330/20 wurde die im Jahr 2002 unterbrochene Dokumentation des Grabungsbefundes zu einem Abschluß gebracht. Finanziert wurden diese Arbeiten durch eine Subvention des Landes Niederösterreich, die von der Marktgemeinde Petronell-Carnuntum beantragt und dem Institut zur Verfügung gestellt wurde.

Auf Parzelle 327/11 sind durch die Grabungen von H. STIGLITZ im nordwestlichen Teil bereits einige Ergebnisse erarbeitet worden, die vor allem Befunde der ersten und der letzten Bauperiode des Kastells erbrachten. In beiden Fällen handelte es sich um langgestreckte Gebäude, die sich auch auf der nach Westen anschließenden Parzelle 330/27 fortsetzten. Die Gebäude der Periode I weisen wiederum zwei Phasen auf, deren ältere auch Reste einer Inneneinteilung zeigen. Von der jüngsten aus Bruchsteinmauerwerk bestehenden Periode IV war auf dieser Parzelle bislang ein etwas über $8 \mathrm{~m}$ breiter Bau ohne Inneneinteilung bekannt.

Mit einer von der Denkmalschutzabteilung des Bundesministeriums für Bildung, Wissenschaft und Kultur zur Verfügung gestellten Subvention sollte in einigen im nordöstlichen Teil der Parzelle 
angelegten Grabungsflächen die Fortsetzung der Verbauung in diese Richtung festgestellt werden. Darüber hinaus war in dem zur Nachbarparzelle 327/10 liegenden Bereich die Südbegrenzung des dort vor einigen Jahren sehr genau untersuchten Gebäudes zu erwarten.

Zwischen diesem Gebäude und den westlich davon liegenden Principia wurden die schon bekannten Schotterschichten der Straße aufgedeckt. Von der südlich an den Principia vorbeiführenden Straße konnten die diversen Straten ebenfalls gut getrennt werden. Nach Osten zu fehlen diese ausgeprägten Schotterungen fast völlig. Ein geschottertes Außenniveau wurde teilweise auch für die Periode Ia festgestellt, während die Pfostengräbchen der Phase Ib es durchschlagen. Zum Teil sehr tief fundamentierte Mauerzüge der Periode IV wurden im südlichen Grabungsabschnitt beobachtet; ob einiges davon der Periode III zugewiesen werden kann, muß offenbleiben.

Am 12. und 13. 11. 2003 wurde die Asphaltierung des zwischen Anton-Widter-Gasse und Soldafeldgasse verlaufenden Kastellwegs durch Auskoffern der obersten Erdschichten vorbereitet. Am West- wie auch am Ostende des Wegs wurde dabei antikes Mauerwerk angerissen. Im Westen waren es schon bekannte Mauern des Kastellbades, im Osten relativ massives Mauerwerk, das ebenfalls bereits unter H. Stiglitz bei Kanalarbeiten angeschnitten worden war. In der in ganzer Straßenbreite abgedeckten Fläche fanden sich im Bereich der Einmündung in die Solafeldgasse südlich der breiten Ost-West-Mauer Reste von Steinsetzungen, die vermuten lassen, daß der Mauer hier eine Portikus vorgelagert war.

\section{Gräberstraße}

Beim Ackern hatte Herr J. KRAUTSIEDER aus Petronell-Carnuntum am Nordrand der Parzelle 330/40 in unmittelbarer Nähe des die Parzelle hier begrenzenden Windschutzgürtels einen bearbeiteten Quaderblock angefahren. Nach erfolgter Meldung wurde am 7. Oktober 2003 mit einer kleinen Grabung begonnen, um die archäologischen Umstände zu klären, wofür dankenswerterweise vom Archäologischen Park Carnuntum (F. Humer) zwei Arbeiter zur Verfügung gestellt wurden. Schon nach den ersten Arbeiten war zu erkennen, daß der $95 \mathrm{~cm}$ breite Quaderblock schräg in die Tiefe verlief und seine Oberkante nicht mehr original erhalten, sondern durch den Pflug unregelmäßig abgebrochen worden war. Auf der nach Süden gerichteten Vorderseite des Blocks wurde eine figurale Szene sichtbar: zwei antithetisch gestellte Pferde mit einer dazwischen stehenden Figur. Die Darstellung schließt mit einer geraden Linie ab, darunter folgt eine $23 \mathrm{~cm}$ breite, glatt gearbeitete Fläche, an welche sich der nur grob behauene Fuß der Stele anschließt. Es handelt sich also um einen noch in situ stehenden Grabstein, von dem nur ein Teil des Reliefs erhalten geblieben ist.

Östlich der Grabstele wurde in einer Tiefe von $0,45 \mathrm{~m}$ ein $60 \mathrm{~cm}$ breiter, an der Oberseite relativ glatter Mörtelguß angetroffen, der an der Ostkante der Grabungsfläche im rechten Winkel nach Norden umknickt. Merkwürdigerweise setzt sich die Mauer, deren Aufgehendes wohl aus Quaderblöcken bestanden haben wird, auf der Südwestseite des Grabsteins nicht weiter fort. Dafür wurde etwas nach Süden versetzt eine andere, sehr viel schmälere und aus Bruchsteinen bestehende Mauer gefunden, die von Südwesten kommt und auf der Höhe des Grabsteins nach Südosten knickt. Offenbar handelt es sich dabei um den Rest eines zweiten Grabbaus.

Aufgrund des schlechten Wetters wurden die Arbeiten am 17. Oktober eingestellt und der Abschluß auf das Jahr 2004 verschoben.

\section{Kultbezirk der Heliopolitanischen Götter - 'Mühläcker'}

Ein Vorbericht über die bisherigen Arbeiten wurde im Manuskript abgeschlossen. M. Kandler hat dafür eine Zusammenfassung über die Organisation und die Ergebnisse der Grabungen 1978-91 erstellt. Der Bericht wird im Carnuntum Jahrbuch 2004 erscheinen. 


\section{Flavia Solva/Frauenberg (Steiermark)}

Im Jahr 2003 wurden auf Parzelle 4/1 (SG, KG Seggauberg), an der höchsten Stelle des Frauenbergs bei Leibnitz, die vom Österreichischen Archäologischen Institut 2002 begonnenen Untersuchungen im Bereich des römischen Tempelbezirks fortgesetzt (St. GroH, H. Sedlmayer, V. Lindinger, E. Pichler, U. Stingel, K. Vondrovec, 27. 4. bis 30. 5. und 21.7 bis 1. 8.). Es gelang, den zentralen Steinbau (Cella) des Kultbaus zur Gänze freizulegen und die unterlagernden prähistorischen Siedlungsreste zu dokumentieren. Unter den Fundamentmauern konnte eine spätlatènezeitlich/ augusteische Bebauung dokumentiert und somit erstmals am Frauenberg der Übergangshorizont von der späten Eisenzeit zur frühesten römischen Kaiserzeit erfaßt werden. Im 1. Jahrhundert n. Chr. bestand auf der Kuppe des Frauenbergs ein Kultbau mit einer 7,4 × 8,9 m großen Cella, der in seinem Grundriß einem gallorömischen Umgangstempel entsprach. In der Cella konnten zwei Gehniveaus nachgewiesen werden. Eine sekundär errichtete einfache Fußbodenheizung und das Fundmaterial aus deren Verfüllschichten bezeugen eine zivile und militärische Nutzung des Gebäudes in der Spätantike.

Bereits während der Ausgrabungen wurde mit der Konservierung des bestehenden Mauerwerks und der Aufmauerung des zentralen Einbaus begonnen. Das gesamte Tempelareal wird anläßlich der Steiermärkischen Landesausstellung 2004 den Besuchern zugänglich gemacht und mit Schautafeln erläutert werden.

Vom 21.-22. 7. 2003 wurde im Auftrag des Bundesdenkmalamts am Süd- und Osthang des Frauenbergs die Erweiterung des bestehenden Friedhofs rund um die Wallfahrtskirche nach Süden archäologisch betreut (Parzelle 6/1, 6/2, 9, 12 und 14/1 [SG, KG Seggauberg]). Zum Zeitpunkt der Intervention durch das ÖAI vor Ort waren die Baumaßnahmen bereits derartig weit fortgeschritten, daß nur noch Teilprofile eines $72 \mathrm{~m}$ langen und $375 \mathrm{~m}^{2}$ Grundfläche messenden Fundamentgrabens dokumentiert werden konnten. Die Profile gaben Aufschluß über prähistorische und römerzeitliche Terrassierungsmaßnahmen im Bereich der Kuppe sowie der Süd- und Osthänge des Frauenbergs, weiters über Siedlungsbefunde auf einer mittleren südlichen Hangterrasse im 1./2. Jahrhundert n. Chr.

Die Bearbeitung des archäologischen Fundmaterials aus der Grabung 2003 im Tempelbezirk am Frauenberg erfolgte durch H. Sedlmayer. Die Methode, alle Fragmente, also auch jedes Wandund Bodenbruchstück, in die statistische Auswertung zu integrieren, wurde bei der Bearbeitung der Funde beibehalten. Um die in einer Harris-Matrix dokumentierte komplexe relativchronologische Abfolge absolutchronologisch einzuordnen, wurde als erster Arbeitsschritt die Fundanalyse von 3124 Fragmenten aus 66 stratigraphischen Einheiten (SE) vorgenommen. Anhand der signifikanten Funde, in erster Linie Gefäßkeramik, konnte als ältester Kontext eine früheisenzeitliche Verfüllschicht mit Hallstattkeramik des Formenspektrums Sulmtalnekropole Phase 2 bestimmt werden. Mehrere Siedlungsniveaus gehören der jüngeren Eisenzeit an, wobei von besonderem Interesse jene Kontexte sind, welche durch Importkeramik in frühaugusteische Zeit datiert werden können. Die Funde aus dem frühkaiserzeitlichen quadratischen Einbau sind im diesjährigen Fundbestand sehr gering und entsprechen in ihrem chronologischen Ansatz denjenigen aus der Kampagne 2002: zweites bis letztes Drittel des 1. Jahrhunderts n. Chr. Ein zahlenmäßig gleichfalls kleines, jedoch durch signifikante Formen sehr aussagekräftiges Ensemble konnte zudem aus dem Befund der Nachnutzung dieses quadratischen Einbaus bestimmt werden: neben glasierter Ware und grober Gebrauchskeramik, welche eine Datierung in das 4. Jahrhundert indizieren, dokumentieren insbesondere ein Schuppenpanzerfragment, ein Stilus und ein Werkabfall der Geweihverarbeitung breitgefächerte Aktivitäten in der jüngsten antiken Siedlungsperiode.

Das im Zuge der Baustellenbeobachtungen am Süd- und am Osthang des Frauenbergs geborgene Fundmaterial (nombre minimum d'individus [NMI 86) wurde zur Gänze zeichnerisch dokumentiert und ausgewertet. Drei Siedlungsbefunde der südlichen Hangterrassen sind aufgrund der relativchronologischen Abfolge und der signifikanten Fundvergesellschaftungen in die 2. Hälfte des 1. Jahrhunderts und in das späte 1./ frühe 2. Jahrhundert zu datieren, neben lokaler Gebrauchskeramik konnte ein Importanteil von 15\% festgestellt und analysiert werden. Darüber hinaus wurde 
durch spezifische Funde der Buntmetallverarbeitung Schmiedetätigkeit in diesem Siedlungsabschnitt aufgezeigt; ein Befund, der sich mit älteren Untersuchungsergebnissen in diesem Areal deckt. Die Fundvergesellschaftungen in den östlichen Hangterrassen indizieren eine Siedlungstätigkeit in der Mitte des 1. Jahrhunderts n. Chr., jüngere Niveaus sind neuzeitlich gestört.

\section{Mautern an der Donau (Niederösterreich)}

Im Jahr 2003 wurde die Fund- und Befundbearbeitung der Grabungen 1997-99 im östlichen Kastellvicus von Mautern/Favianis (FWF-Projekt P13689-SPR »Östlicher Kastellvicus von Mautern/ Favianis«, St. Groh, H. Sedlmayer 2000-2002) weitgehend fertiggestellt. Nach Abschluß der Befundbeschreibung und Interpretation von Detailbefunden erfolgten die Generierung von Periodenund Detailplänen sowie die Auswahl von Abbildungen für die Endpublikation.

Die Bearbeitung des archäologischen Fundmaterials aus den Grabungen 1997-99 im Kastellvicus Ost von Favianis-Mautern erfolgte durch H. Sedlmayer; die Fundauswertung, der Katalog und die Tafeln wurden fertiggestellt. Nachdem 2002 die zeichnerische Dokumentation, die Katalogisierung und die Periodisierung der Befunde abgeschlossen werden konnten, wurden 2003 die Detailanalysen der signifikanten Fundobjekte (rund 19757 NMI) in Hinblick auf die Zeitstellung und regionale bzw. überregionale Vorkommen ausgeführt. Die kontextbezogene Auswertung des antiken Gesamtfundbestands wurde in der breitgefächerten Charakterisierung der materiellen Kultur der Bewohner des Vicus Ost unter Berücksichtigung aller relevanten archäologischen Daten dargelegt, wobei besonderes Augenmerk auf die Art der Fundvergesellschaftungen und deren Genese gelegt wurde. In diesem Zusammenhang erbrachte beispielsweise eine ausführliche Diskussion der Funde aus dem Töpfereiareal neue Erkenntnisse zu den Aktivitätszonen in einem großräumig handwerklich genutzten Areal. Die interdisziplinären Zusammenarbeiten wurden erfolgreich teilweise abgeschlossen: die mineralogisch-petrographischen Analysen von 19 Keramikproben unternahm R. SAUER. Die Ergebnisse belegen für typische Repräsentanten der Gefäßkeramik eine Verwendung lokaler Rohstoffe. Die Bestimmung der 6902 Pflanzenreste wurde von U. THANHeIser beigebracht; die malakologischen Funde bestimmte Ch. FranK. Die Analyse der anthropologischen Reste übernahm A. Teschler-Nicola, die Lesung der Graffiti E. Wedenig, das numismatische Fundspektrum bearbeitete K. Vondrovec; alle Auswertungen wurden in den Katalog integriert und bei der Interpretation berücksichtigt.

\section{St. Peter (Salzburg)}

In St. Peter wurden die erforderlichen archäologischen Untersuchungen im Kreuzhof von Mai bis Juli und im September 2003 von St. KARWIESE fortgesetzt. Die Bauforschung in Kreuzgang und Kirche St. Peter 997-1143 wurde gemeinsam mit W. Schaber (Altstadtamt Salzburg) unternommen.

\section{St. Pölten (Niederösterreich)}

\section{Rosenkranzkapelle}

Grabungsleitung: R. RisY; Gastforscher: M. Comisso, M. Hanuš, P. HarČAn, F. Jaššo, B. und I. ŽUnDALEK (alle Republik Slowakei). Die Finanzierung übernahm die Diözese St. Pölten, die Arbeiten dauerten vom 23. Juni bis 28. August (mit Unterbrechungen) sowie vom 21. Oktober bis 11. November 2003.

Im Bereich des heutigen Diözesangebäudes, dem ehemaligen Chorherrenstift, fanden zahlreiche Renovierungsarbeiten statt. Unter anderem wurde begonnen, die sog. Rosenkranzkapelle, geschaffen 
durch barocke Abtrennung vom südlichen Seitenschiff des Domes, zu revitalisieren und als Tageskapelle einzurichten. Dazu war es notwendig, eine neue Drainage zur Ableitung des Regenwassers entlang der Südfassade des Domes in den Kapitelgarten zu legen. Weiters soll ein zweiter Zugang in die Kapelle, geplant an der Südseite des Domes in der Reiche zwischen Oberbank und Dom, deren Erreichbarkeit erleichtern, da sie bisher nur über das Presbyterium des Hauptdomes betreten werden konnte. In vorbildlicher Zusammenarbeit mit dem Diözesanbauamt und der ausführenden Baufirma STRABAG war es möglich, archäologische Untersuchungen inner- und außerhalb der Rosenkranzkapelle durchzuführen.

Im Innenraum der Kapelle konnten Spuren einer zweiphasigen römischen Bebauung festgestellt werden. Die ältere Phase besteht aus mehreren Gruben und zwei Balkengräbchen. Nach deren Verfüllung und Einplanierung wurde darüber ein Gebäude errichtet, von dem eine in Nordost-Südwest-Richtung verlaufende, ca. 0,55 m breite Steinmauer sowie, an deren Ostseite angesetzt, zwei Zwischenmauern ergraben werden konnten. Sie bestehen aus einer mit flachen Steinen und Ziegeln gebildeten einreihigen Unterlage, auf der ein Lehmgemisch, das vereinzelt ebenfalls noch Steine enthält, aufgetragen worden war. Das nördliche der beiden Mäuerchen entspricht der von B. SARIA 1949 als Einfassung eines Gartens interpretierten Trockenmauer. Ein Abschluß des Gebäudes im Osten konnte aufgrund jüngerer Verbauung nicht festgestellt werden. Im Vergleich zu ihrer Längenausdehnung von mehr als $5 \mathrm{~m}$ liegen also sehr schmale, durch Lehmwände getrennte Zimmer vor, die im Westen von einer Steinmauer, bekannt auf einer Länge von mehr als $6 \mathrm{~m}$, begrenzt waren. Der südlichste, in der Reiche bzw. Bauwich liegende Raum besaß einen Estrichboden, im nördlichsten hingegen fand sich nur noch eine Art Tretniveau, in das ein kleiner birnenförmiger Ofen eingetieft gewesen war. Zu erwähnen ist, daß die Orientierung dieses Gebäudes und auch die der Gräbchen der Phase 1 vom bisher bekannten Stadtraster erheblich abweicht.

Westlich der erwähnten Steinmauer wurde in der Reiche die Fortsetzung des 2001 beim Umbau der Oberbank festgestellten Kanals aufgedeckt. Auch hier konnte die nach Aufgabe des Kanals eingebrachte Planierschicht festgestellt werden, die sehr viele Tierknochen, teils nestartig deponiert, enthielt und aufgrund ihrer Zusammensetzung mit dem Mithraskult in Zusammenhang gebracht werden kann.

Für die Baugeschichte der Klosterkirche des Chorherrenstiftes konnten ebenfalls entscheidende neue Erkenntnisse gewonnen werden. Die im Kapelleninneren aufgedeckten Fundamente können wohl dem spätromanischen, 1228 geweihten Bau zugeschrieben werden. Die an der Südseite liegenden Fundamente sind mit Fuge an das Fundament der Südmauer der Kirche angesetzt. Die Forschung ging bisher allgemein davon aus, daß im Bereich der Rosenkranzkapelle eine freistehende Kapelle gestanden hatte, die in den spätromanischen dreischiffigen Kirchenbau integriert worden sei. In der Reiche zeigte sich eindeutig, daß der Fundamentbereich der heutigen Kirchenwand aufgrund der Mauertechnik einem älteren, vor 1228 zu datierenden Kirchenbau zugeschrieben werden kann. Ein zusätzlicher Beweis sind drei Pfeiler, die nur als ältere Lisenengliederung interpretiert werden können. Aufgrund der Untersuchungen 2003 darf aber die Existenz einer dreischiffigen Basilika bereits im 11. Jahrhundert postuliert werden, die spätestens um die Mitte des 12. Jahrhunderts durch ein Westturmpaar erweitert wurde.

\section{Keller im Bischofstrakt}

Bei der Renovierung eines Kellers im sog. Bischofstrakt wurden am 21. 8. 2003 im Vorfeld der Bauarbeiten maschinell zwei in Nord-Süd-Richtung laufende Schnitte gezogen, da der Keller in der Flucht eines angenommenen Decumanus des römischen Municipiums liegt. Wie aus den Profilen ersichtlich, war dieser Bereich durch Gruben stark gestört, so daß keine römischen Straten aufzufinden waren. 


\section{Kreuzganggarten}

Da im Gartenbereich des Kreuzganges - an dessen Süd- und Ostseite - eine neue Wasserleitung verlegt werden mußte, wurden in Absprache mit dem Diözesanbauamt und der ausführenden Baufirma STRABAG die dafür notwendigen Aushubarbeiten archäologisch beobachtet (18. bis 21. November 2003). Während der südliche Graben im Verlauf einer älteren Wasserleitung gezogen wurde, lag der östliche Graben in noch ungestörtem Gebiet. Zutage kamen sehr gut erhaltene Reste (aufgehendes Mauerwerk, Fußbodenreste) des ehemaligen Klostergebäudes aus der Zeit vor dem barocken Neubau. Dabei handelt es sich um die Fortsetzung des durch Grabungen des Bundesdenkmalamts in den frühen achtziger Jahren des 20. Jahrhunderts im östlichen Kreuzgangflügels festgestellten, östlichen Klostertraktes. Durch die gute Kooperation mit dem Bauamt ist es gelungen, die Befunde im östlichen Graben vor der Zerstörung zu bewahren und die Wasserleitung in diesem Bereich zu verlegen.

\section{Bühne im Hof}

Grabungsleitung: R. RIsY; Mitarbeiter: F. JAKSCHE. Die Finanzierung erfolgte durch NEMUS Grundstücksvermietungs $\mathrm{GmbH}$.

Aufgrund des geplanten Bauprojekts »Erweiterung Bühne im Hof«, Julius-Raab-Promenade 37, fanden von 8. bis 30. September 2003 im Auftrag des Bundesdenkmalamts archäologische Untersuchungen durch das ÖAI statt.

Das Grundstück befindet sich im Vorfeld der römischen Stadt, gerade noch innerhalb des mittelalterlichen Mauerrings, so daß Aufschlüsse zu Stadtrand und Vorstadtbebauung des Municipiums, aber auch zur Stadtmauer des 13. Jahrhunderts n. Chr. zu erwarten waren. In Absprache mit den ausführenden Bauorganen wurde der von Unterkellerungen betroffene Abschnitt des Grundstücks bis auf die Oberkante des eiszeitlichen Traisenschotters unter fachmännischer Beobachtung maschinell abgetieft; nur ein ca. 2,5 m breiter Streifen an der Südseite konnte aus statischen Gründen nicht untersucht werden.

Mit Ausnahme der bekannten neuzeitlichen Gebäude kamen keine älteren Baureste zutage. In den eiszeitlichen Traisenschotter eingetieft fand sich an der Südkante der untersuchten Fläche eine Grube. Das aus deren Verfüllung stammende urgeschichtliche Keramikmaterial ist inhomogen und nach erster Durchsicht und Begutachtung durch A. KRENN-LEEB (Institut für Ur- und Frühgeschichte, Universität Wien) nicht einheitlich einer Zeitstufe zuzuordnen, sondern erstreckt sich vom Spätneolithikum über die Frühbronzezeit möglicherweise bis zur Urnenfelderkultur. Wenn auch der Zeitraum der Verfüllung dieses Objekts derzeit noch nicht exakt bestimmt werden kann, so ist zumindest indirekt der erstmalige Nachweis vorrömischer Siedlungstätigkeit im unmittelbaren Stadtzentrum St. Pöltens gelungen. Der als Siedlungsareal in Frage kommende Bereich erstreckt sich mindestens bis zum Europaplatz, wo bereits 1991 ebenso wie bei Untersuchungen 1992/93 in der Linzerstraße oder am Schießstattring nichtsignifikante, meist als spätbronzezeitlich angesprochene Keramikfunde in Zusammenhang mit einer Schotterlinse festgestellt werden konnten.

Einige Gruben und zahlreiche Streufunde aus der römischen Kaiserzeit wie Keramik, Münzen und Metallgegenstände (z. B. eine Spachtelsonde), jedoch das Fehlen von Gebäuderesten bestätigen die Vermutung, daß wir uns außerhalb des römischen Municipiums befinden, das Areal aber aufgrund der getätigten Funde durchaus in dieser Zeit genutzt und begangen wurde. Von der mittelalterlichen Stadtmauer fand sich nur noch ein kleiner Rest am Westprofil der untersuchten Fläche, und zwar der Fundamentbereich der inneren Mauer der zweischaligen Anlage. Dieser blieb erhalten, weil die Mauer als Kellerwand eines neuzeitlichen Gebäudes genützt worden ist.

Auf Einladung der Diözese St. Pölten wurde im Bereich des ehemaligen Klostergartens wegen des bevorstehenden Baus eines Musikkonservatoriums mit Tiefgarage von 17. März bis 2. Dezember die 2002 begonnene Flächengrabung von P. ScHERrer fortgesetzt. Dabei wurden auf ca. $2000 \mathrm{~m}^{2}$ römische, mittelalterliche und barocke Befunde erforscht. 
Für das Municipium Aelium Cetium konnten ein Decumanus und ein Cardo aufgefunden und annähernd zwei Drittel einer Insula erforscht werden. Dabei wurde etwa im Kreuzungsbereich der Straßen eine mit einem Wohnhaus des 2.-3. Jahrhunderts vollflächig verbaute $(12,3 \times 29,6 \mathrm{~m})$ Parzelle freigelegt, am Nachbargrundstück ein kleiner Tempel und das zweiräumige Versammlungshaus einer Kultgemeinde. Dieses Bauensemble wurde im 4. und 5. Jahrhundert in ein großes, mehrfach umgebautes Wohnhaus mit Fußbodenheizungen einbezogen, zwei weitere beheizte Wohnbauten der Spätantike wurden im ehemaligen Gartenareal südlich des Tempels flächig erforscht. Die Besiedlung des Areals dürfte von hadrianischer Zeit bis mindestens in das 1. Drittel des 5. Jahrhunderts gedauert haben.

Ein spätmittelalterliches Wohnhaus und ein barockes Glashaus ergänzen die Befundsituation.

Die Inlandsgrabungen Carnuntum Auxiliarkastell, Vicus und Mühläcker sowie St. Pölten, Salzburg St. Peter wurden in Belangen der Fundbergung und -restaurierung von K. HeroLD und R. PINGITZER betreut: konserviert wurden Metall-, Stein- und Keramikfunde, Wandmalerei und Ziegelfragmente.

\section{Türkei}

Seit die österreichischen Grabungen in Limyra von der Universität Wien an das Österreichische Archäologische Institut übernommen wurden und eine Reihe gesetzlicher Bestimmungen in der Türkei einen größeren administrativen Aufwand für die Betreuung der archäologischen Forschungen in dem Gastland bedingen, ist der Wunsch nach der Errichtung einer Zweigstelle des Instituts in der Türkei wieder aktuell geworden.

Was in den ersten Jahrzehnten der österreichischen Grabungen in Ephesos möglich war und dem Institut 1998 anläßlich seiner 100-Jahr-Feier in einer öffentlichen Ansprache als freundlicher Wunsch mitgegeben wurde, sollte in absehbarer Zeit tatsächlich realisiert werden. Hinzu kommt, daß ein neues partnerschaftliches Verhältnis der Zusammenarbeit mit türkischen Forschungseinrichtungen, das sich in den letzten Jahren im Rahmen rechtlicher Möglichkeiten fruchtbar entwickelt hat, einen vielversprechenden Weg in die Zukunft weist.

\section{Ephesos}

Die archäologischen Forschungen in Ephesos waren der hauptsächliche Gründungsanlaß für das Institut im Jahre 1898 und bilden noch heute den Schwerpunkt der Auslandsforschungen. Seit Beginn hatte die Österreichische Akademie der Wissenschaften ein besonderes Naheverhältnis zu Ephesos, welches seit 1995 in einem neu geschlossenen Patronanzvertrag für die Forschungen in Ephesos geregelt ist.

Die Grabungskampagne des Jahres 2003 dauerte vom 30. Mai bis 11. Oktober, im November 2003 fand ein zweiwöchiger Survey statt. Die Unternehmung wurde wie bisher gemeinsam mit dem Institut für Kulturgeschichte der Antike der Österreichischen Akademie der Wissenschaften vorgenommen. Als Regierungsvertreter waren uns für die Arbeiten in Ephesos Herr Gökhan BoskurTLAR, Frau Şebnem ÖZkaya, Frau Nil Kocak, Herr Şeyhmus Menekse (alle Generaldirektion für Antiken und Museen, Ankara), Herr Cengiz İçTEN und Frau Pervin BüYüKkOLAnci (Efes Müzesi Selçuk), für die Arbeiten in Belevi Herr Ömer ÖzDEN (Museum Çanakkale) zugeteilt. Für die ausgezeichnete Zusammenarbeit und vielfältige Unterstützung gilt den Genannten ebenso wie der Generaldirektion für Antiken und Museen in Ankara und dem Ephesos Museum in Selçuk unser allerherzlichster Dank.

Im Juni 2003 wurde für die Studentinnen und Studenten der Klassischen Archäologie der Universität Wien ein dreiwöchiges Praktikum abgehalten, das der praktischen Ausbildung und der 
Denkmälerkenntnis diente. Damit kommt der Großgrabung Ephesos auch einer wichtigen Aufgabe in der Nachwuchspflege nach, wofür der gelungene Ausbau des Grabungshauses zu einem Studentenheim willkommene Gelegenheit bietet.

Im angegebenen Zeitraum wurde mit unterschiedlichem Aufwand, teilweise gestaffelt und teilweise parallel, an 17 Projekten gearbeitet, insgesamt 162 wissenschaftliche Mitarbeiterinnen und Mitarbeiter sowie 64 Arbeiter wurden beschäftigt. Die photographische Dokumentation der Kampagne lag in Händen von N. Gail und A. Sulzgruber. Zur Ergänzung der Ergebnisse der Kampagne, über welche im Rahmen des hier verfügbaren Platzes nur kursorisch berichtet werden kann, sei auf die einschlägige Bibliographie in der Anlage verwiesen.

\section{Feldforschung}

\subsection{Hanghaus 2}

Die Forschungen in den Hanghäusern von Ephesos werden in enger Zusammenarbeit mit dem Institut für Kulturgeschichte der Antike an der Österreichischen Akademie der Wissenschaften ausgeführt.

1.1.1 Die Wohneinheiten 4 und 6 des C. Flavius Furius Aptus mit ihrer Malerei-, Mosaik- und Marmorausstattung sowie der Baubefund der Wohneinheiten 3 und 5

(Projektleitung: H. Thür [ÖAW]; Mitarbeiter/-innen: I. Adenstedt, K. Koller, V. ScheibelReiter, N. Zimmermann)

Nach dem erfolgreichen Abschluß der Publikationsvorbereitungen der Wohneinheit 4 und der Vorlage zum Druck in den Forschungen in Ephesos bei der Österreichischen Akademie der Wissenschaften wurde der Schwerpunkt auf die Untersuchung des Baubefundes und der Ausstattung der Wohneinheit 6 gelegt. Die Bearbeitung der Malerei- und Marmorausstattung des Hanghauses 2 und die Erarbeitung von Phasenplänen und Rekonstruktionen wurde durch den FWF mit dem Projekt Nr. P 15242 gefördert.

H. Thür hat den Baubefund der Nordräume der Wohneinheit 6 analysiert, d. h. jener Räume, die an die Wohneinheit 4 angrenzen und deren Erweiterung bzw. Neuerrichtung die massiven Umbauten der Wohneinheit 4 verursachten. Dafür wurde der Baubefund des Marmorsaales 31, der Basilika 8, des Stuckzimmers 8a, der Nebenräume 8b und 8c und der Räume 36 und 36a in einem Katalog erfaßt und für die beiden Haupträume 31 und 8 eine Textfassung des Baubefundes konzipiert. Ein wichtiges Bauelement des behandelten Bereichs ist der Frischwasserkanal, der die Hanghäuser quert und dessen erforderliche Überbrückung die Baumaßnahmen wesentlich beeinflußte; von diesem sind vier Bauphasen zu erfassen.

Eine Diskussion über die Orientierung und damit Zugehörigkeit des Raumes 36c.1 im Obergeschoß führte zu einer Beschäftigung mit den Räumen 32b-d und 37. Dieser auf dem Niveau der Obergeschosse der Wohneinheit 6 und 7 gelegene Bereich hatte über dem tonnengewölbten Raum 38c der Wohneinheit 7 einen offenen Hof, dessen Marmorstylobate an der Süd- und Ostseite - dort überbaut - erhalten blieben. Seine Hoffläche wurde sekundär verkleinert und war mit stuckierten Ziegelsäulen ausgestattet. Auf diesen Hof können Räume an der Ost-, Süd- und Westseite orientiert gewesen sein. Die Räume 32c und 38a.1 bildeten den Süd- und Westumgang, die Räume 36c.1 und 36d.1 gehörten primär zu diesem Hof, sekundär jedoch zum Obergeschoß der Wohneinheit 6. Das Nutzungsverhältnis dieses Bereichs zu den beiden auf der untersten Terrasse gelegenen Wohneinheiten 6 oder 7 bedarf noch der näheren Klärung.

I. Adenstedt hat für die Publikationsvorbereitungen der Wohneinheiten 1 und 2 die vorhandenen Bauphasenpläne überarbeitet und durch einen Obergeschoßplan und ein 3-D-Rekonstruktionsmodell ergänzt. Ihr Hauptziel war die Bearbeitung der Wohneinheiten 3 und 5, deren Baubefund sie im Rahmen einer Dissertation an der TU Wien vorlegen wird. Sie erfaßte den Baubefund der einzelnen Räume in Tabellenform und erstellte einen Katalog der Architekturteile und der Türschwellen. Der vorhandene Plan des Grundrisses wurde anhand einer Vermessung mit Polarvektor und 
Handaufmaß überarbeitet, Architekturdetails wie Bodenbeläge, Türschwellen und der Hypokaustboden im Raum 26 wurden zeichnerisch dokumentiert. Außerdem untersuchte sie die Bauphasen der beiden Wohneinheiten und die Wasserver- und -entsorgung.

K. Koller konzentrierte ihre Arbeiten an den Marmorausstattungen von Wänden und Böden im Hanghaus 2 auf die in situ-Befunde der Wohneinheit 6: In ihr wurden weiße und graue kristalline Marmore aus der Umgebung von Ephesos, bevorzugt aber farbige Dekorgesteine, die aus den bekanntesten Steinbrüchen des Reiches importiert worden waren, für die repräsentative Ausstattung der Räume verwendet. Die Marmorausstattungen aller Räume mit z. T. mehrzonigen Wandsystemen und dekorativen Plattenböden sowie die Brunnenauskleidungen wurden dokumentiert.

Für N. Zimmermann standen - nachdem im Projekt der Wandmalereien die Datierungsdiskussion als prinzipiell abgeschlossen betrachtet werden kann - die Ausarbeitung der Phasen der einzelnen Wohneinheiten und die Erstellung entsprechender Manuskripte im Vordergrund. So konnten nicht nur das Manuskript zur Wohneinheit 4 druckfertig abgeschlossen, sondern auch die Arbeiten an den Manuskripten zu den Wohneinheit 1 und 2 nahezu fertiggestellt werden. In Ephesos wurde die Dokumentation der Malereifragmente aus den Wohneinheit 3, 5 und 6 vervollständigt, deren Ausarbeitung für 2004 vorgesehen ist. Die Malereien erlauben, in jeder Wohneinheit eine Entwicklung vom frühen 2. bis in das mittlere 3. Jahrhundert nachzuvollziehen, die zumeist einen Rückgang von figürlichen Bildthemen mit sich bringt. Bei Besuchen mehrerer Nachbargrabungen konnten anhand unpublizierter Fragmente Elemente einer regionalen Maltradition entdeckt werden.

Die Bearbeitung der Mosaike hat in einem von W. JoBST geleiteten Projekt V. Scheibelreiter übernommen, die für die Mosaikenausstattung der Wohneinheit 4 einige Rekonstruktionen aus dem Fundmaterial vornehmen konnte und dabei auch bezüglich der Ausstattung des zweiten Obergeschosses aufschlußreiche Evidenzen erarbeitet hat.

\subsection{Insula $M / 1$, sogenanntes Freudenhaus}

Die Bauuntersuchungen konnten von D. Boulasikis vorläufig abgeschlossen werden. Sie umfaßten die an der Akademiegasse liegenden Reste des Obergeschosses des sog. Freudenhauses, die geodätisch vermessen und beschrieben wurden. Dabei fanden sich deutliche Hinweise auf eine reiche Ausstattung auch dieser Räume. In spätantiker Zeit wurde das Obergeschoß im Nordosten um eine Latrine erweitert, die Teile der Akademiegasse überbaute. Eine derartig ausgreifende Hauserweiterung ist auch bei den Häusern nördlich des Variusbades auf der gegenüberliegenden Seite zu erkennen. Die Gasse wurde durch private Baumaßnahmen in spätantiker Zeit stark verschmälert. Untersuchungen der Bausubstanz wurden auch im Zwickel Kureten-/Marmorstraße vorgenommen; die Räume wurden geodätisch vermessen und untersucht. Im Bereich des Treppenaufganges zum Bankettsaal konnten Spuren der Vorgängerbebauung nachgewiesen werden. Im Bereich des sog. Freudenhauses wurden mehrere repräsentative Räume photogrammetrisch aufgenommen, im Süd-, Mittel- und Nordteil der Insula Mörtelproben für die Untersuchung ihrer Zusammensetzung entnommen.

Die Fundkomplexe der Insula wurden von S. LADSTÄTtER (ÖAW) durchgesehen und das datierende Material bestimmt.

1.3 Tetragonos Agora

(Projektleitung: P. Scherrer; Mitarbeiter: M. Hofbauer)

Während eines zweiwöchigen Aufenthalts wurden zur Vorbereitung der Publikation einige Vermessungsarbeiten abgehalten und die Befunderhebung zur Bausubstanz der kaiserzeitlich-spätantiken Agoraanlage vorangetrieben. Hinsichtlich des Verlaufs der hellenistischen Stadtmauer wurden die bekannten Befunde überprüft und abschließende Überlegungen zur eventuellen Einbindung des hellenistischen Torbaus unter dem Agora-Nordtor und seiner Interpretation als Koressisches Tor angestellt. 


\subsection{Vediusgymnasium}

Bei den Bemühungen, ein neues Site Management für Ephesos zu entwickeln, entstand vor einigen Jahren die Idee, den Eingang in das Ruinengelände für die Besucher/-innen an den Platz vor der Westfassade des Vediusgymnasiums zu verlegen und dieses touristisch zu nutzen. Voraussetzung dafür sind möglichst vollständige und abschließende archäologische sowie bauhistorische Untersuchungen, die erst die Eckdaten für eine allfällige Nachnutzung dieses Ruinenkomplexes bieten können. Durch eine großzügig gewährte Sonderfinanzierung des Bundesministeriums für Bildung, Wissenschaft und Kultur wurde die materielle Basis für dieses Projekt sichergestellt.

\subsubsection{Archäologie}

(Projektleitung: M. Steskal; Mitarbeiter/-innen: J. Eitler, F. Jaksche, M. Koller [†], M. Peciarová) In der viermonatigen Grabungs- und Aufarbeitungskampagne des Jahres 2003 wurden vier Schnitte zur Klärung der Baugeschichte und grundrißtypologischer Fragen angelegt.

Fortsetzung Schnitt 1/02 - Propylon und Säulenstraße: Um die Verbindung des Propylons mit der zwischen Stadion und Vediusgymnasium verlaufenden Säulenstraße - der Via Sacra - zu klären und um unterschiedliche Straßenniveaus bestimmen zu können, wurde südlich des Haupteingangs des Bad-Gymnasium-Komplexes ein $3 \times 25 \mathrm{~m}$ großer Schnitt angelegt.

Die nördliche Stoa der Säulenstraße, die bereits im Sommer 2002 freigelegt werden konnte, wurde im Zuge der Errichtung des Propylons - das, wie Baufugen belegen, in dieser Form als sekundär anzusprechen ist, - südlich des Eingangs geöffnet. Der Bereich zwischen den mächtigen Türschwellen und dem Stylobat der Säulenhalle wurde dabei mit einem heute nicht mehr vorhandenen Marmorplattenpaviment versehen, dessen Steinfundament und Estrich noch gut erhalten sind. Der südlich vor der Halle verlaufende, tiefer gelegene Straßenkörper wurde über eine Treppe erschlossen. Südlich an die Halle anschließend konnte unter einer mächtigen Schicht aus ehemaligem Aushubmaterial der 20er Jahre des 20. Jahrhunderts und einem rezenten Humushorizont das teils beraubte Kalksteinpflaster einer monumentalen Säulenstraße lokalisiert werden. Der tiefer gelegene Straßenkörper konnte über Treppen begangen werden, die von den höher gelegenen Hallen im Süden und Norden der Straße zum Laufniveau hinabführten. Die Quaderblöcke der Stufen sind großenteils beraubt, ihre Fundamente aber durchweg gut erhalten. Im Süden der Straße wurden noch in der Antike mehrere Pflastersteine, die zugleich als Abdeckung für einen gemauerten West-Ost verlaufenden Kanal dienten, entfernt.

Vom Stylobat der südlichen Halle ist lediglich ein Block in situ erhalten. Er scheint durch ein Erdbeben leicht nach Süden versetzt worden zu sein und ragt nun $15 \mathrm{~cm}$ über sein Fundament hinaus. Ein Parallelbefund ist an der Treppe zur nördlichen Halle zu bestimmen, wo eine als Spolie dienende Säule und ein Quaderblock ebenfalls $15 \mathrm{~cm}$ nach Süden versetzt sind. Der bombierte Straßenkörper selbst fällt nach Süden und Norden leicht ab und weist - wenn auch nicht signifikant - Wagenspuren auf.

In die südliche Halle wurde in der Spätantike offenbar aus Wohnzwecken eine rechtwinkelige Mauer eingebaut; das entsprechende Nutzungsniveau konnte in Form eines Kalkmörtelestrichs bestimmt werden, der unmittelbar über dem ursprünglichen Niveau der Halle aufgetragen wurde. Vom ursprünglichen Hallenboden war lediglich der Estrich erhalten, der über einer massiven, teils ergrabenen Aufschüttung verlegt wurde.

Mit einer Straßenbreite von etwa 11,20 m und einer Gesamtbreite der Säulenstraße inklusive der Hallen von etwa $30 \mathrm{~m}$ stellt der zwischen Vediusgymnasium und Stadion verlaufende Abschnitt der Via Sacra einen der wichtigsten Fahrwege von Ephesos dar. Zumindest bis in das ausgehende 6. Jahrhundert n. Chr. kann eine Nutzung der Straße nachgewiesen werden.

Schnitt 1/03 - Natatio: Zur Klärung der Zerstörung des Gebäudes und der Dachkonstruktion wurde im Bereich der bereits partiell in den 20er Jahren freigelegten Natatio ein maximal 9,20 $\times$ 9,30 m großer Schnitt angelegt.

Unter einer Schicht aus ehemaligem Aushubmaterial konnte ein rezenter Humushorizont bestimmt werden, der wiederum unmittelbar auf dem Versturz des Deckengewölbes liegt. Der mäch- 
tige Versturz aus Ziegeln und Kalkmörtelbrocken belegt das Vorhandensein eines Ziegeldaches. Unter dem Versturz des Deckengewölbes konnte wie in den Räumen V und IIIa eine Brandzerstörungsschicht lokalisiert werden, die die Zerstörung des Raumes für den Beginn des 6. Jahrhunderts n. Chr. fixiert. Eine Brandzerstörung zu dieser Zeit kann aufgrund der Grabungsergebnisse nun für das gesamte Gebäude vorausgesetzt werden. Noch vor der Zerstörung der Anlage wird Raum IV seiner Ausstattung beraubt (Ende 5. Jahrhundert n. Chr.).

Bei der Ausgrabung wurde an der Ostseite des Zentralraumes V ein weiteres Kaltwasserbecken freigelegt.

Schnitt 2/03 - Kaisersaal: Zur Klärung der Datierung des opus sectile-Paviments sowie zur Bergung der unter dem Bodenniveau in einer Planierschicht befindlichen, zerschlagenen Statuen wurde in der Nordwestecke des Kaisersaals eine L-förmige, maximal 7,25 × 6,95 m große Sondage angelegt.

Unter einer rezenten Schicht aus humoser Erde befand sich das bereits in den 20er Jahren freigelegte, überaus schlecht erhaltene, sekundäre opus sectile-Paviment. Der darunter befindliche Estrich bedeckte eine etwa $15 \mathrm{~cm}$ starke Planierschicht, in die zahlreiche Elemente der Originalausstattung nivelliert wurden. Bei den Statuenfragmenten handelt es sich ausnahmslos um zurechtgehauene Köpfe und Extremitäten. Die fehlenden Torsi scheinen teilweise als Bausteine in Mauern verbaut worden zu sein, wie der Fund des Torso einer Aphroditestatue in der Nordmauer der Palästra im Sommer 2002 belegt.

Unter der Planierschicht befand sich ein Estrich, der unmittelbar über einem Steinfundament aufgetragen wurde und zum Aufbau des ursprünglichen Bodens zu gehören scheint. Die bereits im Osten der Palästra angetroffene massive Aufschüttung aus der Bauzeit wurde nicht mehr angegraben.

Das sekundäre opus sectile-Paviment gehört der zweiten großen Ausstattungsphase im 1. Viertel des 5. Jahrhunderts n. Chr. an. Die zurechtgehauenen Statuen scheinen schon zuvor bei einem Erdbeben beschädigt und anläßlich der Verlegung des Bodens als Baumaterial weiter genutzt worden zu sein.

Fortsetzung Schnitt 3/02 - Keller M und N: Um den Zeitpunkt der Einstellung des Badebetriebes bestimmen zu können, wurde im Sommer 2003 die bereits 2002 begonnene Sondage $12 \mathrm{~m}$ weiter nach Süden fortgesetzt (insgesamt $12 \times 2,08 \mathrm{~m}$ ).

Im Keller N konnte unter einer rezenten Schicht und einer Schuttschicht, die einerseits aus der Öffnung des Wirtschaftshofes XII und über das im Westen von Keller N gelegene Präfurnium eindrang, eine massive Holzkohleschicht dokumentiert werden, die Richtung Norden ausdünnt und unmittelbar auf dem Laufniveau des Kellers liegt. Sie definiert zugleich die letzte Nutzungsphase des Bades in der 2. Hälfte des 5. Jahrhunderts n. Chr. Die Holzkohle resultiert folglich von den letzten Heizvorgängen.

Das Laufniveau des Kellers steigt kontinuierlich nach Süden an, um die für die Befeuerung nötigen Materialien über Öffnungen in der Decke in die Wirtschaftshöfe transferieren zu können. Als Bodenniveau konnten Lehmstampfböden bestimmt werden, die über einer Ausgleichsschicht, die unmittelbar auf dem natürlichen Fels lag, aufgebracht waren.

Der Süd-Nord verlaufende Abwasserkanal war mit Abfällen aller Art verfüllt (Tierknochen, Glas, Keramik, Lampen, Architekturglieder etc.) und diente ab der 2. Hälfte des 5. Jahrhunderts n. Chr. zur Deponierung von Müll. Die Kanalabdeckplatten in den Kellern H und M wurden dazu bis auf eine einzige im Durchgang entfernt. Der als Kanalsohle dienende Fels ist bauzeitlich stark bearbeitet und fällt kontinuierlich nach Norden ab. Der Höhenunterschied im Nutzungsniveau zwischen Raum M und N mußte über eine nicht mehr vorhandene Treppe überwunden werden. Die Kanalverfüllung wurde intensiv beprobt und wird in der Kampagne 2004 durch Archäozoologen und Archäobotaniker analysiert werden.

Für die Nutzung des Bad-Gymnasium-Komplexes kann somit festgehalten werden, daß nach der Neuausstattung des Gebäudes im 1. Viertel des 5. Jahrhunderts n. Chr. der Badebetrieb noch intakt war und bis in die 2. Hälfte des 5. Jahrhunderts fortgesetzt wurde.

Zur Periodisierung der einzelnen Nutzungsphasen des Komplexes s. auch vorliegender Band, S. $237 \mathrm{ff}$. 


\subsubsection{Fundbearbeitung}

In Zusammenarbeit mit S. LADSTÄTtER wurde das gesamte keramische Fundmaterial von Schnitt 4/02 der Grabung 2002, von Schnitt 3/02 der Grabung 2002/03 sowie von Schnitt 2/03 der Grabung 2003 aufgenommen und bestimmt.

Die Bearbeitung der Mosaikböden wurde von V. Scheibelreiter fortgesetzt; H. TAeuber nahm die neugefundenen Inschriften auf. G. PlattNer schloß seine Untersuchungen zu den Kompositkapitellen aus dem Vediusgymnasium ab. Die 2002 und 2003 gefundenen Skulpturenfragmente wurden von J. Auinger aufgenommen. Die Tierknochen aus der Grabung 2002 analysierte G. ForStenPointner; das antike Münzmaterial wurde von M. Pfisterer bestimmt.

\subsubsection{Bauforschung}

(Projektleitung: M. LA Torre; Mitarbeiter/-innen: Architekturstudent[inn]en der Fachhochschule Wiesbaden A. Bamberg, M. Bogedan, P. Launer, N. Lorius, M. Schnierer)

\subsubsection{Bauaufnahme und Dokumentation}

Die Bauaufnahme im Thermengeschoß wurde in den Räumen im Norden der Palästra, dem westlichen Peristyl mit seinem Mosaik in der Nordwestecke und dem neuergrabenen Bereich des Frigidariums mit der Natatio im Raum IV vorgenommen. In den Substruktionen wurden die Räume C, D, E, F, G mit der davorliegenden Portikus und etwa die Hälfte der Nordansicht von Osten in Grundrissen und Schnittansichten aufgenommen. Für die bereits gezeichneten Räume wurden noch fehlende Schnittansichten erstellt und Grundrisse ergänzt, so in den Räumen des Caldariums XV, XVI, dem Zentralraum V und der Latrine. Durch Einarbeitung der Planaufnahmen und Detailzeichnungen M. Theuers in die neue Bauaufnahme und den Abgleich mit den bisher angefertigten Zeichnungen von Werkstücken wird die Dokumentation wertvoll ergänzt.

Alle neugefundenen Architekturteile wurden inventarisiert und gezeichnet. Auch die im Freiluftdepot in Ephesos befindlichen Teile (Delphinwangen der Latrine, Fragmente von Marmorbadewannen, Kapitell, Hermen) wurden aufgenommen; zwei vom Vediusgymnasium stammende Werkstücke konnten auf der Agora identifiziert werden

Die Architekturglieder des Kaisersaals wurden provisorisch im Peristyl und in der Palästra aufgelegt.

\subsubsection{Reinigung und Sicherungsmaßnahmen}

Diese Arbeiten erbrachten auch heuer interessante Befunde. Die Säulen der Latrine wurden geordnet und im Impluvium der Latrine aufgelegt. Eine Reihe von Anpassungen wurde vorgenommen, die Gesamthöhe der Säulen konnte bestimmt werden.

Die im Zuge der Altgrabung auf dem opus sectile-Boden des Kaisersaales zurückgelassenen, besonders großen Architekturglieder wurden mit Hilfe des Autokrans herausgehoben. Der Boden wurde durch eine Abdeckung geschützt. Beim Abräumen der aus Architekturgliedern des Kaisersaales zusammengesetzten Rampe im Nordwesten des Peristyls vor der Tür zu Raum IIIc, die in den 20er Jahren angelegt wurde, um eine der Flußgottstatuen abzutransportieren, konnte eine Reihe von Werkstücken wiedergewonnen werden: unter der Rampenkonstruktion fand sich ein großes Stück des Mosaiks des Peristyls, aus dem sich das Ornament für das westliche Peristyl erschließen läßt.

Durch Reinigungsarbeiten in den Räumen in der Nordwestecke der Palästra wurde im Raum XXI (über Raum F der Substruktionen) eine späte Flachdachkonstruktion aus antiken Dachziegeln und Mörtel aufgedeckt. Dieses 'Dach' entstand, als die Räume des Peristyls der Palästra nicht mehr erhalten und die Wände bereits teilweise abgetragen worden waren, die Räume in den Substruktionen aber weiter benutzt wurden. In den Substruktionen wurde auch beim Reinigen in der Portikus vor Raum A eine Rohrleitung aufgedeckt. Bei der Aufnahme der Räume im Osten der Substruktionen stellte sich heraus, daß sie alle während verschiedener Phasen verputzt gewesen waren.

In Raum E wurden sekundäre Einbauten und Veränderungen festgestellt, die auf eine intensive Nachnutzung schließen lassen. Dafür spricht auch ein später opus sectile-Boden in der Portikus vor 
der Nordwand. Auf dem Putz der Ostwand von Raum G sind Vorritzungen für Fresko zu erkennen.

Im Zuge der Umsetzung des 2001 vorgelegten denkmalpflegerischen Konzepts zur Sicherung in ihrer Erhaltung akut gefährdeter Bereiche und zur Gewährleistung der Arbeitssicherheit wurden folgende Maßnahmen ergriffen: Die Böden im Zentralraum V und im Flügelsaal III a wurden mit Kalkmörtel angeböscht und zum Abdecken mit Vlies und Sand vorbereitet. Die Böden im Kaisersaal und im Peristyl wurden abgedeckt. Eine Trockenmauer wurde unter Verwendung der in der Natatio ergrabenen Gewölbeziegel im Norden des Zentralraums V errichtet, um zu verhindern, daß Material aus dem nichtausgegrabenen Bereich im Norden alljährlich in den Zentralraum absinkt. Die 2002 wiederaufgestellten Türgewände wurden mit Kalkmörtel hinterfüllt. In den Substruktionen wurde der gefährliche Ausbruch (Beraubung) zwischen Raum F und G geschlossen, die Wandpfeiler der Eingänge zu beiden Räumen wurden wiederhergestellt. Der in der Portikus der Nordfassade gefundene opus sectile-Boden war aufgrund seines schlechten Erhaltungszustandes vor Ort nicht zu halten, wurde daher abgeklebt und in das Depot gebracht.

\subsection{Theater}

\subsubsection{Bühnengebäude}

(Projektleitung: A. ÖZtüRk [Mimar Sinan Universität Istanbul]; Mitarbeiter/-innen: N. AkBAş, E. Budak, İ. Çokuğraş, M. Demirli, F. Dönmez-Öztürk, M. Hofbauer, S. Madenci, B. Öztürk, Y. SEvİNÇ, M. SKoRIC, E. YILDIRIM)

\subsubsection{Archäologie}

In dieser Kampagne sollte der römische Bühnenbereich eingehender untersucht werden, da bereits die Grabungen 2001 und 2002 gezeigt hatten, daß mit einer komplexeren Abfolge von Bauphasen zwischen der domitianischen Neugestaltung und der spätantiken und frühbyzantinischen Nutzung des ephesischen Theaters zu rechnen ist.

Hauptaugenmerk wurde auf den südlichen Teil der römischen Theaterbühne gelegt, wo zwischen den Interkolumnien H11 bis H14 (hier bis zur südlichen Begrenzungsmauer) mehrere Sondagen (S 01/2003, S 02/2003 und S 04/2003) angelegt wurden. Die doppelte Fundamentierung unter der Bühnenvorderwand und den dahinterstehenden Pfeilern beginnt hier unmittelbar an jenen Steinquadern, die zu dem hellenistischen Orchestrakanal gehört haben dürften. Sie sitzt direkt auf dem gewachsenen Boden. Eine Nutzung des Raumes zwischen den Fundamenten als Kanal ist nicht nachzuweisen. Doch konnte ein späterer Kanal mit Steinplättchenboden in S 04/2003 freigelegt werden. Im Bereich H12/H13 war der Kanal allerdings zur Gänze zerstört. Er schlängelte sich ursprünglich in S-förmiger Linie von der Bühnenvorderwand zwischen den Säulen hindurch, bis zum Sockel der scaenae frons. Von dort verläuft er parallel zu deren Flucht nach Norden weiter.

Punktförmige Fundamentierungen unter den Standplatten der Säulen konnten in allen Fällen nachgewiesen werden.

Das Fundament unter der Parodosmauer wurde auf der Westseite zur Gänze freigelegt. Es ist durchgehend zwei Steinlagen hoch und teilweise in den gewachsenen Verwitterungslehm vertieft. In seiner Art entspricht es den Fundamenten des hellenistischen Bühnengebäudes, und es gibt keinen Grund, es nicht als zeitgleich mit diesen anzusehen. Die darüber errichtete Spolienmauer gehört einer späteren Zeit an. - Im Durchgang zwischen Skene und Orchestra (H7/H8) wurde die östliche Hälfte im Anschluß an Sondage S 01/2001 untersucht.

\subsubsection{Dokumentation}

Während der Kampagne 2003 wurden die Bauaufnahme des Längsschnitts und der Westansicht der in situ erhaltenen Ruine im Maßstab von 1:20 fertiggestellt. Außerdem wurde ein Querschnitt durch das Bühnengebäude aufgenommen, eine digitale Photodokumentation dieser Teile der Skene angefertigt. 
Die zeichnerische Aufnahme der aus dem Verband gelösten Architekturteile im Maßstab 1:10 wurde abgeschlossen. Parallel dazu wurden die Architekturteile des dritten Geschosses der scaenae frons bis zu den Gesimsblöcken katalogisiert.

\subsubsection{Aufräumungsarbeiten}

Seit 1997 werden die erhaltenen Bauglieder des Bühnengebäudes in der Palästra des Theatergymnasiums ausgelegt. Zu Anfang der Aufräumungsarbeiten 2003 wurde der Steingarten in der Palästra des Theatergymnasiums gereinigt, sodann die Bauglieder in der Nordparados in Angriff genommen. Die Architekturteile, die zur scaenae frons gehören, wurden in den Steingarten transportiert und aufgestellt; um die in der Orchestra deponierten Bauglieder umzulagern, wurden zwei Kräne mit 100 und 200 t Tragkraft angemietet. Die Aufräumungsarbeiten sind damit abgeschlossen.

\subsubsection{Untersuchungen der Inschriften}

Die Untersuchungen der Inschriften, die im Theater sowie in der Nähe des Theaters gefunden und schon publiziert wurden, wurden von F. Dönmez-Öztürk unter Einbeziehung der Theaterinschriften im Domitiansdepot vor Ort abgeschlossen.

\subsubsection{Reinigungsarbeiten}

2003 wurden die Reinigungsarbeiten der westlichen Räume mit den Räumen D1, D2 und D3 begonnen, wobei festgestellt werden konnte, daß der Fußboden von Raum D 3 aus Ziegeln besteht. Im Westen des Theaters, vor dem byzantinischen Tor, wurden Platten des Straßenpflasters durch einen Feuerwehrwagen zerstört. Wahrend der Restaurierung der Platten wurde der Kanal in einer Sondage von 1,10 × 1,16 m gereinigt; in der Tiefe von 1,48 m konnte der Boden des Kanals gefunden werden. Bei dieser Sondage kamen eine byzantinische Münze, ein Eisenring und zwei Glasstücke zutage.

\subsubsection{Cavea}

(Projektleitung: M. Döring-WiLliams [Technische Universität Wien]; Mitarbeiter/-innen: V. CapresI, H. Liebich, B. Thuswaldner, R. Kellner, A. Willmer)

Das Projekt »Cavea« ist von vier Hauptzielen bestimmt: In einem ersten Schritt soll ein verformungsgetreues/formtreues Bauaufmaß entstehen, in Kombination von Instrumenten- und Handaufmaß. Das Ergebnis bildet die Grundlage für die bauanalytische Untersuchung zur Rekonstruktion der Baugeschichte und der Bauabläufe der Cavea. Gleichzeitig dient das Aufmaß zur Gewinnung von hochpräzisem Datenmaterial als Basis für den - in einem zweiten Schritt einzusetzenden - Raumscanner. Das Gesamtergebnis von Dokumentation und Analyse schließlich wird in die Entwicklung eines dauerhaften Restaurierungs- und Nutzungskonzepts münden. Hauptgegenstand von Dokumentation und Analyse stellte in der vierwöchigen Kampagne 2003 die prima cavea dar.

Das Große Theater von Ephesos war in der Vergangenheit wiederholt Objekt archäologischer und bauforscherischer Untersuchungen, die sich allerdings in erster Linie auf das Bühnengebäude bezogen (s. o. 1.5.1). Bezüglich der Cavea konzentrierten sich die bisherigen bauforscherischen Analysen auf die 'Randbereiche', d. h. auf die Analemmata und auf die sog. Säulenhalle als oberen Abschluß der summa cavea (zuletzt İ. ATAÇ, Istanbul). Außerdem waren in der Orchestra, der Kontaktstelle zwischen Bühnengebäude und Cavea, kürzlich erste archäologische Sondagen zur Klärung der baulichen Zusammenhänge vorgenommen worden (Leitung M. HofBAUER, ÖAI). Der eigentlich raumbildende Teil des Theaters - also die Stufenfolge seiner drei Ränge - war in den bisherigen Dokumentationen zwar in den geodätischen Vermessungen (Ch. KuRTZE, ÖAI) erfaßt worden, in der Untersuchung der bauhistorischen Entwicklung der Anlage war er jedoch weitgehend unberücksichtigt geblieben.

\subsubsection{Baudokumentation}

Die Bauaufnahme der Cavea stellt aufgrund der Geometrie des Theaterhalbrunds eine besondere Herausforderung dar: wegen der pro Sitzstufe jeweils variierenden Aufsichten ist eine Fülle von Einzelgrundrissen erforderlich. Darüber hinaus sind die Ansichten der Stufen durch die Krümmung 
in der Orthogonalprojektion nur verkürzt erfaßbar - hier bietet sich die dreidimensionale Dokumentation als optimale Lösung für die Präsentation an.

2003 wurde die prima cavea mit einem TCRM von Leica (Software TOTAL = Tachymentrische, Objektorientierte, TeilAutomatische Laservermessung, TU Wien/Ruhr-Universität Bochum) aufgenommen, und die so erstellten Scans wurden als dreidimensional verwertbares Datenmaterial im Anschluß in AutoCAD-Dateien umgewandelt. In einem nächsten Schritt wurden diese Dateien in zweidimensionale Medien - d. h. in Grundrisse, Schnitte oder Ansichten - umgesetzt, die in Form von Prints bzw. Plots als hochpräzise zeichnerische Vorlagen für die Vor-Ort-Ergänzung bzw. Verdichtung der Ergebnisse per Hand dienten. Das Ergebnis ist ein Handaufmaß auf der Basis eines komplexen und extrem dichten 3-D-Instrumentenaufmaßes. Die Dokumentationen wurden darüber hinaus durch Photos, Beschreibungen und Skizzen zu technischen Details komplettiert.

Weiters wurde ein Bauteilkatalog angelegt, in dem Bauelemente wie die Reste der Verkleidung, Treppenstufen und -wangen und auch Teile der Ausstattung wie die erhaltenen Steinbänke und Sessel (Typisierung und Rekonstruktionsversuch des ursprünglichen Standorts) dokumentiert wurden. Ebenfalls berücksichtigt wurden hier technische Details wie Hinweise auf die (nur noch in Spuren erhaltenen) ehemaligen Niederschlagsableitungs- und Absperrsysteme als Grundlage für neue Einsichten in das Verständnis der Antike hinsichtlich Erschließungs- und Zirkulationswegen, Sitzordnungen und Sicherheitsvorkehrungen in öffentlichen Gebäuden.

\subsubsection{Bauanalyse}

Ziel der bauanalytischen Untersuchung ist die Rekonstruktion der Baugeschichte des Theaters von der Antike bis heute. Eine der wichtigsten Aufgaben stellt dabei die Identifikation der in situ verbliebenen Bauteile dar, die Trennung der verschiedenen antiken und nachantiken Bauphasen und ihrer Nutzungsaspekte und nicht zuletzt die Dokumentation und die zeitliche Zuordnung der verschiedenen Restaurierungs- und Sicherungsmaßnahmen des 20. Jahrhunderts (Geschichte der Restaurierung, verschiedene Methoden der Sichtbarmachung bzw. 'Verschleierung' der Eingriffe). Die geometrischen Gegebenheiten der Anlage, ihre architekturtheoretischen Regeln und Regelmäßigkeiten, Störungen und Störfaktoren werden ebenfalls grundlegend berücksichtigt.

\subsubsection{Meßtechnik}

Seine konvexe Muschelform prädestiniert das Theater als Testobjekt zum Einsatz eines Raumscanners, da hierbei sichttote Bereiche nahezu völlig ausgeschlossen sind. Die in der Kampagne 2003 mit TOTAL (s. o.) gewonnenen Meßdaten der prima cavea dienen dabei als hochpräzise Basis bei Datentransfer und Schnittstellenabgleich mit einem Raumscanner (RIEGL TUW-ILScan, TU Wien) und damit gleichzeitig der Entwicklung eines allgemein anwendbaren Konzepts zum Einsatz hochpräzise messender Laser-Tachymeter in Kombination mit optimierten, kompatiblen Raumscannern in der Bauaufnahme. Ziel ist der künftige Einsatz eines solchen Image-Scanners als Meßinstrument für media und summa cavea des Theaters.

\subsubsection{Entwicklung eines dauerhaften Restaurierungs-/Sanierungskonzepts der Anlage}

Die Ergebnisse von Baudokumentation und Bauanalyse werden darüber hinaus der Lösung eines aktuellen Problems dienen, nämlich der Entwicklung eines Restaurierungkonzepts, das die substanzschonende Nutzung der Anlage unter besonderer Berücksichtigung der antiken Vorgaben in Material und Bautechnik, aber auch bezüglich architekturtheoretischer Aspekte wie der Akustik in Zukunft ermöglichen wird.

\subsection{Forschungen in der Oberstadt von Ephesos}

(Projektleitung: St. Groh; Mitarbeiter: V. Lindinger, K. Vondrovec)

\subsubsection{Systematische GIS-Kartierung, Vermessung}

Im Herbst 2003 wurde in einer zweiwöchigen Kampagne die systematische GPS-Kartierung der archäologischen Strukturen in Ephesos weitergeführt. In der bislang vierten GPS-Kampagne wurde 
die Geländetätigkeit des Jahres 2002 fortgesetzt, wobei man in neun Arbeitstagen 4000 Punkte einmaß. Der archäologische Survey umfaßte die südlichen Abhänge des Panayırdağ vom sog. Staatsmarkt (Höhe Bouleuterion) bis zum Theater.

Am Kamm und Plateau des Panayırdağ wurden die Stadtmauer dokumentiert und Teile des südlichen Plateaus vermessen. In den steilen Südhängen konnten im Fels zahlreiche Abarbeitungen (Steinbrüche, Verebnungen) und die oberste Verbauungsgrenze festgestellt werden, der sehr dichte Bewuchs mit bis zu 1,5 m hohen Gräsern erschwerte die Erkennung der archäologischen Objekte. Über den die Kuretenstraße flankierenden Gebäuden sind zwei weitere Insulae in den - vor allem im oberen Bereich - sehr steilen Hängen errichtet worden. Die alten Grabungsschnitte und Mauern entlang der Kuretenstraße wurden neu vermessen.

In Kooperation mit İ. KAYAN (Universität Izmir) wurden im Bereich des Theaters und in der östlich der Oberstadt vorgelagerten Ebene zahlreiche Bohrlöcher sowie der südöstlich der Oberstadt auf einem seichten, durch die Anlage von Weingärten bereits stark verebneten Hügel gelegene prähistorische Siedlungsplatz eingemessen.

Im September wurden von Archeo Prospections ${ }^{\circledR}$ ergänzende und abschließende geophysikalische Messungen mit Georadar und Elektromagnetik im Ausmaß von ca. 10 ha vorgenommen.

\subsubsection{Keramiksurvey}

In Kooperation mit der Österreichischen Akademie der Wissenschaften, Institut für Kulturgeschichte der Antike (St. Groh, S. Ladstätter, V. Lindinger; D. Iro, H. Schwaiger, M. Teichmann, A. WALDNER [Student/-innen der Universität Wien]; 6 türkische Arbeitskräfte)

Im Februar 2003 wurde mit den Vorbereitungen für den ersten systematischen, intensiven Keramiksurvey in der Oberstadt von Ephesos begonnen. Das Plateau der Oberstadt wurde mit 'linewalking' begangen, um einerseits erste Verteilungsmuster von Oberflächenmaterial in das GIS einfließen zu lassen und andererseits die Untersuchungsflächen für die Herbstkampagne auszuwählen.

Im November fand auf zwei frisch gepflügten Feldern in der Oberstadt der intensive Keramiksurvey statt. Im Zuge der Feldarbeiten wurden $10 \times 10 \mathrm{~m}$ große Quadranten ausgesteckt und das gesamte Oberflächenfundmaterial aufgelesen (ca. 150000 Stück). Daneben wurden naturräumliche Daten (topographische Situation, gegenwärtige Nutzung, Bodenart) sowie ortfremdes Material (Ziegelbruch, Steine, Architekturteile) quantitativ erfaßt und aufgenommen. Insgesamt untersuchte man mit dieser Methode 243 Quadranten (189 auf Feld 1, 54 auf Feld 2), etwa 2,5 ha. Das dabei gewonnene Fundmaterial wurde im Anschluß nach Quadranten quantitativ erfaßt, wobei diagnostische Stücke im Detail aufgenommen wurden. Erste Ergebnisse sind der Nachweis einer abhängig von der jeweiligen Zeitstellung unterschiedlich intensiven Nutzung des Areals vom 4. Jahrhundert v. Chr. bis in das 7. Jahrhundert n. Chr. Auch konnten anhand von Fundkonzentrationen und oberflächlich sichtbaren angepflügten Mauerteilen eine Reihe im oberflächennahen Bereich liegender Baustrukturen räumlich eingegrenzt werden.

Im Rahmen des ‘Oberstadtprojekts' erfolgte parallel zu den Geländetätigkeiten die Eingabe der zur Oberstadt relevanten Literatur in eine GIS-bezogene Literaturdatenbank, die Aufnahme und Lokalisierung der bislang auf dem Gebiet der Oberstadt vorgenommenen archäologischen Feldforschungsvorhaben sowie die Analyse der GPS-Survey-Daten im GIS sowie in der projekteigenen Datenbank.

\subsection{Sogenanntes Lukasgrab}

(Projektleitung: A. PÜLz [ÖAW])

Für die Kontrolle verschiedener Maße und der Baubeschreibung wurden am Lukasgrab partielle Reinigungsarbeiten ausgeführt (etwa im Bereich der byzantinischen Treppenanlagen, im Korridor und den beiden zugänglichen Kammern).

Ein bereits bekanntes Fragment des Architravs des kaiserzeitlichen Monuments, das in der Südtreppe sekundär eingebaut worden war, wurde in das Steindepot des Grabungshauses gebracht. Der Marmorblock zeigt an seinen beiden Enden jeweils einen Teil der obersten Faszie sowie das 
anschließende Kopfprofil. Wenige Buchstabenreste belegen, daß sowohl am Innen- wie am Außenarchitrav eine Inschrift angebracht gewesen sein mußte. Der Katalog der Architekturfragmente des kaiserzeitlichen sowie des byzantinischen Baus wurde im Steindepot des Grabungshauses überprüft und vervollständigt.

\subsection{Der Prunkbrunnen des C. Laecanius Bassus}

(Projektleitung: M. Aurenhammer; Leitung vor Ort: K. Jung [Architektur], M. Hofbauer [Grabung]; M. Koller [†, Grabungsassistenz], G. Plattiner [Architekturornamentik], E. Rathmayr [Skulptur], A. Bounegru [Archäologiestudent]).

Ziel dieses neuen, vom FWF geförderten zweijährigen Projekts (Projektnr. 16591 G 02) ist die Publikation des an der Schnittstelle von 'Domitiansgasse' und 'Südstraße' gelegenen Prunkbrunnens. Die Vorlage des Bauwerks vom Typus 'Fassadennymphäum' ist ein Desiderat der Forschung, zumal es einerseits durch die Ehreninschrift gut datiert ist, andererseits sind Architektur und Plastik so umfangreich erhalten (ca. 30\% bzw. 80\%), daß eine fundierte Rekonstruktion möglich ist. Die Endpublikation soll das Bauwerk umfassend - inklusive der Architekturornamentik und der Skulpturenausstattung - im lokalen wie historischen Kontext darstellen.

Grundlage für die Arbeiten sind die Grabungen (G. LANGMANN) und die erste Erforschung des Bauwerks (E. FossEL) in den 60er Jahren und die umfangreichen Vorarbeiten der 80er Jahre von K. Jung (Architektur) und M. Aurenhammer (Skulptur) sowie die zahlreichen Erwähnungen von Bauwerk, Dekoration und Ausstattung in der Sekundärliteratur.

\subsubsection{Archäologie}

Ziele waren die Freilegung der Ruine entsprechend dem in den 60er Jahren freigelegten Zustand und die punktuelle Freilegung der Fundamente. Die Ruine und die angrenzenden Bereiche der Südstraße, der Domitiansgasse und des Staatsmarkts wurden mit Ausnahme des im Osten hinter der Rückwand des Bauwerks gelegenen 'Technikraums' (geplant für die Kampagne 2004) gereinigt. Die rezenten Verschüttungen im Bereich der westlich des Schöpfbeckens liegenden Entwässerungsrinne, des nördlichen Bauwichs, der Südwest- und der Nordwestecke wurden entfernt. Im Rahmen von tiefer greifenden Sondagen wurden die Fundamente an der Südost- und der Nordwestecke freigelegt und dokumentiert. An der Südseite konnte im mittleren Bereich der Anschluß an das originale StraBenniveau der Südstraße freigelegt werden.

Durch die Reinigungsarbeiten und Grabungen konnte die Dokumentation der in den Jahren 1960-63 erfolgten Arbeiten zugeordnet, überprüft und mit den neuen Befunden und Erkenntnissen verknüpft werden.

\subsubsection{Bauforschung}

Im Bereich der Sondagen wurden die Wasserzu- und -abläufe, die Fundamente der Tabernakelfassade, des Hauptbeckens und des Schöpfbeckens sowie des vorgelagerten Ablaufbeckens (Viehtränke) untersucht. Im Anschlußbereich an die Südhalle und das Westtor des Staatsmarkts sowie an die Domitiansgasse und die Südstraße konnte die bauliche Situation vor der Erbauung des Nymphäums abgeklärt werden. Weiters wurde die Situierung des Gebäudes innerhalb der umgebenden Bebauung und des zur Erbauungszeit bestehenden Straßensystems untersucht.

Die in der Ruine und den angrenzenden Bereichen gelagerten Architekturblöcke wurden auf den Staatsmarkt transportiert und dort systematisch aufgelegt. Zusammengehörige Bruchstücke und ursprünglich benachbarte Steine wurden zueinandergelegt, wodurch der originale bauliche Zusammenhang überprüft und teilweise nachgestellt werden konnte und auch neue Erkenntnisse bzgl. der bautechnischen Details (Anschlußtechnik, Bautoleranzen etc.) gewonnen wurden. Im Zuge dieser Arbeiten wurden auch einzelne Blöcke des Unterbaus an originaler Stelle wiederaufgestellt. Die bereits in den 80er Jahren von K. Jung erstellte Bauaufnahme wurde entsprechend den Ergebnissen ergänzt, außerdem wurden in diversen Depots (auch auf der Johannesbasilika) gelagerte zugehörige Architekturbruchstücke gesichtet und, soweit erforderlich, gezeichnet. 


\subsubsection{Architekturdekoration}

G. Plattner begann mit der Dokumentation der Bauornamentik. Ziel ist die Vorlage der Ornamentik des inschriftlich datierten Baus und die Einordnung der Formen in ihrer Zeit. Der Brunnenbau stellt eine der frühesten Architekturfassaden im kleinasiatischen Raum dar. Damit verdienen die Bauform und die Syntax der Ornamentik besondere Beachtung. Vergleiche sind zum einen in Ephesos selbst zu finden, etwa die unmittelbar im Anschluß errichtete Bühnenwand des ephesischen Theaters, zum anderen im lateinischen Westen. Direkte Einflüsse stadtrömischer Ornamente am Brunnen sind wohl durch die Person des Bauherrn selbst zu erklären. Damit ist ein Themenkreis angerissen, der - zumal in der durch Neuerungen reichen flavischen Epoche - in seiner Bedeutung weit über das Einzelmonument hinausführt und einen aktuellen Schwerpunkt verschiedener archäologischer Disziplinen darstellt.

\subsubsection{Skulptur}

E. Rathmayr nahm alle Skulpturen, die im Bereich des Brunnens und in dessen Umgebung gefunden wurden, auf. Grundlage dafür war die Ermittlung der Fundorte anhand der Tagebücher, Fundjournale und der Scheden F. EichLERs. Das Ziel der Arbeiten ist die Scheidung der tatsächlich zugehörigen Denkmäler und die Rekonstruktion der Ausstattung. Die Position einzelner Skulpturen in den Fassaden des Nymphäums konnte bereits diskutiert werden.

\subsubsection{Photographie}

Die gereinigten und (wieder) freigelegten bzw. freigeräumten Bereiche der Ruine wurden photographisch dokumentiert. Weiters wurde mit der Dokumentation der Architekturblöcke begonnen, wobei vor allem die für die Bearbeitung der Architekturdekoration und der Skulpturenausstattung relevanten Architekturteile (Kapitelle, Pfeiler, Reliefsockel, Statuensockel, Kassetten etc.) photographiert wurden.

\subsection{Bouleuterion}

(verantwortlich: L. BIER [†], Brooklyn College of the City University of New York)

Die zeichnerische Aufnahme der Bauteile wurde in zwei kurzen Kampagnen abgeschlossen; die Baubeschreibung wurde vor dem Monument überprüft. Ein Bericht über den Zustand des Gebäudes mit Vorschlägen zur Konservierung wurde vorgelegt. Die Monographie zum Gebäude wird nach dem überraschenden Tod des Verfassers im Jahr 2004 postum in den »Forschungen von Ephesos« erscheinen.

\subsection{Kuretenstraße/Nymphaeum Traiani}

(Projektleitung: H. Thür [ÖAW], Mitarbeiterinnen: U. Quatember, A. Pyszkowski)

U. Quatember hat, unterstützt von H. Thür, die nichtverbauten Architekturteile des Trajansnymphäums neu geordnet und damit die Voraussetzungen für die Neubearbeitung, die sie im Rahmen einer Dissertation an der Universität Wien vorlegt, geschaffen. Bei diesen Aufräumungsarbeiten wurde ein Hermenpfeiler wieder aufgefunden und dokumentiert, der zu dem von R. HansLmayr auf der Beckenbrüstung rekonstruierten Hermenzaun gehört. U. Quatember setzte weiters die zeichnerische Dokumentation der noch nicht aufgenommenen Bauteile fort, kontrollierte und ergänzte die bereits vorhandenen Zeichnungen; für die Gebälkteile des Unter- und Obergeschosses sowie für die Kassettenblöcke, welche gemeinsam die Grundlagen der Rekonstruktion liefern, konnte sie dies abschließen. Außerdem konzipierte sie eine Baubeschreibung des Bauwerks. Mit K. Jung konnten fragliche Punkte der Rekonstruktion diskutiert werden, gemeinsam wurden die Grabungen Milet und Priene zu Studienzwecken besucht.

Außerdem beaufsichtigte U. Quatember die Reinigungsarbeiten an dem unter der Kuretenstraße verlaufenden Kanal, der in diversen Abschnitten einer Restaurierung unterzogen wurde. A. Pyszkowski ergänzte für die Bauphasenpläne der Kuretenstraße östlich des Nymphäums Stein- und Bauaufnahmen der spätantiken Bauphase. 


\subsection{Partherdenkmal}

(Projektleitung: W. Oberleitner; Bauforschung: H. Thür, Mitarbeiterin: A. Pyszkowski)

A. Pyszkowski vollendete die noch ausstehenden Vergleiche der bautechnischen Anschlüsse an ephesischen Bauten der mittleren Kaiserzeit (Nymphäum des C. Laecanius Bassus, Theater, Trajansnymphäum, Hadrianstempel, Serapeion, Vediusgymnasium). Außerdem wurde nochmals der sog. Altarbau - insbesondere unter bautechnischen Aspekten - analysiert. Die Diskussion des Altarbaus als Standort für das Partherdenkmal kann nunmehr beendet werden: weder die Stierkopfgirlandenplatten noch die Figurenfriese sind auf dem Fundament unterzubringen. Die Arbeiten für die Publikation des Parthermonuments sind vor Ort damit abgeschlossen.

\subsection{Meterheiligtum}

(verantwortlich: F. Soykal-Alanyali [Universität Eskişehir]; Mitarbeiter E. Ulaș Ermiş]]

Im Temenos des Heiligtums wurden Reinigungsarbeiten vorgenommen, die Geländebeschreibungen und photographischen Arbeiten wurden fortgesetzt. Die 2001 bei Reinigungsarbeiten gefundenen Terrakotten wurden aufgenommen und photographiert; die Keramik wurde M. KERSCHNER zur Bearbeitung übergeben. Die am Nordostabhang des Panayırdağ bzw. an der Prozessionsstraße liegenden Gräber wurden zum Großteil untersucht und photographisch dokumentiert. Ein weiterer Kultort am Bülbüldağ (sog. Felsthron) wurde untersucht und photographisch dokumentiert.

\subsection{Sogenannte Paulusgrotte}

(Projektleitung: R. PILLINGeR [Institut für Klassische Archäologie der Universität Wien]; Mitarbeiter/ -innen: E. LÄssig, D. ZeNiTI)

Gleichzeitig mit der Restaurierung (s. u. 2.7) erfolgte die zeichnerische Aufnahme der 2002 bei der Renovierung des Höhleneinganges freigelegten Bauskulptur durch D. Zeniti sowie die erste Bearbeitung auch der älteren 1996-98 gefundenen Stücke durch E. Lässig.

\subsection{Meryemana}

(verantwortlich: A. PÜLz [ÖAW, Institut für Kulturgeschichte der Antike])

Anstoß für diese Untersuchungen war ein im Jahr 2003 in Selçuk aufgetauchtes Gerücht, dem zufolge in Meryemana, ca. $80 \mathrm{~m}$ westlich der heutigen Kapelle, das Grab Marias zu lokalisieren sei; dieses Gerücht wurde von der Presse aufgegriffen und verbreitet. Daraufhin ordnete die Antikenverwaltung der Türkischen Republik eine wissenschaftliche Untersuchung durch das österreichische Grabungsteam in Ephesos an.

Das Grabungsareal befindet sich ca. $80 \mathrm{~m}$ westlich der Marienkirche von Meryemana an der AuBenseite der östlichen Peristylhalle einer antiken Villenanlage. Eine geophysikalische Prospektion durch die Universität Izmir (S. Akci) hatte hier zwei ca. $2 \times 2 \mathrm{~m}$ große Anomalien etwa 80-100 cm unter dem heutigen Laufniveau festgestellt. Zur Untersuchung dieser beiden Stellen wurden zwei Sondagen (SO 1und SO 2) angelegt.

Nördlicher Schnitt (SO 1): In der Südhälfte der Sondage (Größe: ca. 4,5 × 3 m) kamen bereits nach $30 \mathrm{~cm}$ der gewachsene Fels sowie eine postbyzantinische, Ost-West verlaufende Mauer ans Tageslicht; sie endet direkt an der Außenschale der Ostwand des Peristyls. Im Norden der Sondage konnte dagegen eine bereits 1898 untersuchte Wasserleitung partiell wieder freigelegt werden, deren Kanalführung in den gewachsenen Fels geschlagen ist. Über eine Falleitung direkt vor der Peristylwand wurde das Wasser weiter in ein Becken im Zentrum des Peristyls geführt. Dieses ist Teil einer späthellenistisch-frührömischen, auf mehreren Ebenen errichteten Villa, die man ebenfalls bereits im ausgehenden 19. Jahrhundert partiell untersucht hatte.

Das in SO 1 entnommene Fundmaterial stammt vorwiegend aus rezenten Schuttschichten (Altgrabung). Lediglich im Bereich von 0,5-1 m östlich der Peristylmauer wurden noch ungestörte Straten angetroffen. 
Südlicher Schnitt (SO 2): In Sondage 2 (Größe: $2 \times 2,5 \mathrm{~m}$ ) wurden unter einer lediglich $35 \mathrm{~cm}$ starken rezenten Schuttschicht (Funde: Dachziegel- und Porzellanfragmente, eine Bratpfanne, Patronenhülsen, Flaschenfragmente, Dosenöffner etc.) vier Stufen einer Ost-West orientierten Treppe samt den beiden Wandungen freigelegt. Über diese ehemals siebenstufige Anlage konnte man noch bis in die 1. Hälfte des 20. Jahrhunderts das Peristyl der Villa in Richtung Osten verlassen.

Die relevanten und nicht rezent gestörten Fundkomplexe wurden von S. LADSTÄTTER (ÖAW) durchgesehen und das datierende Fundmaterial zeichnerisch aufgenommen. Festgestellt werden konnte, daß es sich durchweg um hellenistische Funde des 2./1. Jahrhunderts v. Chr. handelt, wogegen kein einziger römischer oder spätantiker Scherben anzutreffen war.

Es ist keine Überraschung, daß das angebliche Grab Marias nicht angetroffen wurde, überraschend war allerdings, daß die Ergebnisse der geophysikalischen Prospektion von den archäologischen Untersuchungen nicht bestätigt werden konnten. Zusammenfassend kann festgestellt werden, daß die Grabungen außer den erwähnten Informationen zur römischen Villa keine neuen Ergebnisse erbracht haben. Großenteils traf man vielmehr auf bereits bekannte Befunde.

\subsection{Vermessungsarbeiten}

(M. Hofbauer, Ch. Kurtze)

\subsubsection{Stadtgebiet}

Die Bauaufnahme des Theaters unter Leitung von M. DöRING-WILLIAMs erhielt praktische Unterstützung bei der Vermessung von Detailpunkten an sichtbaren Kanten der imma cavea (Kerkides I, IX, X, XI). Durch weitere geodätische Bestimmung von Paßpunkten kann gewährleistet werden, daß die lokalen Aufnahmen der Architekten bei Bedarf in den einheitlichen Koordinatenrahmen von Ephesos transformiert werden können. Für den Zweck der photogrammetrischen Auswertung wurden im sog. Freudenhaus (M1; Bearbeitung D. BoulAsIKIS) und in einigen ausgewählten Kammern an der Südseite der Agora (Leitung P. SCHERrer) eindeutig identifizierbare Paßpunkte an einigen Mauern gemessen. Weiters wurde die Fundlage eines Sarkophags südöstlich des Panayırdağ an der Damianosstoa tachymetrisch bestimmt. Östlich an das Meterheiligtum angrenzend konnte der Verlauf einer historischen Mauer vermessen werden. Die Dokumentation beinhaltet auch digitale photographische Aufnahmen.

\subsubsection{Belevi}

Für archäologische und bauforscherische Zwecke des Projektes Belevi erfolgten folgende Vermessungsarbeiten in Zusammenarbeit mit P. Ruggendorfer und R. Heinz: tachymetrische Aufnahme der neuen Sondagengrenzen und weiterer Details mit anschließender digitaler Planerstellung, Koordinatenbestimmung von Detailpunkten für die Einpassung archäologischer Pläne, Bestimmung von Höhenpunkten mit geometrischem Nivellement, Paßpunktvermessung für die Entzerrung von Profilphotographien und Aufnahme der derzeitigen Situation des Zufahrtsweges im Osten des Monuments. Alle Messungen konnten vor Ort verarbeitet und sowohl analog als auch in digitaler Form weitergeleitet werden.

\subsection{Ayasoluk}

(Projektleitung: Ş. Pfeiffer-Taş; Mitarbeiter/-innen: I. Avci, M. Gülersoy, A. Kricki, Ch. Kurtze, B. Olcay, F. Öztürk, K. Stingl, Ç. Salman, J. Vroom, F. Yilmaz; K. Herold und S. Ílhan [Restaurierung])

Alle Feldarbeiten in den Bauwerken wurden im Einvernehmen mit dem Eigentümer dieser Monumente, der Generaldirektion für Stiftungen, gemäß einem Protokoll vom 8. 9. 2000 geleistet.

1.16.1 İsa Bey Hamam1

Die Arbeiten am İsa Bey Hamamı konzentrierten sich auf die Überprüfung der Bauaufnahme sowie die Abklärung abschließender Fragen im Hinblick auf die geplante Publikation. In diesem Zusam- 
menhang konnten wichtige Ergebnisse zu den Bauphasen, zur Haustechnik und zur Ausstattung der Innenräume erzielt werden. Durch die Abhebung einer Bodenplatte unmittelbar vor dem Durchgangsbereich von Raum 1 zu Raum 2 konnte nachgewiesen werden, daß der Raum 1 mindestens zwei unterschiedlich angelegte Bodenniveaus hat. Die Veränderung des Bodenniveaus kann auch durch mehrere Hinweise in den Innenräumen bestätigt werden.

$\mathrm{Zu}$ den architektonischen und historischen Untersuchungen kam die Fortsetzung der technischen Vorsorge für die notwendigen statischen Sicherungsmaßnahmen, die vor allem im Bereich der Kuppelkonstruktionen notwendig waren. Weitere substantielle Konservierungs- und Restaurierungsarbeiten sowie Ergänzungen der statischen Stabilisierung betrafen vor allem die Bausubstanz der Kuppeln.

1.16.2 Anonymer Hamam westlich der İsa Bey Moschee (Hamam III)

Nach den entsprechenden Reinigungen der Ruine konnte im Jahr 2003 die intensive Bauaufnahme fortgesetzt und in bezug auf die sichtbar anstehenden Mauern vorerst abgeschlossen werden. Das gesamte Gebäude wurde photographisch dokumentiert. Um erste Informationen über die Baugeschichte, die Raumfunktionen sowie die Ausstattung der umgebenden Räume zu bekommen, wurden drei Sondagen angelegt.

Sondage 1 diente der Bauabfolge zwischen dem Räumen 4 und 14, die durch eine deutliche vertikale Baufuge getrennt sind. Eine vermauerte Türöffnung weist ein ca. 0,70 m hohes, unregelmäßig verfülltes Fundament auf, die darüber ansetzende Vermauerung selbst zeigt eine dem Mauerwerk des Gebäudes entsprechende Bautechnik. Sondage 2 wurde ebenfalls in Raum 13 an der Außenseite der Nordwand vom Raum 12 angelegt, welcher mit deutlicher Baufuge angesetzt und als Wasserdepot zu deuten ist. In Sondage 3 sollten die Nutzungsphasen, das Bodenniveau, die Funktion und Ausstattung des Raumes 14 untersucht und den Ergebnissen von Sondage 1 gegenübergestellt werden. In dieser Westwand wurden zwischen Niveau 6,28 und 6,52 m zwei übereinanderliegende Wasserrohre angetroffen, die mit einem minimalen Gefälle von Süden nach Norden verlaufen und ungestört durch die Vermauerung der oben genannten Türöffnung geführt sind. Ihr Ende finden sie nach ca. 1,80 m etwa in der Mitte der Wand, darunter sind im roten Wandputz die Ansätze eines Brunnenbeckens erhalten geblieben, für welches sie offensichtlich den Zulauf von Kalt- und Warmwasser bildeten. Das ursprüngliche Bodenniveau war festzustellen, vom Bodenaufbau ist allerdings nur an der Nordwestecke der Rest eines Steinbelags erhalten geblieben. Entsprechend der Außenseite der Mauer liegt unter dem Bodenniveau der zugemauerten Türöffnung eine grobe Fundamenteinfüllung, Zeitstellung und Funktion der Türöffnung sind noch zu klären. Im Ostprofil der Sondage sind Reste der Ausstattung des Raumes mit einem Hypokaustsystem angetroffen worden, welches offenbar von Süden aus beheizt wurde.

\subsubsection{Kale Dibi Hamamı (Hamam IV)}

Die ersten Untersuchungen zu bau- und kunstgeschichtlichen Aspekten des sog. Kale Dibi Hamamı im Bereich des Campingplatzes »Garden« westlich des Burgbergs wurden ausgeführt und die Vermessung des Vorjahres überprüft. Die von der Gemeinde zugesagte Einzäunung der Ruine mußte auf das Jahr 2004 verschoben werden, so daß 2003 weitere Arbeiten nicht möglich waren.

\subsection{Das Mausoleum von Belevi}

Das Projekt zur abschließenden Bearbeitung dieses herausragenden Grabmonuments ist am Institut für Kulturgeschichte der Antike an der Österreichischen Akademie der Wissenschaften beheimatet und findet im Rahmen der Ephesos-Konzession des ÖAI statt. Die Personalkosten werden durch eine Sonderfinanzierung der Österreichischen Akademie der Wissenschaften und in einem FWFProjekt sichergestellt, das ÖAI stellt die Arbeiterkosten und die technische Infrastruktur zur Verfügung und sorgt für die Unterbringung und Verpflegung der Mitarbeiter/-innen im Grabungshaus. 
1.17.1 Archäologie und Dokumentation

(Projektleitung: P. Ruggendorfer [ÖAW, Archäologie]; Mitarbeiter/-innen: H. Liko, L. Zabrana; Praktikanten: A. Albayrak, S. GÜNDÜZ, A. ÖZYurt)

Eine der wesentlichen archäologischen Aufgaben im Rahmen der Grabungen am Mausoleum stellte die Untersuchung des Terrains entlang der Südseite und vor der Grabkammer dar. In diesem Areal, bei dem es sich teilweise um den letzten erhaltenen originalen Versturz- und Abbauhorizont nach dem Abschluß der Altgrabungen von 1930-35 handelte, wurden daher im Jahr 2003 drei Sondagen geöffnet. Anhand des Ostprofils von SO 13, das den Südhang vom Stufenunterbau bis auf die rund $6 \mathrm{~m}$ höher liegende Felsterrasse durchgehend schneidet, können nun klare Aussagen zur Anlage des Mausoleums, dem Bau der Wasserleitung sowie zur Zerstörung bzw. Abbaugeschichte der beiden Monumente getroffen werden:

Der Stufenunterbau des Monuments ist zu großen Teilen direkt auf dem Fels aufgesetzt, wo dies nicht möglich war, dienen einzelne Blöcke zum Niveauausgleich. Hinweise auf einen vor der Grabkammer in den Fels eingetieften Bothros, wie er am Maussolleion von Halikarnassos festgestellt wurde, fehlen. Überraschend schmal ist der Abstand von der südlichen Außenwand des Monuments zu dem Südhang, der nur knapp $3 \mathrm{~m}$ beträgt. In der Kaiserzeit wurde in diesen Zwischenraum die nach Ephesos führende Wasserleitung eingebaut, deren Nordwand auf den Stufenunterbau aufgesetzt ist und deren Sohle etwa auf dem Niveau der Trittfläche der untersten Stufe verlief. Eine rund 0,50 m dicke Erdpackung schützte das Gewölbe der Leitung vor herabstürzenden Architekturteilen. Über dieser Packung liegt noch zusätzliches Material, das vom Hang im Süden abgerutscht ist. Beide Schichten gemeinsam erreichen eine Dicke von ca. 2 m; an der Oberkante fanden sich zahlreiche große Wandverputzplatten mit dicken Sinterresten, die während einer Reparatur der Wasserleitung in der 2. Hälfte des 3. Jahrhunderts n. Chr. abgeschlagen und aus dem Kanal entfernt wurden.

Oberhalb der Verputz- und Sinterplatten lagen in dichtem Verband die Reste eines mächtigen Architekturversturzes, der sich aus Teilen des Obergeschosses zusammensetzte. An seiner Unterkante, die etwa $4 \mathrm{~m}$ über der Oberkante der Euthynterie liegt, fanden sich über mehrere Meter verstreut die Fragmente zweier Kassettenreliefs mit der Darstellung einer Kentauromachie. Das erste Fragment, zusammengesetzt aus mehreren Bruchstücken, ist ein Teil des bislang fehlenden Kassettenfeldes Süd 3 (B 03/SK 28 und 29) vom Interkolumnium über der Grabkammer, welches einen in heroischer Nacktheit kämpfenden Lapithen zeigt. Das zweite ist ein Bruchstück des Reliefs Süd 2 (B 03/SK 32) mit dem Oberkörper und dem bärtigen Kopf eines Kentauren.

An der Westseite des Mausoleums wurden weitere vier Sondagen (SO 7, 8, 11 und 14) geöffnet und dabei Straten aus der Entstehungszeit des Monuments angetroffen.

\subsubsection{Bauforschung}

(Projektleitung: R. Heinz; Mitarbeiter/-innen: M. Akar, E. Coşkunçay, A. Ercivan, B. Eret, K. Güler, G. Kaymak, U. Kögl, D. Zeniti; Ch. Kurtze [Vermessung])

Die Arbeiten der Bauforschung widmeten sich der weiteren zeichnerischen Dokumentation des in situ-Bestands des Sockels und der Aufnahme des verstreuten Steinmaterials nach technischen Kriterien. Die Arbeiten konzentrierten sich auf die steingerechte Rekonstruktion der Gesimsblöcke des Obergeschosses, die an ihrer Rückseite Einarbeitungen aufweisen, welche als Auflager für die großen U-förmigen Kassettenblöcke der dritten Schicht dienten. Die theoretischen Zuordnungen der einzelnen Blöcke wurden durch zahlreiche Architekturproben direkt am Stein überprüft. Drei Gesimsblöcke zusammen ergeben die Ausnehmung für zwei Kassettenblöcke. An den Eckfeldern tritt an jeweils einer Seite ein vierter Gesimsblocktyp auf, der keine Einarbeitungen besitzt, da er parallel zur Spannrichtung der Kassettenblöcke verlegt wurde.

Durch die Anmietung eines großen Autokrans eröffnete sich die Möglichkeit, das schwer zu erreichenden Steinmaterial vor und um die Südwestecke auf die Auslegeterrassen zu verlagern und aufzunehmen. Die Gebälkzone dieser Ecke konnte steingerecht rekonstruiert und die Ergebnisse durch Architekturprobe überprüft und vor Ort bestätigt werden.

Bei der Grabung wurden neue Dachplatten aufgedeckt; dabei ist ein Ichsenblock, der einen weiteren Beleg für die nach innen geneigten Dachflächen der Peristasisüberdeckung darstellt und für 
die Bestätigung der Rekonstruktion von besonderer Bedeutung ist. Im Anschluß an die Ichsenblökke sind zwei weitere Dachplatten zu rekonstruieren, die im Vergleich mit den Standardblöcken eine deutlich geringere Breite aufweisen und die Ecklösung des Daches näher definieren. Schicht 5 und 6 (letzte von der Nordwand) der Dachplatten haben sauber und eben gearbeitete Lagerflächen, sie sitzen direkt auf dem Mauerwerk der Hofwände.

Die steingerechte Rekonstruktion der Grabkammer wurde überarbeitet, und die verschleppten Bodenplatten und Wandblöcke der untersten Schicht wurden wieder in ihre ursprüngliche Lage zurückversetzt.

Auch die Stellung der Südwand des Hofes läßt sich nunmehr genauer bestimmen: zwei Pfeilerblöcke mit Anathyrosis für den Anschluß der Fußbodenplatten sind tiefer als jene der West- bzw. der Ostwand, ähnlich den Nordwandpfeilern. Die Tiefe der Südwand kann durch zwei Binderblöcke des Mauerwerks ermessen werden, sie entspricht etwa jener der Nordwand.

\subsection{Fernwasserleitungen}

(Projektleitung: G. Wiplinger:, Mitarbeiter: G. Jansen, P. Kessener, S. Piras)

Die Geländebegehungen konzentrierten sich auf die zwei längsten der vier bisher bekannten Fernwasserleitungen, d. h. auf die Değirmendere-Leitung und zwei ihrer Zuleitungen (Sultaniye und Mercankuyusu) sowie auf die Kayapinar-Leitung; hier vor allem auf unbekannte Streckenabschnitte, die vor zwei Jahren unberücksichtigt blieben und auch bisher von keinem der früheren Forscher behandelt wurden. Es ist beachtlich, daß zwei neue Zuleitungen, sieben bisher unbekannte Aquäduktbrücken und ein Tunnel neu entdeckt werden konnten. Durch die Neufunde und die Gesamtsituation der Leitungen konnten auch detaillierte Einblicke in die Eigenheiten der Leitungen gewonnen werden. Weiteres Ziel war auch die Lösung von im ersten Arbeitsjahr 2001 angerissenen Problemen und die Untersuchung der kritischen Punkte.

\subsubsection{Değirmendere-Leitung}

Von dem Abschnitt zwischen Başkemer-Aquäduktbrücke und Kuşadası sind nur wenige Streckensegmente erhalten. Es konnte geklärt werden, daß die Leitung nicht um den Değirmen Tepe herumzieht, sondern im Sattel durch den ca. $170 \mathrm{~m}$ langen Akrepli-Tunnel mit drei heute noch erhaltenen Schächten geführt wird. Die erste einbogige Brücke ist die Cuma-akşam-Aquäduktbrücke. Der von uns als Kalafat bezeichnete Tunnel konnte im Sattel zwischen Kalafat und Çamli Tepe mit 11 runden Einstiegschächten gefunden und streckenweise begangen werden, wobei der letzte begangene Abschnitt bis zum Tunnelende $300 \mathrm{~m}$ lang ist. Der gewölbte Tunnel hat einen Querschnitt von 35-70 × 170-210 $+\mathrm{x}$ cm. Über der Sohle sind zwei türkische Betonrohrleitungen verlegt, von denen die jüngere noch Wasser führt. Die Tiefe der Schächte schwankt zwischen 3,8 und ungefähr 25,0 m.

Nach dem Tunnel muß die Leitung wieder in das Damlacik-Tal Richtung Başkemer-Aquäduktbrücke hineingezogen sein, doch konnten hier keine Reste gefunden werden. Einziges Zeugnis der Leitung vor dem nächsten großen Tal ist ein zufällig offengebliebener, im Querschnitt $75 \times$ $75 \mathrm{~cm}$ großer und 1,25 m tiefer Revisionsschacht, der auf eine andere Konstruktion in diesem Streckenabschnitt hinweist. Weitere Schächte sind vermutlich durch landwirtschaftliche Tätigkeit verschüttet und nicht mehr aufzuspüren. Erst am Fuß des hohen Pilav Tepe wurden drei Aquäduktbrücken entdeckt. Die ersten beiden Brücken, die wir nach den Tälern als Zincirlikuyu- und Kocakelle-Aquäduktbrücken bezeichnet haben, weisen im unteren Bereich der Pfeiler mächtige Steinquader mit exakter Fugenschichtung auf. Darüber befindet sich ein mit Bruchstein verkleideter Kern. Die Zincirlikuyu-Brücke hatte nur einen Bogen, während die Kocakelle-Brücke mit zwei Bögen das jeweils kleine Tal überspannte. Zwischen den beiden Brücken ist die Leitung im Querschnitt an einer neu angelegten Straßenböschung deutlich zu sehen. Eine völlig andere Konstruktion weist die dritte Sabancik-Aquäduktbrücke mit einer Länge von ca. $235 \mathrm{~m}$ und einer Höhe von ca. $21 \mathrm{~m}$ auf. Sie überspannt mit einem großen Mittelbogen das Tal, während im oberen Geschoß im Südosten zunächst acht kleine, dann eine unbestimmbare Anzahl größerer Bögen zu rekonstruieren sind. Der 
kürzere Brückenabschnitt im Nordwesten wurde vermutlich nur von einer durchgehenden Mauer ohne Bögen gebildet und hatte einen einzigen nachweisbaren Durchgang. Kurz nach dieser Brücke ist die Leitung durch die Bebauung von Kuşadası gänzlich zerstört, bis sie über dem Atakule Hotel wieder aus dem Häusermeer heraustritt.

Sultaniye-Zuleitung: Außer der römischen Quellfassung nahe dem Dorf Sultaniye und der Kelebek-Aquäduktbrücke, auf der die Leitung von Norden nach Süden das Bahcecik-Tal überquert, sind nur Tonrohrfragmente gefunden worden, welche lediglich die Hanglage angeben. Die Leitung muß demnach nach der Kelebek-Brücke am Südhang hoch über der Bahçecik-Boğazi-Aquäduktbrükke gelaufen sein und zieht in den Sattel vor Kuşadası hinein, so daß sie - wenn überhaupt - sehr weit im Süden in die Değirmendere-Leitung einmündete.

Mercankuyusu-Zuleitung: Bereits 2001 wurde eine Zuleitung am Auslauf der MercankuyusuAquäduktbrücke festgestellt. Heuer wurde die Einmündung freigeputzt und der Leitungsquerschnitt im Straßenprofil entdeckt. Die Leitung zog höher am Hang parallel und in Gegenrichtung zur Değirmendere-Leitung an die Brücke heran. Möglicherweise steht sie in Verbindung mit der Sarırenkli-Aquäduktbrücke, doch konnten keine weiteren Abschnitte mehr entdeckt werden.

\subsubsection{Kayapinar-Leitung}

Von der Quelle, die heute noch als Kayapınar bezeichnet wird, aber keine Spuren einer römischen Quellfassung aufweist, bis kurz vor dem Mausoleum von Belevi wurden kaum Reste der Leitung angetroffen. Die Leitung lag hier nur sehr niedrig über der Talsohle, was den Vorteil hatte, daß sie nicht weit in die Täler hineinziehen mußte und auch keine aufwendigen Brückenkonstruktionen benötigte. Der Nachteil dieses tiefen Verlaufes lag aber damals wie heute in der Zerstörung des Bauwerks durch landwirtschaftliche Nutzung der unmittelbaren Umgebung. In römischer Zeit mußte bereits wenige Jahre nach Inbetriebnahme der Leitung ein Gesetz erlassen werden, welches in einer im Museum von Tire ausgestellten Inschrift (Inv. 780) erhalten ist und das jegliches Pflügen und Pflanzen im Abstand von $10 \mathrm{Fuß}$ beiderseits des von Claudius Aristion gestifteten Gerinnes und das Anbringen von Öffnungen in der Stadt bei Androhung einer Geldstrafe von 12500 Denaren verbot. Mit der Inschrift kann nun die Kayapınar-Leitung eindeutig als die von Claudius Aristion gestiftete Leitung identifiziert werden, da die - aufgrund der in der Inschrift am Nymphaeum Traiani genannte Länge von 210 Stadien noch in Frage kommende - DeğirmendereLeitung hoch über der Küste am Steilhang liegt und daher nicht durch die Landwirtschaft gefährdet war.

Erst kurz vor dem Mausoleum von Belevi sind geringe Reste des Gerinnes erhalten. Im gesamten Mausoleumsbereich wurde die Leitung vermutlich in der 2. Hälfte des 3. Jahrhunderts erneuert; darauf weisen einerseits Münzfunde aus den neuen Grabungen, andererseits der im Mausoleumsbereich abgeschlagene Sinter. Ungefähr $200 \mathrm{~m}$ westlich des Mausoleums ist sogar ein $2 \mathrm{~m}$ langer Abschnitt mit Gewölbe erhalten, bevor ein kleiner Wasserdurchlaß und die Mausoleum-Aquäduktbrücke die Stützmauer unterbrechen. Erst die an der Kreuzung von Belevi nach Selçuk und Izmir liegende Belevi-Aquäduktbrücke, die bereits vor zwei Jahren vermutet wurde, bildet die Fortsetzung der Leitungsreste nach Ephesos.

Am Panayırdağ konnte im Bereich des Meterheiligtums eine weitere Brücke gefunden werden, die als Meter-1-Aquäduktbrücke bezeichnet wird, während die 2001 gefundene als Meter-2-Aquäduktbrücke umbenannt wird.

In der Stadt Ephesos selbst konnte erstmals der Kanal unter der Cavea des Theaters begangen werden. Weiters wurden Überlegungen zum Nymphaeum Traiani angestellt, da hier die Leitung möglicherweise nicht endete, sondern in einem Bogen an den anderen Hang geführt wurde und Richtung Westen unter den beiden Hanghäusern die tiefer gelegenen Bereiche der Stadt, wie z. B. Agora und Hafen, mit Wasser versorgte. Diese Arbeitshypothese bedarf allerdings noch einer gründlichen Untersuchung. Weitere Diskussionspunkte in der Stadt waren das sog. Lukasgrab, die Wasserversorgung des Vediusgymnasiums und des 'Wasserschloßes’ des C. Laecanius Bassus. 


\section{Restaurierung}

(Projektleitung: K. Herold; Mitarbeiter/-innen: G. Acur, E. E. Acman, St. Becker, M. Çetinel, E. Çolak, C. Eger, C. Esen, E. Fischer, N. Gustavson, E. Hösl, S. İlhan, V. Loiskandl, E. Losi, M. Milcin, D. v. Miller, B. Müllauer, P. Pingitzer, M. Riemer, S. Sandner, M. Sprenger, P. Süss, D. Taner, C. Toy, K. Türk, A. Togay)

\subsection{Hanghaus 2}

Im Hanghaus 2 konnte mit der Sicherung von Ziegelmauerwerk begonnen werden. Dazu wurden am östlichen Tonnenrestbogen des Raumes H2/36c alle Risse mit Mörtel abgedichtet und mit Injektionsmörtel 'Malta' ausgespritzt und gefüllt, eine größere Fehlstelle mußte neu zugemauert werden. Nach dieser 'Probearbeit' und den dabei gewonnenen Erfahrungen soll in Zukunft versucht werden, auch kompliziertere statische Mängel an der Ziegelarchitektur im Hanghaus 2 durch Rißverpressungen zu beheben.

Der 1987 im Zuge des damals geplanten Schutzbaus gehobene und neuverlegte Mosaikboden im Peristylumgang der Wohneinheit 3 (H2/16b) konnte heuer an der Nord- und Ostseite (Zugang zum 'Musenzimmer') gereinigt und in seinen Fehlstellen gesichert werden. Zur Reinigung wurde ein $\mathrm{Naßwirbelstrahlverfahren} \mathrm{angewandt,} \mathrm{noch} \mathrm{von} \mathrm{der} \mathrm{Bergung} \mathrm{verbliebene} \mathrm{Klebereste} \mathrm{waren} \mathrm{mit} \mathrm{dem}$ Skalpell zu entfernen. Die dabei festgestellten Haftungsmängel, vor allem im Nordabschnitt, sind 2004 mit einer Kieselsäureestertränkung durch die nun offenen Fugen zu beheben. Die Fehlstellen wurden mit Mörtel (Kalk-Weißzement-Marmormehl) geschlossen und mit Stempel in dazupassender Mosaikstruktur gestaltet und abschließend koloriert.

Das Zusammensuchen von Sockelplattenfragmenten des Marmorsaals 31 konnte sehr erfolgreich fortgesetzt werden. Gleichzeitig wurden die aneinanderpassenden Fragmente geklebt und auch schon mit der Montage an der Nord- (Platte 2, 3), Süd- (Platte O, P, Q) und Westwand (Platte A, G, H, I) begonnen. Die antike Verlegetechnik wurde mit Haken aus Bronze oder Eisen und mit Ziegelsplittmörtel als Hohlraumfüllung ausgeführt. Bei der modernen Applizierung wird nach langer und reiflicher Überlegung nun doch auf die antike Mörtelhinterfüllung verzichtet. Der Festigkeitsverlust des Mörtelpakets und die Haftungsmängel zum Mauerträger sind kaum zu beheben - Konsolidierungsaufwand, Zeit und Kosten, bei letztendlich ineffizientem Ergebnis und Risiko, daß das Mörtelpaket doch irgendwann wieder auf die aus vielen Teilen zusammengeklebte Marmorplatte drückt, begründen zusammenfassend diesen zerstörenden Eingriff. An jener Stelle, an der gesichert eine Sockelplatte montiert werden kann, wird der Ziegelsplittmörtel abgeschlagen, auf historische Aussageträger untersucht, die freigelegte Mauer photographiert (in Zukunft ist auch eine zeichnerische Dokumentation durch Archäologen vorgesehen), die Platte in ihrem ursprünglichen Abstand vor die Mauer gestellt und mit epoxidharzverklebten Haken fixiert und abschließend der Raum zwischen Plattenrückseite und Mauer mit Polyurethanschaum gefüllt.

Im Nordumgang des großen Hofes 31a erfolgte die Bergung des stark zerbrochenen und lose aufliegenden, zunehmend auseinanderfallenden Plattenbodens, danach erfolgte die Klebung der Fragmente; nach Abschluß der archäologischen Untersuchung soll der Boden wiederverlegt werden. Die schon 2002 begonnenen Arbeiten an den Säulen dieses Peristylhofes wurden fortgesetzt, die Säulen der Nord- und Westseite präsentieren sich jetzt, ergänzt und retuschiert, als einheitliche Monolithe.

Die Restaurierungsarbeiten an den Wandmalereien im 'Musenzimmer' - Oberflächenreinigung, Fehlstellensicherung und Retusche - konnten heuer abgeschlossen werden. Wie wiederholt berichtet, war die Reinigung mit einem Mikrowirbelsandstrahlverfahren, naß unterstützt, erfolgreich, die Fehlstellen wurden originalniveaugleich mit Kalkmörtel geschlossen und in rekonstruierbaren Bereichen in Strichtechnik ergänzt. Entgegen einer puristischen Befundkonservierung, die ein entstandenes Verfallsbild einzufrieren versucht, ist damit diese Wandmalerei auch im Aussehen dem ursprünglichen angenähert, präsentiert sich diese Raumausstattung als ein im möglichen Ausmaß authentisches Dokument antiker Wohnkultur, die im Laufe der Geschichte entstandene Verschmutzung und Beschädigungen sind als unwichtige, den Eindruck verfälschende Zeugnisse der Vergänglichkeit durch gezielte Restaurierungseingriffe beseitigt oder zumindest abgeschwächt. 
Die Arbeiten an den einst abgenommenen Wandmalereien des Sokrateszimmers der Wohneinheit 4/7 wurden fortgesetzt. 2003 konnten drei Plattenabschnitte vom Gipsbett befreit und mit einem Kalkmörtelbett versehen werden. Das Aufbringen des Aluwabenträgers mußte jedoch auf das folgende Jahr verschoben werden.

Als wesentliche Konservierungsarbeit während dieser Kampagne kann die Korrektur der schiefstehenden Nordmauer in 32e beschrieben werden. Der beidseitige Wandmalereischmuck wurde dazu mit Gewebe gesichert. Die Wandmalereifläche von der Mauerseite im Raum 32f wurde abgenommen, die Ziegelmauer abgetragen. Die Wandmalereifläche im Raum 32e wurde senkrecht gestellt, die Ziegelmauer wieder aufgemauert und gleichzeitig die senkrecht gestellte Wandmalerei mit Mörtel verbunden. Schließlich wurde die abgenommene Wandmalereifläche auf einem Aluwabenelement appliziert und dann an ihrer ursprünglichen Stelle wieder montiert.

\subsection{Artemisreliefblock in der Akademiegasse}

Die laut Recherchen schon bei der Freilegung abgesprengte rechte südliche Steinvorderkante des Artemisreliefblocks in der Akademiegasse wurde ausgebaut, in den Bruchflächen gereinigt, verklebt, gekittet und retuschiert. Da der gesamte Block schief steht und der darüber gebaute Ziegelbogenansatz auf die rechte Seite drückt, ist die offensichtlich statische Schadursache damit zwar nicht behoben, weil sich aber seit der Freilegung keine Verschlechterung ausgewirkt hat, bleibt zu hoffen, daß die Gesamtkonstruktion stabil ist und dieser Minimaleingriff ausreichend war. Ein erneutes Wegdrücken dieser Blockkante würde ein Auseinandernehmen und Waagrechtstellen der Konstruktion bedeuten.

\subsection{Vediusgymnasium}

Die im Vediusgymnasium gefundenen Skulpturfragmente wurden soweit gereinigt, daß ihre Zusammengehörigkeit überprüft, Klebungen und die archäologische Aufnahme vorgenommen werden konnten. Die Reinigung erfolgte vorwiegend mechanisch mit Skalpell, diversen Bürsten und Ultraschallmikromeißel; wenn keine Farbfassungsreste festzustellen waren, auch naß unterstützt.

\subsection{Kleinfundkonservierung}

Hier ist vor allem der Abschluß der Reinigung des Silbermünzschatzes von Beçin hervorzuheben (vgl. unter 3.7.2); die restlichen ca. 10000 Münzen wurden gereinigt. Der Schatzfund von Beçin ist ein Gemeinschaftsprojekt der Türkischen (TÜBA) und der Österreichischen Akademie der Wissenschaften; das ÖAI übernahm dabei die Restaurierung der Münzen.

Weiters wurden in Vorbereitung von archäologischen Publikationen zahlreiche Keramik- und Glasobjekte des Altbestands konserviert.

\section{5 İsa Bey Hamamı}

Im İsa Bey Hamam 1 konnten die Sicherungsarbeiten an den Kuppeln fortgesetzt werden. Bei der kleineren südlichen Kuppel der Mittelachse wurden an der Außenhaut alle organischen Ablagerungen entfernt und die bereits vorhandenen oder durch die Reinigung gebildeten Löcher in den Fugen mit Kalkmörtel geschlossen. In den anderen Badehäusern konnten Sicherungsarbeiten (Festigungsinjektionen) an der Stuckinnenraumausstattung kontinuierlich ausgeführt werden.

\subsection{Belevi}

An einer in Belevi gefundenen Reliefplatte (s. o. 1.17.1) und am Sarkophag des Mausoleums wurde die Oberflächenreinigung mit Laser erprobt. Nach Festlegung der Abtragschwelle der Schmutzschicht und der Zerstörungsschwelle des Steins konnte gezielt die Marmoroberfläche freigelegt werden. Bei dieser Gelegenheit muß die Reinigung neben der rein optischen Verbesserung als konservierende Maßnahme hervorgehoben werden, da die Ablagerungen sich immer auch verfallsfördernd, zermürbend und in der Folge abwitternd oder abkapselnd und sodann abplatzend auf die Steinoberfläche auswirken. Der Einsatz des Geräts hat sich bewährt. Aufgrund der sensiblen Optik ist jedoch, auch wenn dieser Lasertyp mittlerweile baustellentauglich sein sollte, immer mit technischen Problemen zu rechnen. 


\subsection{Sogenannte Paulusgrotte}

(Leitung: F. Ghizzoni; Mitarbeiterinnen: G. Fulgoni, S. Gianoli, S. Salvatori; J. Weber [Universität für Angewandte Kunst, Wien])

2003 gelang es, in vierwöchiger Arbeit beinahe den gesamten hinteren Teil der Grotte wenigstens grob von dem alles bedeckenden Anstrich zu befreien. Dabei kamen an der Ostwand fünf Malschichten zutage. Die älteste davon ist eine direkt auf den Fels aufgebrachte rosa Putzschicht. Darüber folgt ein gelbumrandeter blauer Kreis mit $46 \mathrm{~cm}$ Radius und einer auf einem Viergespann in den Himmel fahrenden Figur sowie darunter Malinschriften, welche die vier Paradiesflüsse bezeichnen. Darüber blieb von der drittältesten Schicht ein fruchttragender Baum erhalten. In der vierten Lage folgt - mit Fortsetzung an der Süd- und Westwand - eine Reihe überlebensgroßer Heiliger mit dem sitzenden Christus in der Mitte, alles in bester Qualität. Auch von der letzten (fünften) Malschicht hat sich an der Ostwand ein größerer Teil mit einem Soldatenheiligen samt Lanze erhalten. Der Beischrift zufolge dürfte es sich um Georg handeln. Mit Ausnahme dieses Stratums, das der Ikonographie nach in das 11.-13. Jahrhundert zu setzen ist, haben wir es durchweg mit antiken, d. h. vorikonoklastischen Fresken zu tun, für die es kaum Vergleichbares gibt.

\section{Fundbearbeitung}

\subsection{Artemision}

3.1.1 Stratigraphie und Keramikfunde vor der Zeit des Kroisos

(Projektleitung: M. Kerschner; Mitarbeiter/-innen: M. Blömer, St. Faust, St. Karl [Keramik]; S. SNOWADSKY, M. WeIssL [Stratigraphie])

Die Bearbeitung der Keramikfunde aus den Grabungen von A. BAmmer konzentrierte sich auf die Sondagen 810, 1020 und 1021 im östlichen Bereich des Sekos des Kroisostempels. Bei der Auswertung der Stratigraphie der Sondage 810 konnte wie in den benachbarten Sondagen 740 und 1021 das Außenniveau zum frühen Peripteros festgestellt werden, das über einer Aufschüttung mit spätund subgeometrischen Funden angelegt wurde. Darunter dehnt sich auch in diesem Bereich die bereits im Bereich der Zentralbasis nachgewiesene protogeometrische Anschüttung aus.

\subsubsection{Kleinfunde}

(Projektleitung: U. Muss; Mitarbeiter/-innen: B. Bühler, D. CanimoĞlu, M. Dewailly)

\subsubsection{Terrakotten (U. Muss, M. Dewailly)}

Die Funde aus Terrakotta umfassen ein breites zeitliches Spektrum, das von der späten Bronzezeit bis in die hellenistische Zeit reicht. Tonfiguren gehören - neben der Keramik - zu den ältesten Objekten, die aus dem Artemision bekannt sind. Auch 2003 konnten weitere Anpassungen vorgenommen werden: drei Fragmente gehören zum Gewand einer spätbronzezeitlichen Figur vom Typus 'Göttin mit den erhobenen Händen', der von U. Muss bereits für die Rekonstruktion des großen bronzezeitlichen Tonkopfes (Art. 93/K 967) angenommen wurde.

Eine größere Gruppe bilden die Darstellungen von Boviden protogeometrischer und geometrischer Zeit, sie stammen aus einer Zeit, als wertvolle Votive aus Gold oder Elfenbein noch fehlen.

Besonders viele Votive gehören in das 7. und 6. Jahrhundert v. Chr. Sie alle wurden in Schichten gefunden, die älter sind als der archaische Tempel und stammen aus Arealen unter dem Kroisostempel, von der Nordseite des Tempels sowie von der sog. nördlichen Kultbasis. Im 7. Jahrhundert war es besonders beliebt, aus einem Tonklumpen Figuren herzustellen, die an ihrer Vorderseite mit einer Matrize in so hohem Relief gearbeitet sind, daß sie den Eindruck vollplastischer Statuetten erwecken. Solche Figuren, mit denen wohl Göttinnen gemeint waren, sind sowohl durch einen lokal hergestellten zyprischen Typus als auch durch die einzige Serie vertreten, die aus dem Artemision bis heute bekannt ist: sie war schon seit den Grabungen von D. G. Hogarth bekannt und ist durch die österreichischen Grabungen um weitere fünf Exemplare erweitert worden. 
Eine größere Gruppe (etwa 60 Stück) bilden auch die 'plastischen Vasen' wie Alabastra, Aryballoi und Askoi, die etwa aus der Mitte des 6. Jahrhunderts stammen. Nicht bei allen handelt es sich um Importe aus Rhodos oder Samos, sondern nach der Zusammensetzung des Tons zu urteilen um lokal hergestellte Imitationen.

Für die geplante Publikation wurde ein Konzept erarbeitet, die entsprechenden Objekte im Museum in Selçuk wurden einer erneuten Autopsie unterzogen. Eine Auswahl von im Depot des Grabungshauses aufbewahrten Terrakotten wurde digital photographiert. Ein Besuch im Museum von Izmir erweiterte die Kenntnis von unpublizierten Terrakotten aus Bayraklı und Erythrai.

3.1.2.2 Technologische Untersuchung von Gold- und Silberfunden (B. Bühler)

Methode und Ziel dieses Teilprojekts sind die Beobachtung und photographische Dokumentation technischer Merkmale (z. B. Werkzeugspuren und Lötstellen) an den Gold- und Silberfunden mit einem Stereomikroskop mit integrierter Kamera, was eine Rekonstruktion des Herstellungsprozesses der untersuchten Objekte ermöglicht. Zusätzlich wurden auch Hinweise zu Funktion und Dauer des Gebrauchs der einzelnen Objekte gesammelt. Der Schwerpunkt der technologischen Untersuchung lag auf der Blechbearbeitung, vor allem sollte anhand der im Mikroskop sichtbaren Merkmale geklärt werden, welche Verfahren (Pressen mittels positiver und negativer Model, Treibziselieren, Punzieren, Ritzen) bei der Gestaltung des Dekors der zahlreichen Appliken angewendet worden sind. In weiterer Folge wurde versucht, die bisher untersuchten Exemplare nach herstellungstechnischen Gesichtspunkten zu gliedern. Die Untersuchung bzw. Dokumentation einiger Objektgruppen (z. B. der Appliken, der anthropomorphen und tierförmigen Statuetten, der Nadeln, Fibeln und Ohrringe) im Museum in Selçuk konnte abgeschlossen werden.

\subsubsection{Bernstein (A. Bammer und U. Muss)}

Aus den österreichischen Grabungen im Artemision ist Bernstein seit 1977 mit einem Einzelfund bekannt, der an der Westseite des archaischen Tempels geborgen werden konnte. Eine zahlenmäßig reiche Gruppe ergaben die Grabungen im Areal der sog. Zentralbasis. Das Material Bernstein muß von besonderer Bedeutung für die Frühzeit des Artemisions gewesen sein, Funde dieser Art sind aus keinem der umliegenden Heiligtümer bekannt geworden. Perlen und Anhänger verschiedenster Größen und Formen bilden eine Gruppe aus diesem Material. Eine weitere Gruppe bilden Z-förmige Gebilde, Objekte mit kreisförmiger Verzierung und zwei Köpfe, alle diese Objekte sind verschieden und mehrfach durchbohrt. Zur Zeit wird an der Rekonstruktion der beiden Gruppen gearbeitet. Es stellte sich heraus, daß es ohne Modelle kaum möglich sein wird, schlüssige Vorschläge für die Rekonstruktion dieses einmaligen Ensembles zu erarbeiten. Im Museum und im Grabungshaus wurden ausgewählte Objekte unter dem Mikroskop vergrößert und photographiert, um Herstellungstechniken (Bohren, Schleifen etc.) dokumentieren zu können. Außerdem wurden die im Grabungshaus aufbewahrten Bernsteinfunde digital photographiert.

\subsubsection{Archaische Architektur des Tempels (Ae. OHNESORG)}

Ae. Ohnesorg traf vor allem weitere Vorbereitungen für die Publikation. Die Baubeschreibung der Tempelruine wurde vor Ort überprüft. Einige tiefliegende Zonen, zu denen es noch Fragen gibt, waren wegen des hohen Grundwasserspiegels jedoch nicht zugänglich. Einzelne Messungen wurden an Resten des Fundaments und des Aufgehenden sowie an den Bauteilen, die sich in den Depots des österreichischen Grabungshauses befinden, nachgeholt. Einige Fragmente wurden neu zeichnerisch und photographisch aufgenommen. Auch wurde in den Depots des Museum Selçuk nach dort aufbewahrten Fragmenten Ausschau gehalten.

Gemeinsam mit U. Muss wurden die noch unpublizierten Fragmente der reliefierten Kuben und Trommeln sowie des Simenfrieses im Hinblick auf einen Beitrag in der Monographie zum Kroisostempel durchgesehen. Diejenigen Fragmente, die Fugen oder sonstige architektonische Merkmale aufweisen, wurden gezeichnet sowie alle Fragmente von U. Muss photographiert. 
3.1.4 Hellenistisch-römische Skulptur (U. Muss)

U. Muss studierte und photographierte die bei den späthellenistisch-frührömischen Gebäuden im Norden des Artemisions gefundenen Skulpturen im Steindepot des Grabungshauses sowie den im Museum aufbewahrten großen weiblichen Kopf Art. 89/K 2075.

\subsection{Tetragonos Agora}

Unter der Leitung von P. Scherrer wurde die Publikationstätigkeit betreffend das Fundmaterial der Grabungen 1987-2001 fortgesetzt.

3.2.1 Archaische Keramikfunde

(Projektleitung: M. Kerschner; Mitarbeiter: St. Faust)

Aufgenommen wurden die spätgeometrischen und archaischen Keramikfunde aus jenen Kontexten, die in Zusammenhang mit dem klassischen Brunnen AB stehen.

\subsubsection{Klassische Keramik}

E. TrinkL schloß ihre Arbeiten am Material aus dem Brunnen AB und an der schwarzgefirnißten Keramik klassischer Zeit mit der Prüfung der Manuskripte vor den Objekten ab. Außerdem wurde die Photodokumentation durch die Aufnahmen einiger restaurierter Ganzgefäße ergänzt.

\subsubsection{Amphoren}

Im Zuge der Amphorenforschung (T. BEZECZKY unter Mitarbeit von Á. VARI und P. HÁrshEGYI) konnte die Aufnahme und Beschreibung der Funde von der Tetragonos Agora abgeschlossen werden.

\subsubsection{Terrakotten, Glas}

F. Soykal-Alanyali nahm die Terrakotten aus den Brunnen AB und LB auf. M. Schätzsschock erledigte die zeichnerische und deskriptive Aufnahme aller Glasfunde aus den Agora-Grabungen 1987-2001; aussagekräftige Fundobjekte wurden photographiert.

\subsection{Hanghaus 2}

Die Bearbeitung der Funde erfolgt in einer Kooperation mit der Österreichischen Akademie der Wissenschaften, Institut für die Kulturgeschichte der Antike (S. LADSTÄTTER), welche mit freien Mitarbeiter/-innen, die größtenteils vom FWF finanziert werden, organisiert wird.

3.3.1 Keramik

(Projektleitung: S. Ladstätter [ÖAW]; Mitarbeiter/-innen: T. Bezeczky, P. Hárshegyi, A. Martin, I. Kowalleck, T. Krampl, K. Roth-Rubi, Á. VÁri)

Im Zuge der Amphorenforschung (T. Bezeczky unter Mitarbeit von Á. Vári und P. Hárshegyi) konnte mit der Aufnahme der späthellenistischen und römischen Amphoren aus dem Hanghaus 2 begonnen werden. Die keramischen Funde aus der Wohneinheit 4 des Hanghauses 2 wurden für die Publikation von S. Ladstätter neuerlich gesichtet, die Aufnahme und die photographische Aufnahme wurden vervollständigt. Anschließend erfolgte dem Publikationskonzept des Hanghauses 2 entsprechend die Aufnahme der Funde aus den Wohneinheit 3 und 5 (S. Ladstätter unter Mitarbeit von T. Krampl und I. Kowalleck). Ein Abschluß der Arbeiten ist für 2004 geplant.

Schließlich seien die Arbeiten über die italische Sigillata aus den Hanghäusern (A. Martin) erwähnt, deren Dokumentation vor Ort abgeschlossen wurde. Derzeit wird an einer Manuskripterstellung gearbeitet. Ferner wurde die Aufnahme der dünnwandigen Keramik (K. Roth-Rubi) fortgesetzt.

\subsubsection{Kleinfunde aus Metall und Bein}

Die zeichnerische Aufnahme und Dokumentation der Metall- und Beinobjekte aus den Wohneinheiten 1 und $2 \mathrm{im}$ Depot des Grabungshauses durch S. JILEK wurde abgeschlossen, wobei neben 
einzelnen Bronzeobjekten vor allem die Eisen- und Bleifunde gesichtet und gezeichnet wurden. Gleichzeitig erfolgten Korrekturen an den bereits vorhandenen älteren Zeichnungen und die Erstellung eines vorläufigen Katalogs.

\subsection{Keramik und Kleinfunde verscbiedener Fundorte}

3.4.1 Frühe Keramik vom Ayasoluk

(Projektleitung: M. Kerschner; Mitarbeiter M. StANKe)

Die Kooperation mit M. BüYÜKkolanci (Universität Pamukkale, Denizli, vorher Efes Müzesi Selçuk) zur Publikation der 1996-2002 vom Efes Müzesi Selçuk unternommenen Grabungen in den spätbronzezeitlichen und frühgriechischen Schichten des Ayasoluk-Hügels wurde fortgesetzt. Die vom ÖAI übernommene Bearbeitung der Keramikfunde konzentrierte sich heuer auf die Grabungen des Jahres 2002 an der Westseite des Ayasoluk-Hügels (Sondage 32 D). Dort wurde knapp unterhalb der byzantinischen Befestigungsmauer eine kreisrunde Felsausarbeitung ('kuyu 2') freigelegt, die in der mittelgeometrischen Epoche verfüllt worden war. Mit der einheitlichen Verfüllung, die nur vereinzelte ältere Fragmente enthielt, konnte zum ersten Mal in Ephesos ein geschlossener Befund aus dem 9./1. Hälfte des 8. Jahrhunderts v. Chr. dokumentiert werden.

\subsubsection{Reliefbecher, Lampen}

(Projektleitung: S. LadstätTER [ÖAW]; Mitarbeiterinnen: A. Giuliani, Ch. RogL)

Die Bearbeitung der Reliefbecher (Ch. Rogl) und Ephesos-Lampen (A. Giuliani unter Mitarbeit von J. Struber und S. Guderna) wurde fortgesetzt. Besonderes Augenmerk lag dabei auf der photographischen Dokumentation einzelner Stempelmotive, die im Rahmen einer Datenbank verwaltet werden sollen.

\subsubsection{Terrakotten vom 'Staatsmarkt' und dem Südtor der Agora}

C. LANG-Auinger (ÖAW) vervollständigte den Katalog der figürlichen Terrakotten aus den Grabungen am Staatsmarkt. Weiters gehören zum Fundmaterial Fragmente von Architekturterrakotten. Vier Fragmente stammen von einem hellenistischen Tonfries: ein Kopf, zwei Fragmente mit Ranken und eines mit einer bemerkenswert schönen Volute.

Die anderen Architekturterrakotten lassen sich in zwei Gruppen einteilen. A 1 umfaßt 27 Fragmente eines Frieses, der von einem Kymation bestehend aus Leiste, Hohlkehle, Eierstab und Perlstab bekrönt ist. 13 Fragmente stammen vom Kymation, wobei mehrere eine Stoßfläche aufweisen. 11 Fragmente gehören der Frieszone an: u. a. zwei, die je einen nach rechts und einen nach links blickenden Symposiasten zeigen, und drei Gorgonenköpfe. Sechs Fragmente sind mit offenen Palmetten geschmückt; vier dieser Fragmente weisen rechts eine Stoßfläche auf, die eine Palmette in der Mitte der Länge nach in zwei Hälften teilt. Einer der Symposiasten trägt einen Efeukranz, der andere eine Binde mit eingefügten Schmuckelementen. Die ausdrucksstarken Gorgonengesichter sind von Buckellocken gerahmt. Symposiasten, Gorgonen und Palmetten waren wie das Kymation mit weißem Stuck überzogen, der Friesgrund war rot gehalten. Kymation und Fries ergeben eine Gesamthöhe von ca. $25 \mathrm{~cm}$. Die Rückseiten sind teilweise versintert, lassen aber dennoch graue Mörtelspuren erkennen, ein Fragment schwach rosa gefärbten Mörtel.

A2 umfaßt 15 Fragmente; je ein Fragment mit einer linken und einer rechten Stoßfläche ist erhalten. Dem Kymation fehlt der Perlstab, und die Lanzettblätter zwischen den Eiern ohne Schalen sind als Tropfen und Pfeilspitzen ausgebildet, sofern sie nicht bereits ohne Lanzettblätter aus den Modeln gezogen worden sind. Drei Fragmente zeigen Teile von Gorgonenköpfen sowie von zwei geschlossenen, in der Länge halbierten Palmetten, die je eine Stoßfläche bilden. Die Gesamthöhe des Frieses beträgt $27 \mathrm{~cm}$, wobei 7,5 cm auf das Kymation entfallen. Dieser Fries war einheitlich mit weißem Stuck überzogen. An den Rückseiten blieb teilweise rosa Mörtel haften.

Stilistische und technische Indizien weisen darauf hin, daß die Friese verschiedenen Zeitstufen angehören. 
F. Soykal-Alanyali beendete die Bearbeitung der Terrakotten vom Südtor der Tetragonos Agora.

\subsubsection{Kleinfunde von der Marienkirche}

(Projektleitung: St. KARWIESE, Mitarbeiterin: P. TuRNOvSKY)

Im Rahmen dieser Abschlußkampagne für die Publikation der Kleinfunde von der Marienkirche wurden vor allem Kontrollen an der Funddokumentation vor- und ergänzende Daten aufgenommen. Zusätzlich aufgenommen wurden die Funde der Sondagen 2/92 und 2/93 (Keramik, Glas, Bronze). Ebenso wurden einige im Efes Müzesi gelagerte Objekte dokumentiert. Schließlich wurden für die Publikation Photos von 170 Fundstücken angefertigt.

3.4.5 Mittelalterliche und nachmittelalterliche Keramik

(Mitarbeiterin: J. VRoOm, Institute of World Archaeology, University of East Anglia, Norwich)

Die Dokumentation aller Funde der Grabungsjahre 1999 und 2002 aus dem İsa Bey Hamamı konnte abgeschlossen werden, ca. 130 Stück wurden auch zeichnerisch aufgenommen. Außerdem wurde mit der Aufnahme der Funde des Jahres 2003 aus dem Hamam III begonnen.

\subsection{Architektur}

\subsubsection{Kaiserzeitliche Bauornamentik in Ephesos}

(verantwortlich: G. PLATTNER)

Im Jahr 2003 wurde das Projekt »Ephesische Kapitelle« von G. Plattner vorläufig abgeschlossen. In einem GIS wurden, soweit zugänglich, alle in Ephesos und Umgebung befindlichen korinthischen, korinthisierenden und kompositen Kapitelle kartiert und Grunddaten erfaßt. Über die Benutzeroberfläche des GIS ist es somit möglich, zu allen Bauteilen Informationen über Typus und Dimensionen sowie ein digitales Photo abzufragen. Zur Bearbeitung der Bauornamentik des C. Laecanius BassusNymphäums vgl. o. 1.8).

3.5.2 Architekturdekoration der spätantiken und frühbyzantinischen Zeit

(verantwortlich: E. Russo [Universität Bologna])

E. Russo setzte die Dokumentation der byzantinischen Architekturdekoration aus Ephesos in Depots des Efes Müzesi und am Ayasoluk fort.

\subsection{Skulptur}

(Projektleitung: M. Aurenhammer; Mitarbeiterinnen: M. Heinz, J. Auinger, E. Rathmayr)

Für die Publikation der ephesischen Porträts - ein österreichisch-britisch-türkisches Kooperationsprojekt - überprüfte M. Aurenhammer Katalogtexte vor den Originalen. Außerdem begann sie mit der Aufnahme von Denkmälern der Ausstattung des Theaters. Im Rahmen des FWF-Projekts P 15112 (Sarkophage aus Ephesos) studierte M. Heinz die Sarkophage in den Archäologischen Museen in Istanbul. In Selçuk wurden die Arbeiten am Katalog und die digitale Photographie der Objekte fortgesetzt, außerdem wurden mehrere Sarkophage vom Gelände in ein Depot verbracht.

Zur Bearbeitung der Skulpturenausstattung des C. Laecanius Bassus-Nymphäums durch E. Rathmayr vgl. hier unter 1.8. Im Rahmen ihrer Dissertation »Die Skulpturenausstattung des Vediusund des Ostgymnasiums« an der Universität Wien setzte J. Auinger die Bearbeitung der Denkmäler in den Museen in Selçuk und Izmir fort. Außerdem wurden die Neufunde aus dem Vediusgymnasium (s. o. 1.4) aufgenommen (die Funde des Jahres 2002 vollständig, die zahlreichen Funde des Jahres 2003 teilweise).

Außerdem wurde eines der kleinen Depots in den Substruktionen der Domitiansterrasse ausgeräumt und neu geordnet. Dabei wurden neben zahlreichen Architekturfragmenten (auch einigen des C. Laecanius Bassus-Brunnens) Skulpturen aus dem Vediusgymnasium und dem C. Laecanius Bassus-Brunnen wiedergefunden. 


\subsection{Numismatik}

3.7.1 Fundmünzen der Grabungen in Ephesos

(Projektleitung: M. Alram [Numismatische Kommission der Österreichischen Akademie der Wissenschaften]; Mitarbeiter: M. Pfisterer)

In der Saison 2003 wurden insgesamt 83 Fundmünzen bearbeitet. 20 Stück kamen aus dem Vediusgymnasium, die Spanne reicht von hellenistischer bis in die osmanische Zeit. Leider waren viele so schlecht erhalten, daß eine präzise Bestimmung nur selten möglich war. Die 30 Münzen aus dem Theater reichen von Alexander dem Großen bis in die Neuzeit. Ein großer Anteil davon fällt in die constantinische Zeit. Besonders interessant sind hier auch die Funde moderner Münzen, die in so großer Anzahl von der häufigen Frequentierung des Theaters in der Neuzeit zeugen. Von der Marmorstraße vor dem Theater stammt ein in der Standardliteratur bisher nicht verzeichneter Follis des Phocas aus den Jahren 602/03.

Eine kleine Münzreihe von vier Stück vom Nymphaeum Traiani stammt aus dem 4. und 5. Jahrhundert. Die sechs Fundmünzen der Grabung am Mausoleum von Belevi waren ausgesprochen schön erhalten und erstrecken sich vom Ende des 4. Jahrhunderts über eine Münze des Lysimachos bis in augusteische Zeit. 12 Münzen aus dem Kanal der Kuretenstraße sind hauptsächlich spätantik, sieht man von einer stark verschliffenen Großbronze wohl der 1. Hälfte des 3. Jahrhunderts ab.

Das Hamam III erbrachte neben drei islamischen Münzen auch einen anonymen byzantinischen Follis des 11. Jahrhunderts. Die Streufunde waren, wie meistens, spätantik. Vom nördlichen Mittelpfeiler des Magnesischen Tores stammt ein Centenionalis des Honorius oder Theodosius II., der in der Zeit zwischen 408 und 423 geprägt wurde. Bei den Hanghäusern wurde eine aus Gallien stammende Imitation eines Antoninian des 3. Jahrhunderts gefunden.

\subsubsection{Münzschatzfund von Beçin}

(Projektträger: Österreichische und Türkische Akademie der Wissenschaften, ÖAI, Kunsthistorisches Museum; Projektleitung: R. H. ÜNAL [Universität Izmir]; F. KRINZINGER [ÖAW und ÖAI; M. Alram [ÖAW und KHM]; Koordination: Ş. Pfeiffer-Taş [ÖAW]; Mitarbeiter: N. Schindel, G. TeOman)

Ziel dieses Projekts ist die Reinigung, Dokumentation und Publikation des im Jahr 2000 aufgefundenen Münzschatzes von Beçin, der neben ca. 60000 Akce aus dem 16. Jahrhundert auch 826 europäische Silberprägungen enthielt.

2003 wurden insgesamt 8000 osmanische Münzen in die Datenbank eingegeben (Ș. PfeifferTaş, N. Schindel). Zudem wurden 79 Münzklumpen aufgenommen. Für die naturwissenschaftlichen Untersuchungen wurden 172 Münzen ausgewählt, von denen Proben entnommen und nach Wien geschickt wurden. Außerdem wurden 6 europäische Prägungen dokumentiert. Die restlichen gereinigten 9588 Münzen wurden bestimmt, vorsortiert und dem Museum in Izmir übergeben, so daß 2004 mit der Aufnahme begonnen werden kann (Ş. Pfeiffer-Taş, G. Teoman).

Von Ş. Pfeiffer-Taş wurden außerdem die Literaturrecherche und das Studium der Quellen über die Wirtschaftsgeschichte fortgesetzt. Neben der Auswertung der diesen Zeitraum betreffenden Informationen aus den Mühimme Defterleri wird versucht, auch in anderen Defters die verschiedenen Befehle und Verordnungen aus unterschiedlichen Quellen herauszufinden und systematisch zu ordnen. Dazu wurde mit der Katalogarbeit der Prägungen Murads III. von der Münzstätte Kostantiniye begonnen. Zudem fanden auch materialtechnische Untersuchungen statt.

\subsection{Epigraphik}

(Projektleitung: H. TAeuber, Institut für Alte Geschichte, Altertumskunde und Epigraphik der Universität Wien)

Im Rahmen des zweiwöchigen Aufenthalts wurde an folgendem Inschriftenmaterial gearbeitet:

1) Für den epigraphischen Teil des Sarkophag-Projekts (s. o. 3.6) wurden die verbliebenen annähernd 40 Fragmente im Inschriftendepot der Domitiansterrasse revidiert. 
2) Die systematische Aufnahme der Inschriften im Freiluftdepot wurde abgeschlossen. Insgesamt ergab die Auflistung 181 Inschriften, davon 110 unpublizierte. Die neuen Inschriften wurden photographiert, abgeklatscht und ihre Daten und Lesungen erfaßt. Darunter befanden sich zahlreiche, z. T. ausführliche Grabinschriften sowie eine postume Ehrung der Faustina I., Gattin des Antoninus Pius.

3) Im İsa Bey Hamam1 wurden 18 neue Inschriften aufgenommen. Eine monumentale Platte nennt einen Faustinianus, wahrscheinlich ein Mitglied der prominenten Familie der Fabii Faustiniani, sowie einen Patroboulos (erbliches Mitglied der Gerusie).

4) Graffiti und Dipinti aus dem Hanghaus 2, speziell jene aus den Wohneinheiten 1 und 2, wurden für die bevorstehende Publikation einer abschließenden Revision unterzogen. Auf einem abgenommenen und bisher unzugänglichen Wandmalereifragment befand sich die Zeichnung eines Vogels. Auf einer Marmorleiste des Marmorsaales war das Wort »katakephala«, also »kopfüber« (als Anweisung zur Anbringung), eingeritzt.

5) Aus dem Vediusgymnasium kamen drei neue Inschriften. Eine davon nennt P. Vedius Antoninus (um welche Person der Dynastie es sich handelt, ist vorläufig offen) in seiner Funktion als grammateus presbyteron, also Sekretär der Gerusie.

\subsection{Osmanische Grabsteine}

(Projektleitung: Ş. PfeIfFER-TAș; Mitarbeiter: M. GüLERSOY)

Im Freiluftdepot wurden 33 anpassende Inschriftenfragmente zusammengeklebt, so daß 17 vollständige Grabsteine mit Inschriften gewonnen wurden. Außerdem wurden 27 neue Stücke aufgenommen und dokumentiert. Mit Erlaubnis der Direktion wurde auch im Museum in Tire mit der Dokumentation der dort verwahrten islamischen Grabsteine mit Inschriften begonnen, wodurch sich ein sehr eindrucksvoller Vergleich des Denkmälerbestandes ergibt. Im Jahr 2003 konnten insgesamt 103 Objekte aufgenommen werden.

\section{Interdisziplinäre Zusammenarbeit}

\subsection{Keramikarchäometrie}

(M. Kerschner; S. Ladstätter [ÖAW]; H. Mommsen [Helmholtz-Institut für Strahlen- und Kernphysik, Universität Bonn]; B. PICHLER, R. SAUER [Institut für Konservierungswissenschaften und Restaurierung - Technologie, Abteilung Archäometrie, Unversität für angewandte Kunst, Wien])

Im September 2003 konnte der Survey zur Erfassung von Keramikrohstoffen in der unmittelbaren Umgebung von Ephesos abgeschlossen werden (S. Ladstätter, B. Pichler, R. Sauer). Die Probenentnahmestellen konzentrierten sich auf die Region nordwestlich des Stadtgebiets bis zur Einmündung in das kleine Kaystros-Tal. Die Probenserie erfaßt nun ca. 230 Stück, die sich derzeit in Präparation bzw. wissenschaftlicher Bearbeitung befinden. Durch Schwermineral- sowie Dünnschliffanalysen, Brenn- und Magerungsversuche sowie die Herstellung von Mischtonen soll eine möglichst breite Basis von Gruppen geschaffen werden, die den ephesischen Töpfern als verwendbare Keramikrohstoffe zur Verfügung gestanden haben könnten.

Die Ergebnisse der bisherigen chemischen und petrographischen Analysen wurden anhand der Originalstücke sowie in Zusammenhang mit der Geologie der Region Ephesos diskutiert. Um eine Konkordanz zwischen den chemischen und petrographischen Herkunftsgruppen zu erstellen, wurden ausgewählte Vertreter der mittels Neutronenaktivierungsanalyse festgestellten Herkunftsgruppen nun auch für Dünnschliff- und Schwermineralanalysen beprobt. Durch diese Parallelbeprobung sollen jene lokalen und regionalen chemischen Herkunftsgruppen, für die bisher noch kein geeignetes Referenzmaterial gefunden werden konnte, mit den Ergebnissen des Rohstoffsurveys verglichen und dadurch lokalisiert werden.

Ergänzend zur bereits erstellten ephesischen Probenserie wurde ein Methoden- sowie Probenaustausch mit der Grabung Priene etabliert (W. Raeck, U. Mandel, N. Fenn). 


\subsection{Geologische Untersuchungen}

(Projektleitung: İ. Kayan [Universität Izmir]; Mitarbeiter-/innen E. CAngören, M. DoĞan, B. HocaoĞLu, V. Minisker, L. Uncu, P. Ünlüpinar)

In Fortsetzung der geologischen Untersuchungen führten İ. Kayan und sein Team 9 Tiefbohrungen im Derbentdere-Tal zwischen Selçuk und dem Panayırdağ sowie zwei Bohrungen vor dem Theater aus.

\subsection{Anthropologische Untersuchungen}

(Projektleitung: K. Grossschmidt; Mitarbeiter: F. Kanz [Medizinische Universität Wien, Zentrum für Anatomie und Zellbiologie])

\subsubsection{Gladiatorenfriedhof}

Es erfolgte die detaillierte Aufnahme und Dokumentation der kranialen Traumata der Gladiatorenskelette aus den Grabungen im Jahr 1993 mittels forensischer Methoden zur Beschreibung, Illustration, Interpretation und Feststellung der Verletzungsabfolge. Hierdurch ist für jedes Gladiatorenskelett die verwendete Waffe und die Position des Angreifers ableitbar. Die Häufigkeiten der verheilten Schädelverletzungen der einzelnen Individuen wurden ebenfalls erhoben und die Qualität der medizinischen Versorgung beurteilt. Die minimale Anzahl von Individuen (NMI), die auf dem Gladiatorenfriedhof bestattet wurde, wurde festgestellt. Die Berechnung des NMI beruht bei dieser Analyse auf den Skelettelementen bzw. -regionen, die besonders häufig überdauert haben: Os petrosum, Os occipitale, Os aygomaticum und der Glabellaregion. Nach der Bestimmung der NMI in den unterschiedlichen grabungstechnisch definierten Abschnitten des Gladiatorenfriedhofes kann von zumindest 47 Gladiatoren auf diesem Friedhof ausgegangen werden. Die tatsächliche Anzahl bestatteter Individuen dürfte allerdings um einiges höher liegen, da die Skelette einen hohen Dislokationsgrad aufwiesen und der Friedhof nicht in seiner Gesamtheit ergraben wurde.

Trainingsmarken an den Gladiatorenskeletten: Aufnahme und Morphometrie aussagekräftiger Muskelansatz- und -ursprungsmarken an den Gladiatorenskeletten (DAM 1993) und an einer Kontrollgruppe (DAM 1994, DAM 1992, DAM 1993, DAM 1991) zur möglichen Abklärung der betreffenden Gladiatorenkategorie. Es wurden hochauflösende standardisierte Photos der Muskelansätze und -ursprünge ausgewählter Knochen der Gladiatorenskelette hergestellt, vor allem an der Ulna (Ansätze des Musculus brachii und des Musculus triceps brachii) und am Os occipitale (Ansatz der Nackenmuskulatur). Die Präzision der Methode wurde durch wiederholte Standardaufnahmen derselben Knochen validiert.

Ernährungsrekonstruktion der Gladiatoren: Die Probenvorbereitung der Knochenproben aus den Gladiatorenskeletten für die chemische Analyse wurde abgeschlossen. Erste stichprobenartige Messungen der Elementkonzentrationen von Strontium (Sr), Zink ( $\mathrm{Zn}$ ) und Blei (Pb) ergaben folgendes Bild: Die Sr/Zn-Verteilung läßt auf eine vorwiegend vegetabile Ernährung der Gladiatoren schließen und steht damit in gutem Einklang zu den schriftlichen Quellen. Auch die Pb-Verteilung deutet auf einen geringen Zugang zu 'teuren' Nahrungsressourcen hin (u. a. kein Pb-Eintrag aus den Behältern zur Fruchtsirupeindickung). Vor der vollständigen Analyse aller Knochenproben der Gladiatorenskelette und Vergleichsproben soll die Möglichkeit der zusätzlichen Analysen von N- bzw. C-Istopen (M. Popp, Institut für Pflanzenphysiologie) abgeklärt werden, da der Informationsgewinn um einiges höher liegen würde.

Pithos I \& II aus dem Gladiatorenfriedhof: Ziel war die osteologische und paläopathologische Neubearbeitung des menschlichen Leichenbrandes aus Pithos I und Pithos II der Grabungskampagne Damianosstoa 1993 sowie die Abklärung hinsichtlich des möglichen Kontextes innerhalb des Gladiatorenfriedhofes.

Die Schätzung der Mindestindividuenzahl mußte aufgrund des neu interpretierten Belegungsvorganges (zusammenhängende Belegung) adaptiert werden. Es konnte bei der Auswertung der Ossa petrosa (Felsenbein) und der Zähne eine Mindestindividuenzahl von lediglich 15 festgestellt werden. 
4.3.2 Sogenanntes Lukasgrab

Abklärung der Belegungsreihenfolge des Apsisgrabes aus dem sog. Lukasgrab (LK 1999). Die Reihenfolge der Belegung dürfte wie folgt stattgefunden haben: Individuum 7+2 (Erstbelegung) $<$ Individuum $5<$ Individuum $6<$ Individuum $3+1<$ Individuum 4 (Letztbelegung).

Im Vordergrund stand die Frage, ob die sandige Trennschicht, die von dem Archäologen A. PüLZ registriert wurde, einer Einebnung für eine Zweitnutzung entsprach und die somit entstandenen zwei Schichten (Apsis oben und Apsis unten) jeweils exklusive Belegungen beweisen. Demnach dürfte kein Individuum in beiden Schichten repräsentiert sein; dies war allerdings sehr wohl bei Individuum 6 der Fall.

Eine weitere Frage war die stratigraphische Lage der beiden Kinderskelette (Ind 1 und Ind 2). Da beide Belegungsschichten jeweils ein Kind inkludierten, kann die untere Belegung nicht als 'Gründerbelegung' in Frage kommen.

\subsection{3. İsa Bey Hamamı}

Anfertigung publikationstauglicher Photographien und Überarbeitung der bisherigen anthropologischen Befunde aus den Grabungskampagnen İsa Bey Hamam1 2001 und 2002; osteologische und paläopathologische Analyse eines zusätzlichen menschlichen Skelettes (IBH8MS) aus der Kampagne 2002.

Letztes, nur z. T. erhaltenes - vor allem Becken und untere Extremitäten - weibliches Individuum (30.-45. Lebensjahr) weist eine Reihe pathologischer Veränderungen am Skelett auf: u. a. eine rechtsseitige Sakralisation des 5. Lendenwirbels und starke arthrotische Veränderungen in beiden Kniegelenken (Gelenksflächen der rechten und linken Patella).

\subsection{Archäozoologische Untersucbungen}

(Projektleitung: G. Forstenpointner; Mitarbeiter: A. Galik, G. Weissengruber [Institut für Anatomie der Veterinärmedizinische Universität Wien]; V. ONAR)

\subsubsection{Archäozoologisches Feldlabor}

Die Referenzsammlung des archäozoologischen Feldlabors Ephesos konnte durch Import und die Präparation angekaufter Individuen auf einen Gesamtbestand von 168 Ganz- und Teilskelette von 25 Säugetier-, 26 Vogel- und 69 Fischarten erweitert werden.

\subsubsection{Vediusgymnasium}

Die tierischen Reste aus den Schnitten 1 und 3 konnten vollständig analysiert werden und bieten wichtige Hinweise auf die Konsumgewohnheiten des spätantiken Ephesos. Von etwa 1900 untersuchten Fragmenten wurden 1666 Fundstücke tierartlich und anatomisch bestimmt, wobei eine eindeutige Dominanz von Schafen und Ziegen (ca. 60-70\%) gegenüber Schweinen und Rindern (jeweils 15-20\%) zu erkennen ist. Charakteristische Selektionsmuster in der Skeletteilrepräsentanz sowie das Spektrum der nachgewiesenen Arten deuten vor allem für die Funde aus Schnitt 3 auf einen funktionellen Zusammenhang mit Tavernen hin, die in unmittelbarer Nähe der Deponierung lokalisiert werden können. Aufgrund des Fundreichtums und der gesicherten Stratigraphie des Abfalldepots aus Schnitt 3 wurden im Zuge der weitergeführten archäologischen Untersuchung dieses Grabungsabschnitts insgesamt 8001 an Erdproben aus mehreren definierten Positionen der Sondage geborgen. Dieses Material soll 2004 einer genauen bioarchäologischen Untersuchung auf der Basis von Naßsiebe- und Flotationsmethoden unterzogen werden.

\subsection{3 İsa Bey Hamam1}

Die Analyse der tierischen Reste aus der wichtigen Sondage 1/01 konnte abgeschlossen werden. 600 bestimmbare Fragmente der insgesamt 671 untersuchten Fundstücke belegen die überwiegende Nutzung von Schafen und Ziegen (ca. 80\% gegenüber etwa 20\% Rinderknochen) durch die spätseldschukisch bis frühosmanisch zu datierende Verbrauchergemeinschaft, die in der analysierten 
Abfallvergesellschaftung repräsentiert wird. Auffallende Abnutzungsspuren an den Mittelhand- und -fußknochen der kleinen Wiederkäuer sind wohl im Sinn der Verwendung von Tierhäuten als Transportbehälter zu interpretieren, müssen aber noch genauer untersucht werden. Darüber hinaus wurden alle bei der Grabung geborgenen Tierreste gesichtet und hinsichtlich des für die archäozoologische Analyse notwendigen Zeitaufwandes beurteilt. Gemeinsam mit den Ergebnissen der Keramikuntersuchung wird dieser Datensatz die Grundlage für die Planung einer abschließenden Untersuchungskampagne im folgenden Grabungsjahr bieten.

\subsubsection{Ayasoluk-Siedlungsgrabung}

Der freundlichen Erlaubnis von M. BüYÜKKOLANCI war es zu verdanken, daß eine kleine Probe mehrheitlich verbrannter Knochen aus einem mittelgeometrisch datierten Siedlungsbefund (vgl. zur Keramikforschung am Ayasoluk hier unter 3.4.1) auf dem Ayasoluk-Hügel untersucht werden konnte. Die geringe Zahl von 18 bestimmbaren Fragmenten erlaubt keine verläßlichen Aussagen zu den Formen der Haustierhaltung im eisenzeitlichen Ephesos, es sind aber bemerkenswerte Ähnlichkeiten zu den zeitgleichen Befunden aus dem nahe gelegenen Artemision zu erkennen; besonders ist hier auf eine leichte Dominanz der Schweinereste sowie auf die außergewöhnlich kleinwüchsige Bauform der Rinder zu verweisen. Weitere Untersuchungen an Tierresten aus Siedlungsschichten des prähistorischen Ephesos sind höchst wünschenswert, um auf der Grundlage einer ausreichend breiten Materialbasis die spezifischen Muster der Tiernutzung im kultischen Umfeld den Resten kommunaler Ernährungsgewohnheiten gegenüberstellen zu können.

\section{Limyra}

Die österreichischen Forschungen in Limyra wurden nach der Emeritierung von J. BORCHHARDT im Jahr 2001 vom Institut für Klassische Archäologie der Universität Wien an das Österreichische Archäologische Institut übernommen, mit der Leitung wurde Th. MARKSTEINER betraut. Eine Reihe Publikationsprojekte sind im Gange; die Feldforschungen konzententrieren sich auf den Westteil der Stadt. Mit Unterstützung der türkischen Generaldirektion für Stiftungen, welche Eigentümerin des Grabungsareals ist, und dem Museum von Antalya ist es gelungen, in der komplexen Grundstücksfrage eine tragbare Lösung für die Zukunft zu skizzieren.

Die Kampagne in Limyra dauerte vom 4. August bis zum 24. September 2003. Die Arbeiten erfolgten mit bis zu 30 einheimischen Arbeitskräften und 20 wissenschaftlichen Mitarbeiterinnen und Mitarbeitern. Die Grabungen standen unter der Leitung von Th. MarksteInER, Stellvertreter war A. Konecny. Die Bearbeitung der Keramik übernahm J. Gebauer. Unser herzlicher Dank für die gute Zusammenarbeit gilt dem Regierungsvertreter Ant AтASоY (Ankara). Die Kampagne war dank der Erteilung der Genehmigung durch die Generaldirektion für Bauten und Museen im Kultusministerium in Ankara möglich. Die Finanzierung erfolgte durch den Fonds zur Förderung der wissenschaftlichen Forschung (Projektnr. P15688-G02) und das Bundesministerium für Bildung, Wissenschaft und Kultur. An den Arbeiten in den Sondagen und Depots waren die studentischen Mitarbeiter/-innen O. Babayiğit, M. Gessl, K. Handan, I. Meis, M. Polat, U. Schuh, D. Svoboda, H. Schwaiger und A. VAcEK beteiligt. Die Reinigung und Bestimmung der Fundmünzen übernahm J. GoreCkI, die Glasfunde bearbeitete S. BALDo. Die photographische Dokumentation fertigte E. Andel, die Restaurierungsarbeiten führten K. TürK und S. İlHAN aus. Für die zeichnerische Aufnahme der Blöcke des Bogentores am Ptolemaion war N. PiePer zuständig, G. STANzL setzte die Inventarisierung der architektonischen Werkstücke des Ptolemaions fort. Ihnen allen sei für ihre wertvolle Mitarbeit gedankt.

2003 wurde das im Jahr zuvor begonnene Grabungsprojekt in der Weststadt von Limyra fortgesetzt und die Sondage 30 um $4 \mathrm{~m}$ nach Osten erweitert (Sondage 36): damit sollten das in Sondage 30 teilweise freigelegte Gebäude nachantiker Zeitstellung weitgehend freigelegt und zusätzlich die unter ihm zu erwartende stratigraphische Abfolge ausführlicher dokumentiert werden. In Sondage 31 und Sondage 9W1 erfolgte die Abtragung der Kulturschichten hangseitig der klassischen Stadt- 
mauer von Limyra. Sondage $9 \mathrm{O} 1$ wurde nach Norden erweitert, um die bereits teilweise freigelegte Bebauung des späten 5. Jahrhunderts v. Chr. in einer größeren Fläche zu erforschen. Demselben Zweck diente auch die Grabung in der östlich an Sondage 9O1 anschließenden Sondage 35. Die zwischen der klassischen Stadtmauer und einer südlich von dieser parallel verlaufenden, in die römische Kaiserzeit datierenden Mauer angelegte Sondage 9S wurde bis unter den Fuß der Stadtmauer abgetragen und nach Osten erweitert, um die Schichtenabfolge im Vorfeld der Befestigung zu dokumentieren. Daneben erfolgte die Anlage von vier kleineren Sondagen etwa 25 m östlich des Südtors in der Stadtmauer von Limyra. Sie sollten dazu dienen, die in diesem Bereich durch einige Unregelmäßigkeiten im Verlauf der Kurtine angezeigte Lage einer großen, der klassischen Mauer vorgelagerten Bastion abzuklären. Auch wurden eine kleinflächige Sondage östlich des Kenotaphs angelegt und im Südbereich der Weststadt Reinigungen getätigt. Die Resultate dieser Arbeiten können wie folgt zusammengefaßt werden:

Der Befund östlich des klassischen Südtors läßt sich als Beleg für das einstige Bestehen einer $15 \mathrm{~m}$ breiten und mindestens $8 \mathrm{~m}$ weit vor die Kurtine vorspringenden, annähernd rechtwinkeligen Struktur - einer Bastion oder eines Turms - interpretieren. Im Inneren war der Baukörper mit Schotter verfüllt und von Kastenmauern versteift. Das Bauwerk bildete die östliche Begrenzung eines im Westen von der großen Eckbastion der Südmauer der klassischen Stadtbefestigung von Limyra flankierten, feindseitig offenen Hofs. In seiner Nordwestecke lag, von beiden Flankierungsbauten gut geschützt, das direkt an die Eckbastion angeschobene Südtor.

In den direkt an der Innenseite der klassischen Siedlungsmauer liegenden Sondagen 9, 31 und 35 wurde die Befestigungsmauer über eine Strecke von annähernd $30 \mathrm{~m}$ freigelegt. Entlang ihrer Innenschale lag eine Abfolge roh zugehauener Steinbasen; drei Stück wurden freigelegt, über ihnen dürfen hölzerne Stützen rekonstruiert werden. Der Laufgang auf der Mauerkrone war, wie diese Pfostenbauten belegen, mit einer hölzernen Konstruktion verbreitert, was wohl aufgrund der mit 1,30 m relativ schwachen Mauerstärke der Befestigungsmauer notwendig war. In Sondage 35 fußten darüber hinaus in der Schotterung hinter der Befestigungsmauer zwei etwa 2,5 m von Innenschale der Stadtmauer zurückgenommene Konstruktionen aus großformatigen Bruchsteinen, deren Oberlager annähernd auf gleicher Höhe liegen. Dieser Befund wird vorläufig als Unterbau einer auf die Epalxis der Stadtmauer führenden Treppe aus vergänglichem Material interpretiert. Die Fläche westlich der Bruchsteinkonstruktionen wies eine von Bebauung freigehaltene, geschotterte Oberfläche auf. Sie war nach Norden zu durch eine als Terrassierung anzusprechende, parallel zum Hang laufende Mauer begrenzt, von der in Sondage 35 ein Abschnitt freigelegt werden konnte. Diese schneidet stellenweise in die Nordmauer des 2002 teilweise freigelegten Antenbaus A ein, überlagert den Nordabschnitt des östlich davon liegenden Baus B und wurde folglich nach deren Zerstörung errichtet.

Im westlichen Grabungsbereich wurde in den Sondagen 31 und 9W1 ein an die Innenschale der Stadtmauer gelehntes zweiräumiges Gebäude (C) freigelegt. Es haben sich 0,60 m starke Mauern aus im Lehmverband versetzten, kleinformatigen Bruchsteinen erhalten. Auf diesem etwa $1 \mathrm{~m}$ hohen Sockel aus Steinmaterial dürften sich Lehmziegelmauern erhoben haben. Das Gebäude konnte durch eine axial in seiner Westfront liegende Tür betreten werden. Ausweislich einer Herdstelle auf seinem Lehmboden diente es zu Wohnzwecken. Der stratigraphische Bezug datiert den Bau in die Zeit direkt nach der Errichtung der Stadtmauer im frühen 4. Jahrhundert v. Chr.

Die Schotterfläche hinter der klassischen Befestigungsmauer bedeckte und versiegelte die Reste mehrerer kleiner Antenbauten, die vor dem Bau der Stadtmauer am Hang gestanden sind. Zwei von ihnen konnten in den Sondagen $9 \mathrm{O} 1$ und 35 vollständig freigelegt werden. Sie waren über axial gelegene Türen in ihren Südfronten zu betreten. Eine Herdstelle in Gebäude A in Sondage 9O1 zeigt, daß es sich um Wohnbauten handeln dürfte. Aufgrund der stratigraphischen Abfolge muß ihre Errichtung vor dem Ende des 5. Jahrhunderts v. Chr. stattgefunden haben.

Im Zuge von Arbeiten im Südbereich der Weststadt wurden zumeist an der Oberfläche zahlreiche Fragmente der baulichen Ausstattung des sog. Kenotaphs für Gaius Caesar geborgen; sie stammen von Architekturgliedern und dem Fries. Auch wurde ein Fragment eines marmornen Werkstücks mit lesbischem Kyma des 6. Jahrhunderts v. Chr. gefunden. In Sondage 38 wurde byzantinische Verbauung auschnittsweise erfaßt. 
Die Arbeiten des Ptolemaion-Programms standen vorrangig im Zeichen der Fundbearbeitung, grabungsarchäologische Aktivitäten beschränkten sich auf die Bergung einiger Blöcke des kaiserzeitlichen Bogentors aus dem Flußbett östlich des Monuments. Die zeichnerische und photographische Aufnahme architektonischer Werkstücke des Ptolemaions (G. Stanzl) und des Bogentors (N. Pieper) wurde fortgesetzt. Zahlreiche Fragmente der Bauausstattung der Kirche am Ptolemaion, darunter mehrere Kapitelle, Schrankenplatten, Ständer u. a. wurden zusammengesetzt, restauriert und dokumentiert.

\title{
Wissenschaftliche Veranstaltungen
}

(von Institutsangehörigen und projektgebundenen Mitarbeiterinnen und Mitarbeitern der Zentrale Wien zu Forschungsprojekten des ÖAI)

\section{Vorträge und Posterpräsentationen}

\author{
Inlandsprojekte
}

Vorträge

St. GroH, Neue Grabungen am Frauenberg bei Leibnitz. Vortrag zur Jahreshauptversammlung des Archäologischen Vereines Flavia Solva, Frauenberg, 3. 7. 2003.

St. Groh - H. Sedlmayer, Töpferwerkstätten im Kastellvicus Ost von Favianis/Mautern (Noricum). Jahrestagung des West- und Süddeutschen Verbandes der Altertumsforschung, Ingolstadt/ Deutschland, 10.-13. 6. 2003.

Dies., New research in the military vicus of Mautern/Favianis (Austria). ROCT-Workshop on Contextual Archaeology, Universität Leuven/Belgien, 12.-13. 12. 2003.

M. Kandler, Amphitheater in Carnuntum. Vorlesung am Institut für Theaterwissenschaften der Universität Wien, 20. 1. 2003.

P. Scherrer, Wohnen und Arbeiten im römischen St. Pölten (Aelium Cetium). NÖ Landesarchiv St. Pölten, 9. 12. 2003.

Poster

H. Zabehlicky, gemeinsam mit I. Draxler (Geologische Bundesanstalt) und U. Thanheiser (VIAS), Eine kaiserzeitliche Tenne in Bruckneudorf (Parndorf), Österreich. Ein Schritt auf dem Weg zum Grundstoff der Macht. 19. Internationaler Limeskongreß, Pécs, September 2003.

H. Zabehlicky, gemeinsam mit W. VetTERs (Universität Salzburg), Der lange Winter der Römer. 6. Deutsche Klimatagung. Klimavariabilität. 2003, Potsdam, September 2003 und Association for environmental Geology, Wien, 10. 10. 2003.

\section{Ephesos (Türkei)}

Vorträge

St. GroH, Das Stadtbild von Ephesos im Spiegel neuer methodischer Ansätze. Hauskolloquium am Institut für Klassische Archäologie der Universität Wien, 26. 3. 2003.

DERS., Integrated prospection in the upper town of Ephesus. XIXth International Symposium CIPA 2003, Antalya, 5. 10. 2003.

Ders., Virtual Reality in Ephesos: Das Oberstadtprojekt. Jahreshauptversammlung der Gesellschaft der Freunde von Ephesos, Wien, 10. 11. 2003.

R. Hanslmayr, Der Bedeutungswandel des griechischen Hermenmals in römischer Zeit im Spiegel der Hermen aus Ephesos. 10. Österreichischer Archäologentag, Graz, 7.-9. 11. 2003.

M. Kerschner, Phokäische Thalassokratie oder Phantom-Phokäer? Die frühgriechischen Keramikexporte im westlichen Mittelmeer im Licht neuer archäometrischer und archäologischer Unter- 
suchungen. Graduiertenkolleg »Archäologische Analytik« der Johann Wolfgang-Goethe-Universität Frankfurt am Main, 16. 1. 2003.

DERs., Ephesos zur Zeit der Ionischen Wanderung. Institut für Klassische Archäologie der JohannesGutenberg-Universität Mainz, 20. 1. 2003.

Ders., Ephesos zur Zeit der Ionischen Wanderung. Hauskolloquium am ÖAI Athen, 27. 3. 2003.

DERS., Lydische Weihungen in griechischen Heiligtümern. Humboldt-Kolleg »Stranieri e non cittadini nei santuari del Mediterraneo antico«, Università degli Studi di Udine, 20.-22. 11. 2003.

G. KLEBINDER-Gauss, Bronzeschmuck aus dem Artemision von Ephesos. Symposium »Schmuck und Tracht der Antike im Laufe der Zeit« des Lehrstuhls der Klassischen Archäologie der Universität Trnava, Modra-Harmonia, 19.-22. 11. 2003.

St. KLotz, Photogrammetry in Ephesos - Recording Basic Spatial Data. XIXth International Symposium CIPA 2003, Antalya, 3. 10. 2003.

F. Krinzinger, Ephesos - die jüngsten Projekte. Archäologische Gesellschaft Innsbruck, 11. 3. 2003.

DERs., Ephesos - die Forschungsarbeiten 2002. 25th International Symposium of Excavations, Surveys and Archaeometry, Ankara, 29. 5. 2003.

DERs., Ephesos 2003. Jahreshauptversammlung der Gesellschaft der Freunde von Ephesos, Wien, 10. 11. 2003.

M. LA Torre, Neuaufnahme der Bauforschung am Vediusgymnasium in Ephesos. Karlsruhe, 3. 3. 2003.

U. Muss, Das Artemision von Ephesos in römischer Zeit. 10. Österreichischer Archäologentag, Graz, 7.-9. 11. 2003.

DiEs., Bauten und Funde römischer Zeit im Artemision von Ephesos. Deutsches Archäologisches Institut Istanbul, 17. 11. 2003.

G. Plattner, Ephesische Kapitelle des 1. und 2. Jhs. n. Chr. Transfer von Architekturkonzepten und Ornamentformen. Österreichisches Historisches Institut, Rom, 6. 6. 2003.

Ders., Die 'Anaglypha Hadriani' in Rom. Deutsches Archäologisches Institut Rom, 10. 6. 2003.

Ders., Ost und West. Römische Architekturen in Kleinasien. 10. Österreichischer Archäologentag, Graz, 7. 11. 2003.

A. M. PüLz, Zur Funktion der Goldappliken aus dem Artemision von Ephesos. Symposium »Schmuck und Tracht der Antike im Laufe der Zeit« des Lehrstuhls der Klassischen Archäologie der Universität Trnava, Modra-Harmonia, 19.-22. 11. 2003.

B. Pulsinger, Perlen und Anhänger aus dem Artemision von Ephesos. Symposium »Schmuck und Tracht der Antike im Laufe der Zeit« des Lehrstuhls der Klassischen Archäologie der Universität Trnava, Modra-Harmonia, 19.-22. 11. 2003.

P. Scherrer, Die Herrscherideologie Traians und ihr Niederschlag in städtischen Bauprogrammen. Deutsches Archäologisches Institut Istanbul, 12. 3. 2003.

Ders., Das Serapeion von Ephesos. Symposium des Deutschen Archäologischen Instituts Istanbul »Die Rote Halle in Pergamon und der Kult ägyptischer Gottheiten im Imperium Romanum«, Pergamon, 5.-7. 9. 2003.

DERS., Die hellenistischen und römischen Stadttore in Kleinasien. Symposium »Stadttore - Puertas de la Ciudad« der Real Fondacion de Toledo und des Deutschen Archäologischen Instituts Madrid, Toledo, 25.-27. 9. 2003.

Ders., Der Fries des Hadrianstempels von Ephesos, eine Botschaft auf drei Ebenen. 10. Österreichischer Archäologentag, Graz, 7.-9. 11. 2003.

H. Taeuber, Das Parthermonument - Historische Grundlagen. Kolloquium »Das Partherdenkmal von Ephesos«, Wien, 27.-28. 4. 2003.

E. TrinkL, Artefacts Related to Preparation of Wool and Textile-processing found in the Terrace Houses of Roman Ephesos. „Ancient Textiles: Production, Craft and Society«. Copenhagen/ Lund, März 2003.

M. WeIssL, Die Entwicklung des Sekos im Artemision von Ephesos. Deutsches Archäologisches Institut Athen, Gastvortrag für den Aigeiros-Verein, 13. 2. 2003. 
Ders., Das Artemision von Ephesos zur Zeit des lydischen Reiches. Religionswissenschaftliches Symposium »Offizielle Religion politischer Oberschichten und lokale Religionsausübung unterschiedlicher Volksgruppen. Kleinasien und angrenzende Gebiete vom Beginn des 2. bis zur Mitte des 1. Jahrtausends«, Bonn 20. 2. 2003.

Ders., Altäre im Artemision von Ephesos. 10. Österreichischer Archäologentag, Graz, 7.-9. 11. 2003.

Ders., Das Artemision von Ephesos. Institut für Klassische Archäologie der Eberhard-Karls-Universität Tübingen, 13. 11. 2003.

Poster

U. Muss - A. Bammer, Early Coastal Topography of Ephesus and its archaeological setting. 2nd International Kemer Underwater Days, Antalya, 16.-19. 5. 2003.

Dies. (gemeinsam mit K. Koller, M. Aurenhammer, L. Moens, P. de Pape und J. de Donder), Study of Marble Provenance from the Artemision of Ephesus. Asmosia VII, 7th International Conference, Thassos, 2.-7. 6. 2003.

$$
\text { Limyra (Türkei) }
$$

Vorträge

Th. Marksteiner, Die Ergebnisse der Kampagne Limyra 2002. Hauskolloqium am Institut für Klassische Archäologie der Universität Wien, 23. 1. 2003.

Ders., Das Ptolemaion von Limyra und die Weststadtgrabungen. Centre d'archéologie Bordeaux, 19. 3. 2003.

Ders., Ergebnisse der Kampagne 2002 der Limyra-Grabung. 25th International Symposium of Excavations, Surveys and Archaeometry, Ankara, 31. 5. 2003.

Ders., La Lycie. Kolloquium »Archéologie de l'Empire Perse«. Collège de France »Réseau international d'études et de recherches achéménides«, Paris, November 2003.

Varia

Vorträge

K. Herold, Konservierung des Istanbuler Palastmosaiks im Februar 2003. Tagung der österreichischen Bodenfundrestauratoren und Veranstaltungen des Österreichischen Restauratorenverbandes.

G. Plattner (gemeinsam mit H. R. Goette, S. Kucher), Die archäologische Bilddatenbank in Kooperation mit dem DAI und dem Museum der Schönen Künste Budapest. Deutsches Archäologisches Institut Berlin, 12. 2. 2003.

Ders. (gemeinsam mit K. Stump), Die archäologische Bilddatenbank in Kooperation mit dem DAI und dem Museum der Schönen Künste Budapest. Deutsches Archäologisches Institut Rom, 5. 3. 2003.

P. SCHERrer, Lokale Identität in den Städten in Noricum und Westpannonien. Symposium »Lokale Identitäten im Imperium Romanum«, Wiener Neustadt, 23.-27. 4. 2003.

Ders., Die keltischen Gottheiten in Pannonien, ein Überblick. Symposium des Projekts F.E.R.C.AN, Graz, 9.-12. 10. 2003.

M. Steskal - G. PlattNer - N. Gail, Präsentation der Bilddatenbank ImageFinder. ÖAI Wien, 24. 1. 2003.

M. STESKAL - N. Gail, Präsentation der Bilddatenbank des Österreichischen Archäologischen Instituts. Landesmedienzentrum Karlsruhe, 16. 10. 2003.

H. ZABEHLICKY, Frühchristliche Kirchen im östlichen Mittelmeerraum - Ein Überblick. Jahresvortrag des Vereins zur Förderung der christlichen Archäologie in Österreich, Wien, 19. 5. 2003. 


\section{Ausstellungen, Veranstaltungen und Öffentlichkeitsarbeit}

St. GroH arbeitete an der Gestaltung der Steirischen Landesausstellung 2004 »Die Römer« in Kooperation mit Joanneum Research Graz. In Ephesos betreute er ein ORF-Team der ModernTimes-Redaktion für einen am 3. 10. 2003 ausgestrahlten Bericht über das Projekt »Die Topographie der Oberstadt von Ephesos « und gab ein Interview für die ORF-Ö1-Redaktion Wissenschaft, Bildung, Gesellschaft über die Forschungen in der Oberstadt von Ephesos.

M. KANDLER arbeitete an verschiedenen Ausstellungen mit: Mythos Pferd, Steirische Landesausstellung Schloß Piber, 1. 5.-2. 11. 2003 (Katalogbeitrag, Leihgaben, Einrichtung der Vitrinen); Die Römer und ihr Erbe. Fortschritt durch Innovation und Integration, Ausstellung des Landesmuseums Mainz, 2. 2.-25. 2. 2003 (Leihgabe); Rímané a Germáni, Ausstellung des Städtischen Museums Brno, 30. 4.-26. 10. 2003 (Leihgaben); Marc Aurel und Carnuntum, Ausstellung anläßlich der 100-Jahr-Feier der Eröffnung des Museums Carnuntinum 2004 (Vorarbeiten: Konzept, Leihgaben, Katalog); Vorbereitung der Dokumentation über die Grabungen im Auxiliarkastell für das Kulturhaus Petronell (Museumsverein Auxiliarkastell Petronell-Carnuntum) 2004. Weiters führte er die Teilnehmer der 14. Internationalen Roman Military Equipment Conference (ROMEC) am 28. 8. 2003 und eine Exkursion der Gesellschaft für Archäologie in Niederbayern (Dr. Karl Schrock, Deggendorf) am 25. 9. 2003 durch Carnuntum.

St. KLOTZ organisierte das jährlichen Treffen der »Arbeitsgemeinschaft der Vermessungsingenieure in der archäologischen Bodendenkmalpflege«, das von 28. 4.-2. 5. 2003 in Ephesos stattfand.

Im Foyer des St. Pöltner Rathauses wurde unter wissenschaftlicher Leitung von P. SCHERRER ein Lapidarium eingerichtet, in dem die Steindenkmäler zum municipium Aelium Cetium aufgestellt und mit entsprechenden Erklärungen versehen sind. Für die 2004 geplante Ausstellung »St. Florian und seine Zeit« in Enns-Lauriacum wurden Ausstellungsstücke aus Cetium ausgewählt und entsprechende Katalogtexte und Poster verfaßt. P. Scherrer organisierte auch das Symposium »Internationales Arbeitsgespräch über Terra Sigillata in St. Pölten« mit 40 Teilnehmern aus 6 Ländern (28.-29. 3. 2003).

G. Wiplinger war mit der Vorbereitung des Symposiums »Cura Aquarum in Ephesus« (Oktober 2004) betraut.

Am 10. 11. 2003 fand die alljährliche festliche Jahresversammlung der Gesellschaft der Freunde von Ephesos statt. N. Zimmermann (ÖAW) und St. Groh (ÖAI Wien) hielten die Festvorträge »Malerei im Hanghaus 2 in Ephesos« und »Virtual Reality in Ephesos: Das Oberstadtprojekt«. Anschließend lud die Vereinigung der Österreichischen Industrie zu einem Empfang.

\section{Administratives}

\section{Redaktion}

M. Aurenhammer oblag wie in den vorangegangenen Jahren die Redaktion des Jahresberichts Ephesos 2002 für ÖJh 72, 2003. Sie arbeitete auch an der Indexerstellung des Bandes C. Lang-Auinger (Hrsg.), Hanghaus 1 in Ephesos. Funde und Ausstattung, FiE VIII 4 (2003) und verfaßte die englischen Resümees.

Redaktion, Organisation und Produktionsbegleitung der im Jahr 2003 erschienenen Publikationen des Instituts lag bis Ende April in Händen von B. BRANDT, mit 1. 5. 2003 übernahm G. WLACH als Karenzvertretung die Redaktionsaufgaben. Folgende Publikationen wurden betreut: A. Kaltenberger, Mittelalterliche bis frühneuzeitliche Keramik aus Mautern an der Donau, 4. ErghÖJh (erschienen im April 2003); U. Schädler - P. Schneider, Ein frühes Tondach aus dem Artemision von Ephesos, 6. ErghÖJh (erschienen im Jänner 2004); K. Adler-Wölfl, Pannonische Glanztonware aus dem Auxiliarkastell von Carnuntum, 7. ErghÖJh; ÖJh 71, 2002 (erschienen im Mai 2003); ÖJh 72, 2003 (erschienen im April 2004).

M. Aurenhammer und G. Wlach stellten die »Eckpunkte zur Strukturplanung des ÖAI« zusammen. 


\section{Archive}

\section{Dokumentationsarchiv}

G. WLACH war für die Unterstützung bei Recherchen und Bereitstellung von Material aus dem Dokumentationsarchiv für aktuelle Forschungen des ÖAI und auswärtige Anfragen zuständig, sie gab auch Hilfestellung bei Recherchen zu Material in Zusammenhang mit Diplomarbeiten.

Die Bearbeitung der Archivalien wurde fortgesetzt. Das Material zum ehemaligen Jugoslawien wurde geordnet und erfaßt, das Material zu Niederösterreich, Oberösterreich, Vorarlberg nach Orten geordnet.

Die Photos ohne Negative aus dem Bestand Ephesos (darunter z. T. Aufnahmen von A. Schindler) wurden digitalisiert.

\section{Photoarchiv}

G. WLACH betreute auch die Diathek und das Photoarchiv und leistete Hilfestellung bei Recherchen und Anfragen.

Planothek

I. BEndA-WeBer betreute das Planarchiv und war mit Zeichenarbeiten für verschiedene Projekte des Instituts befaßt.

\section{Epigraphisches Archiv}

Das epigraphische Archiv und die damit verbundene Korresponenz- und Auskunftstätigkeit übernahm weiterhin H. TAEuber (Institut für Alte Geschichte, Altertumskunde und Epigraphik der Universität Wien).

\section{Bibliothek}

Die Bibliothek unter der Leitung von M. Bodzenta und M. KERschner als Bibliotheksreferenten umfaßt die Bibliotheken der Zentrale Wien, der Zweigstellen Athen und Kairo sowie die Grabungsbibliotheken Ephesos und Carnuntum.

Der Bandzuwachs für alle Bibliotheken betrug 2728 Bände im Jahr 2003 (Zentrale Wien: 1106 Bände), die Anzahl der laufenden Zeitschriften und Reihen beträgt hiervon 867 (Zentrale Wien: 695), der Gesamtbuchbestand mit dem Jahr 2003 betrug 94164 Bände (Zentrale Wien: 69377 Bände).

Der hohe Buchzuwachs kann nur gehalten werden, da die Bibliothek einen intensiven Tauschverkehr pflegt, welcher im Jahr 2003 komplett berarbeitet wurde: mit insgesamt 276 Tauschpartnern können 383 Zeitschriften- und Reihentitel eingetauscht werden.

Die Bibliothek Wien ist gemeinsam mit der Fachbibliothek für Klassische Archäologie aufgestellt. 2003 hatte die Bibliothek 166 Tage geöffnet (1 453 Öffnungsstunden). Es wurden 3750 Benutzer der Bibliothek betreut.

Mit dem Jahr 2003 wurde die Zusammenarbeit mit der Fachbibliothek für Klassische Archäologie intensiviert. Es wurde eine Bibliothekskommission eingerichtet, deren Mitglieder die Bibliothekare und die Bibliotheksreferenten der beiden Institutionen sind, um u. a. einen effizienteren Literaturankauf zu erreichen. 
Der EDV-Bestand des Instituts wurde unter dem zuständigen Referenten St. GroH kontinuierlich aufgerüstet und ältere Komponenten sukzessive ersetzt. Weiterhin steht hier H. PIRIBAUER einmal in der Woche für die EDV zur Verfügung.

Neu organisiert wurde in erster Linie der Instituts-Server, die hierarchisch gestaffelten Zugriffe und die Verwaltung des Mail-Servers. Weiters wurde der Bilddatenbank-Server in das Netzwerk gestellt und der Zugriff für Institutsangehörige ermöglicht. Besonderes Augenmerk liegt auf der Sicherheit des Netzwerks; neben softwarebasierter Sicherung wurde die Anschaffung einer Hardware-Firewall beschlossen und in die Wege geleitet, die externe Zugriffe nur für ausdrücklich legitimierte Benutzer möglich macht. Die Sicherung von Serverdaten wird in periodischen Abständen auf Band vorgenommen. Für das Ablegen der hochauflösenden Bilder der Bilddatenbank wurde Kontakt mit dem EDV-Zentrum der Universität Wien aufgenommen.

\section{Bilddatenbank}

Mit der Anschaffung von Hardware und dem Softwarepaket ImageFinder im Dezember 2002 wurde die Grundlage für die Erstellung einer Bilddatenbank gelegt. Die bereits vorhandenen Reproduktionen älterer Glasplattennegative wurden eingespielt, ebenso vor allem aktuelle Bilder der Forschungskampagnen in Ephesos aus den Jahren 2002 und 2003. Damit umfaßt die Datenbank Ende des Jahres 2003 bereits fast 10000 Bilder. Die Beschlagwortung erfolgt unter der Kontrolle der Verantwortlichen. Die photographische Verwaltung liegt in den Händen von N. GaIL, die administrative in jenen von M. Steskal (Konsulent: G. Plattner; Mitarbeiter/-innen: L. Zabrana, A. LYKKE und J. EITLER). 


\section{ZWEIGSTELLE ATHEN}

$\begin{array}{ll} & \text { Personal } \\ \text { Leitung: } & \text { Dr. Georg LadstÄtTer } \\ \text { wissenschaftliches Personal: } & \text { Dr. Walter Gauss (ab 1. 10. 2003) } \\ & \text { Dr. Detlev Kreidd (bis 31. 3. 2003) } \\ & \text { Dr. Christa Schauer } \\ \text { Grabung Lousoi: } & \text { Univ.-Doz. Dr. VeroniKa Mitsopoulos-LeON } \\ \text { Verwaltung: } & \text { Petra RitTer (bis 31. 8. 2003) } \\ \text { Haushalt: } & \text { Sabine Kabourelis (ab 17. 7. 2003) } \\ & \text { Chrysoula DoulBeri }\end{array}$

\section{FeLdFORSCHUNGSPROJEKTE}

\section{Lousoi (Achaia)}

Die Grabungen in Lousoi wurden vom 1. Juni bis 11. Juli 2003 von V. Mitsopoulos-Leon geleitet, mit den Mitarbeiter(inne)n G. LadstÄtter (Grabung, Architektur), Ch. Schauer (Bearbeitung Keramik und Dachterrakotten), K. Bernhardt, Ch. Faller, M. Golin (Grabung), K.-V. v. Eickstedt (photographische Aufnahmen). Als Vertreterinnen des griechischen Antikendienstes (6. Ephorie Patras) betreuten Georgia Alexopoulou und Georgia Merti (vor Ort) die Grabung.

An Feldforschungen erfolgten im Flurbereich 'Stadio' Grabungen zur Halle und zum Ringhallentempel sowie eine Reinigung der Bebauung auf der Terrasse I im Westen des Tempels.

Die Untersuchungen zur Halle umfaßten fünf Schnitte im Norden und in der Mitte des Baus, um weitere Aufschlüsse zu dessen architektonischer Gestalt zu gewinnen. Ein Ost-West verlaufender Fundamentzug weist im Norden der Halle auf einen geschlossenen Raumflügel mit den Innenmaßen von 10,90 auf 12,50 m, der durch zwei Stützen in zwei Schiffe gegliedert war. Als Auflager für die südliche Stütze diente eine Kalksteinplatte, welche mit zwei weiteren Kalksteinplatten aufwendig fundamentiert worden war. Die bautechnischen Einarbeitungen am Oberlager der Euthynterie der Ostfront erlauben die Rekonstruktion der aufgehenden Architektur folgendermaßen: Der nördliche Flügelraum verfügte im Osten über eine Orthostatenreihe und darüberliegendes Lehmziegelmauerwerk. Genau an der Stelle, wo die Südmauer des Nordflügels in die Ostfront einbindet, beginnt die offene Kolonnade vermutlich mit Stützen aus Holz. Dieselbe Gestaltung ließ sich in den vergangenen Jahren für den geschlossenen Südflügel nachweisen.

Aus den zahlreichen Sondagen zum Fundament dieses Baus läßt sich derzeit folgendes zusammenfassen: die zweischiffige Halle $(65,29 \mathrm{~m} \times 12,05 \mathrm{~m})$ ist nach einem klaren System auf der Grundlage der korrespondierenden Jochweiten der Front- und Innenstützen $(2,25$ und 4,50 m) entworfen. Die Länge entspricht 28 und die Breite 5 Frontjochen. Diesem Rhythmus folgt die Anordnung der beiden geschlossenen Flügel, wobei der Nordflügel sechs und der Südflügel vier Frontjoche umfaßt. Die Ansicht der Front ist durch die offene Kolonnade und die asymmetrisch angeordneten geschlossenen Flügel bestimmt. Bemerkenswert ist dabei, daß die Kolonnade mit $17 \mathrm{zu}$ ergänzenden Stützen etwa nur 60\% der Länge des Gebäudes ausmacht.

Im Inneren wird ein langrechteckiger Saal, der mit 8 zu ergänzenden Innenstützen in zwei Schiffe geteilt ist, mit zwei geschlossenen Flügelräumen kombiniert, welche ihrerseits unterschiedlich 
gestaltet sind: Im Norden befindet sich ein großer Saal mit vermutlich zwei Innenstützen, der südliche Flügel ist in zwei Räume geteilt. Auch wenn die Nutzung dieser Flügelräume aus dem Grabungsbefund nicht abzuleiten ist, weisen die unterschiedlichen Raumauffassungen wohl auf unterschiedliche Funktionen; analog zur Hallenarchitektur im allgemeinen ist vermutlich an Bankett-, Archivräume oder anderes zu denken. Wie aus den Grabungen der vergangenen Jahre abzuleiten ist, wurde diese Halle in frühhellenistischer Zeit errichtet.

Für den Platz im Osten der Halle weist die Sondage in der Gebäudeachse auf ein zeitgleiches Niveau in Form einer befestigten Lehmpackung. Weiter im Osten befindet sich unmittelbar vor dem Bau eine sorgfältig mit Dachziegelbruch ausgelegte, annähernd rechteckige Grube (ca. 4,00 m auf mindestens 4,20 m), welche nach Auflassung der Halle eingerichtet wurde. Vermutlich steht diese derzeit nur z. T. freigelegte Anlage mit einer tonverarbeitenden Werkstätte in Verbindung.

Im Bereich des Ringhallentempels auf einer höher gelegenen Terrasse $80 \mathrm{~m}$ im Osten der Halle wurde zunächst das vollständig erhaltene Fundament des westlichen Sekosbereichs freigelegt. Westlich einer Nord-Süd verlaufenden Mauer, welche den Sekos in zwei Abschnitte trennt, befindet sich ein annähernd quadratischer Saal $(7,90 \times 7,70 \mathrm{~m})$, der durch zwei Reihen von je drei Stützen in drei Schiffe geteilt ist. Erhalten haben sich die Fundamente in Form von Kalksteinplatten über Lagen aus Bruchsteinen. Westlich dieses '6-Säulen-Saales' schließt der Sekos in Form eines quergelagerten Raumes (Innenmaße: 7,90 × 2,80 m) ab, welcher grundrißtypologisch einem Opisthodom entspricht.

Wie aus den Grabungen des Vorjahres bereits bekannt, schließt an den '6-Säulen-Saal' im Osten die Cella an, von der sich vermutlich der Unterbau der Kultbildbasis unmittelbar im Osten der Nord-Süd verlaufenen Trennmauer erhalten hat. Aus einer Sondage im Bereich der südlichen Stützenreihe ergibt sich, daß auch die Cella mit einer lichten Weite von $7.90 \mathrm{~m}$ durch zwei Stützenreihen in drei Schiffe gegliedert ist.

Eine Sondage im Südpteron erbrachte die Fundamentplatte der (von Westen gezählten) 9. Stütze der Ringhalle. Ein stark korrodiertes Eisenplättchen ist aus seiner Fundlage vermutlich mit dem im Jahr zuvor geborgenen Komplex der Proxenie-Inschriften aus Bronze in Zusammenhang zu bringen. Für eine Befestigung des Pterons zwischen den Kalksteinplatten der Außenstützen fehlen Hinweise, so daß sich aus diesen punktuellen Untersuchungen der Peristase die Frage ergibt, ob letzte überhaupt fertiggestellt wurde.

Nach einer vorläufigen Einschätzung umfaßt der Ringhallentempel $(15,70 \times$ mindestens 39,00 m) eine Peristase mit 6 auf mindestens 14 Stützen und einen Sekos mit einer lichten Weite von 7,90 m. Der Sekos gliedert sich in einen östlichen Abschnitt mit einer langrechteckigen Cella, die sich vermutlich auf einen Pronaos öffnet, und in einen westlichen Abschnitt mit dem '6-Säulen-Saal' und dem Opisthodom. Eine vorläufige Datierung der Errichtung des Baus weist gestützt auf Fundmaterial aus den Untersuchungen des Jahres 2002 und auf die grundrißtypologischen Kriterien in die spätarchaische Zeit, eine spätere Nutzung zumindest für den eingeschränkten Bereich der Cella ist für die hellenistische Zeit anzunehmen. Trifft die derzeitige Interpretation des Grundrisses mit einem zweigeteilten Sekos und dem Fehlen eines Adytons zu, so ist bemerkenswert, daß dieser Ringhallentempel dem archaischen Apollontempel in Korinth deutlich näher steht als den arkadischen Tempeln, woraus für die nordwestarkadische Stadt Lousoi das Spannungsfeld zwischen Arkadien und der Nordküste der Peloponnes einmal mehr deutlich wird. Funktional ist dieser Tempel, dessen Dedikation noch offen ist, wohl dem Stadtheiligtum von Lousoi zuzuweisen, auch wenn die nachgewiesene monumentale Gestaltung des öffentlichen Zentrums in Form der Stoa erst in den frühen Hellenismus weist.

Auf der Terrasse I unmittelbar im Westen des Tempels wurden die an der Oberfläche sichtbaren Reste eines rechteckigen Gebäudes $(8,25 \times 5,75 \mathrm{~m})$ gereinigt. Auf einem 0,65 m breiten Fundament hat sich das aufgehende Mauerwerk in Form von Orthostatenblöcken erhalten, welche unverklammert versetzt sind. Die Steinblöcke an der Nordwestböschung von Terrasse I weisen dieselben Abmessungen auf und sind diesem Bau zuzuordnen. Anathyrosebearbeitung an der AuBenseite dieser Blöcke macht wahrscheinlich, daß diese als Spolien in den Verband gekommen sind. Eine parallel verlaufende Mauer, 2,80 m im Süden, ist in kleinteiligem Kalksteinbruch errichtet und steht offenbar in keinem direkten Bezug zum Rechteckbau. 
Aus der exakten Ausrichtung dieser Bebauung auf die Ost-West-Achse des Peripteraltempels ist abzuleiten, daß der Rechteckbau Teil der architektonischen Ausgestaltung des Stadtheiligtums darstellt. Trifft die Spolienverwendung zu, dann ist die Errichtung des rechteckigen Gebäudes wohl mit der hellenistischen Phase des Tempels in Verbindung zu bringen.

Parallel zu den laufenden Grabungen wurde Fundmaterial aus den bereits abgeschlossenen Grabungsbereichen bearbeitet. Für das Artemisheiligtum wurden die Untersuchungen von V. Mitsopoulos-Leon zum figürlichen Votivmaterial fortgesetzt. 2003 wurde von Ch. Schauer mit der Bearbeitung der erhaltenen Dächer aus dem Artemisheiligtum und aus der Wohnbebauung des Flurbereiches 'Phournoi' begonnen.

\section{Survey 'Gremoulias' (Chelmos), Kalavriton (Achaia)}

Als Kooperationsprojekt (Synergasia) von griechischem Antikendienst respektive der 6. Ephorie Patras (vertreten durch G. AleXopoulou) und ÖAI Athen (vertreten durch G. LADSTÄTtER) fand mit den Mitarbeiter(inne)n K. Bernhardt, Ch. Faller und M. Golin von 7. bis 10. Juli 2003 im Flurbereich 'Gremoulias' (Chelmos), Kalavriton, ein Vermesssungssurvey statt.

Auf einem Geländesattel (Seehöhe 1200 m), der 3 km südöstlich von Kalavrita bzw. 7 km nordöstlich des antiken Lousoi liegt, konnte G. Alexopoulou 2001 antike Reste lokalisieren, die auf eine monumentale Bebauung hinweisen und nun den Ausgangspunkt archäologischer Feldforschungen darstellen: als erster Schritt wurde eine Geländevermessung mit der Kartierung und Dokumentation der Baureste vorgenommen.

Topographisch handelt es sich um eine Ost-West orientierte Terrasse (ca. $60 \times 25 \mathrm{~m}$ ), die im Osten und Westen von Geländeanstiegen, im Norden von einem unzugänglichen Felsabbruch und im Süden von einem sanft abfallenden Hang begrenzt wird. Im Norden dieser Terrasse zeigt sich ein ca. $6 \mathrm{~m}$ langes Ost-West orientiertes Fundament mit großformatigen Blöcken aus lokal anstehendem Konglomeratgestein. An verstreut liegenden architektonischen Werkstücken ist vor allem auf ein nahezu vollständig erhaltenes dorisches Geison aus Poros mit den Gesamtabmessungen von $1,00 \times 0,81 \times 0,34 \mathrm{~m}$ hinzuweisen. Aus den Maßbezügen der Kleinflächen wie Mutulenplatten und Viae ist eine dorische Säulenordnung mit einer Jochweite von ca. 2,50 m abzuleiten. Die Durchbildung des Stirnprofils legt vorläufig eine vorhellenistische Datierung dieses Baugliedes nahe. Weiters waren mehrere fragmentierte Bauglieder aus nichtlokalem Marmor festzustellen, welche über geglättete Sichtflächen und an den Anschlußflächen stellenweise über Anathyrose und Stemmlöcher verfügen. Darüber hinaus fanden sich zahlreiche weitere architektonische Werkstücke aus lokalem Kalkstein und Poros, darunter kleinst zerschlagene Fragmente kannelierter Säulentrommeln sowie punktförmige Häufungen von Dachziegelbruch.

Diese Werkstücke belegen eine monumentale Bebauung der Terrasse, von welcher sich vermutlich noch Fundamentabschnitte in situ erhalten haben, vor allem das indikative Geison weist auf einen großdimensionierten Bau in dorischer Ordnung. Der Schluß liegt nahe, in der Bebauung der Gremouliasterrasse an ein Heiligtum mit einem dorischen Sakralbau zu denke. Es ist durchaus wahrscheinlich, daß dieses vermeintliche Heiligtum mit einem antiken Wegesystem in Zusammenhang steht, welches die Ebene von Kalavrita über die Hochebene des Chelmosmassivs mit den Landschaften Achaias verbindet.

\section{Grabung Aigeira (Achaia)}

Die Grabungen in Aigeira wurden vom 30. August bis 8. Oktober 2003 von G. LADSTÄTTER geleitet, als Mitarbeiter(inne)n waren Ch. Faller, F. Höflmayer, B. Schrettle (Grabung), Th. Hagn (Fundaufnahme), R. SAUER (geologische Studien) und G. KLEBINDER-Gauss (Funde Akropolisgrabung) anwesend. Als Vertreterin des griechischen Antikendienstes (6. Ephorie Patras) betreute Stella TsIRONI die Grabung. 
Die Feldforschungen umfaßten auf der 'Solonterrasse' die Grabungen unmittelbar im Norden der Akropolis im 'Banketthaus' und im 'Westbau' sowie Untersuchungen zur hydrogeologischen Situation.

Für das 'Banketthaus', dessen öffentliche Bestimmung aus dem Andron mit 11 Klinen, aus dem Baderaum mit 4 Sitzbadewannen und aus dem Fehlen eines Oikos abzuleiten ist, weisen die bisherigen Grabungen von der Errichtung in der Mitte des 4. Jahrhunderts v. Chr. bis zur intentionellen Auflassung im ausgehenden Hellenismus auf mehrere Nutzungsphasen. Die Untersuchungen konzentrierten sich auf den Südwestbereich des Gebäudes, wo dicht gelagerte Mauerzüge, Nutzungsschichten und Störungen auf relativ kleinem Raum $(8 \times 4 \mathrm{~m})$ detaillierte Hinweise auf diese Bauabfolge liefern.

Der Kernbau $(18 \times 15$ m) der spätklassischen Gründungsphase verfügte im Süden über eine weitere Raumachse für Betriebseinrichtungen respektive im Südwesten über die heiztechnischen und wasserwirtschaftlichen Anlagen für den Baderaum. Ein bereits 2002 angeschnittenes Wasserreservoir wurde vollständig untersucht. Der rechteckige, mit Kalkmörtel verputzte Schacht wird durch die Südmauer des später eingerichteten Beckenraumes gestört, so daß der ursprüngliche Nordabschluß nicht mehr festzustellen ist. Mit dem Grundriß von 1,30 m auf mindestens 1,30 m und einer Tiefe von $1,45 \mathrm{~m}$ verfügte das Reservoir über eine Speicherkapazität von mindestens 2,45 $\mathrm{m}^{3}$ und versorgte den angrenzenden Baderaum mit Wasser. Das Fundmaterial aus Dachziegelbruch, fragmentierten Kochtöpfen und zerscherbter Feinkeramik weist die Verfüllung des Reservoirs in den späten Hellenismus. Nach Ausweis mehrerer Fundamentzüge setzt sich dieser Servicetrakt weiter nach Osten fort.

Im Laufe des 3. Jahrhunderts v. Chr. wird im Osten des Reservoirs nach Demontage der Vorgängerbebauung ein rechteckiger Raum $(4 \times 2,5 \mathrm{~m})$ mit einer Planierpackung aus Kieselsteinchen in hartem Lehm und einem Brunnen eingerichtet. Neben indikativer hellenistischer Keramik und Dachziegelbruch fand sich in dieser Packung eine vollständig erhaltene männliche Figurine aus Ton, die in spätgeometrisch-früharchaische Zeit datiert. Der kreisförmige Brunnen (Dm 1,20 m) ist in die Planierpackung und den anstehenden roten Lehm abgeteuft und wurde zunächst bis in eine Tiefe von 1,40 m ausgegraben. Die Verfüllung enthielt dicht gepackten Dachziegelbruch hellenistischer lakonischer Ziegel über großformatigen Konglomeratbrocken; nach unten folgt eine harte Lehmpackung mit reduziertem Anteil von Dachziegelbruch und kleineren Steinen. Neben spärlicher, stark zerschlagener Gebrauchskeramik fand sich in dieser Packung ein fragmentiertes tönernes Ensemble aus hellenistischer Zeit, welches auf einer Standplatte einen von einem felinen Tier flankierten Altar wiedergibt, sowie eine fragmentierte korinthische Tonsima. Da mit einer Tiefe des Brunnenschachts von ca. $10 \mathrm{~m}$ zu rechnen ist, erlaubt das derzeit geborgene Fundmaterial noch keinen chronologischen Aufschluß über die Verfüllung.

Gegen Ende des 3. Jahrhunderts v. Chr. wird der Baderaum mit den vier Sitzbadewannen aufgelassen. Der ersatzweise eingerichtete kleinere Beckenraum mit einer Sitzbadewanne im Bereich der 'Serviceachse' führt zur Überbauung des Wasserreservoirs und zur teilweisen Demontage der Mauern des 'Brunnenraumes', wobei der Brunnen weiterhin in Funktion stand.

Überträgt man die Bauabfolge des Südwestbereichs auf die Nutzung des gesamten Baus, so ist folgende Baugeschichte abzuleiten: Das öffentliche genutzte 'Banketthaus' aus der Mitte des 4. Jahrhunderts v. Chr. erfährt im Laufe des 3. Jahrhunderts v. Chr. neben kleineren Bauänderungen einen einschneidenden Umbau. Die Ablöse des Baderaumes mit vier Wannen durch den kleineren Bekkenraum mit einer Sitzbadewanne weist auf einen Rückbau der Badekapazität und im weiteren vermutlich auf eine geänderte Nutzung als privates Wohnhaus. Dieser Umbau ist durch die Einbeziehung der südlichen Raumachse mit einer Vergrößerung des Gebäudes verbunden. Im ausgehenden Hellenismus bzw. der beginnenden Kaiserzeit wird der Bau intentionell verlassen.

Der in Sondagen untersuchte 'Westbau' befindet sich von einer Nord-Süd verlaufenden Straße getrennt unmittelbar im Westen des 'Banketthauses'. Die Grabungen im Südostbereich erbrachten einen rechteckigen Raum $(2,5 \times$ mindestens $2,5 \mathrm{~m})$, dessen Mauerwerk zahlreiche Spolien aufweist. Zur Versetzung dieser Mauern wurde das anstehende, stark nach Norden abfallende Konglomerat teilweise geglättet, das Gefälle wurde durch eine Planierpackung ausgeglichen. Diese bereits 2002 angeschnittene Packung wurde bis zum gewachsenen Fels untersucht und erweist sich als geschlos- 
sener Fundkontext. Das Fundspektrum umfaßt Pithos- und Amphorenfragmente, Gebrauchs- und Kochkeramik, indikative Typen schwarzgefirnißter Feinkeramik wie Skyphoi, Kantharoi, Schalen und Teller sowie Tonlampen aus dem 3. Jahrhundert v. Chr. Weiters fanden sich in dieser Packung neben hellenistisch lakonischem Dachziegelbruch Fragmente bemalter korinthischer Firstziegel aus spätarchaisch-frühklassischer Zeit, die sich von den zeitgleichen Dächern der Akropolisgrabung deutlich unterscheiden. Somit weisen diese Fragmente auf einen noch unbekannten Bau dieser Zeitstellung.

Für die Durchbildung und Funktion des Westbaus fehlen noch Hinweise, chronologisch ist davon auszugehen, daß der untersuchte Abschnitt nicht vor dem 3. Jahrhundert v. Chr. errichtet wurde und spätere Änderungen aufweist.

Bei der Fortsetzung des geologischen Surveys wurden die hydrogeologischen Bedingungen der Solonterrasse für den Brunnen im 'Banketthaus' untersucht.

Der großräumige geologische Aufschluß am Westabbruch des Plateaus zeigt eine $8 \mathrm{~m}$ starke Konglomeratbank über einer wasserfesten Mergelpackung. Das mit wasserführenden Spalten durchzogene Konglomerat fällt nach Osten in Richtung des Brunnens ein, demnach liegt der Brunnen, für welchen mit einer Tiefe von ca. $10 \mathrm{~m}$ zu rechnen ist, an einer mit Erfahrung gewählten Stelle. Vor dem Hintergrund bereits erfolgter Untersuchungen zur Wasserversorgung von Aigeira gewinnt dieser bislang erste nachgewiesene Brunnen im Stadtgebiet besondere Bedeutung: Die hellenistische Unterstadt breitet sich auf wasserfesten Mergelbänken aus, welche für die Anlage von Brunnen nicht geeignet sind. Folgerichtig wird die Unterstadt durch ein hellenistisches Leitungssystem mit Wasser versorgt, das von einer Quelle im Süden über 1,5 km, teilweise unterirdisch, in die Stadt geführt wird. Die Bebauung der ca. $40 \mathrm{~m}$ über diesem Leitungssystem liegenden Solonterrasse nutzte die Ausläufer des Konglomerats der Akropolis, welches Wasser über dem dichten Mergel speichert, das durch Abteufung von Brunnen erschlossen werden kann.

Die Fundbearbeitung konzentrierte sich auf das Material der abgeschlossenen Akropolisgrabung und umfaßte die weitere Bearbeitung der prähistorischen und mykenischen Funde unter der Leitung von S. Deger-Jalkotzy und Mitarbeiter(inne)n (Mykenische Kommission der Österreichischen Akademie der Wissenschaften) und die Bearbeitung des Komplexes der geometrischen und archaischen Bronzefunde durch G. Klebinder-Gauß im Museum von Aegion.

Organisiert wurde die Erneuerung des schadhaften Daches des Grabungshauses, die diesbezüglichen Arbeiten wurden im Jänner 2004 abgeschlossen.

Die wissenschaftlichen Bediensteten verfolgten des weiteren ihre laufenden Forschungsprojekte:

G. LADSTÄTtER arbeitete an der Dokumentation und Auswertung der Grabungsbefunde von Lousoi, Gremoulias und Aigeira und verfaßte die erforderlichen Berichte, seine Forschungen beschäftigen sich mit verschiedenen Themen der angeführten Grabungen. Ch. SCHAUER hielt sich vom 10.-17. März 2003 in Olympia auf, um die Funde aus einer im Jänner 2003 erfolgten Nachgrabung im kaiserzeitlichen Bau nördlich des Prytaneions, an dessen Publikation sie beteiligt ist, aufzunehmen (Forschungsprojekt des Deutschen Archäologischen Instituts unter der Leitung von U. SINN: „Olympia in der römischen Kaiserzeit und der Spätantike«). Im Rahmen dieses Projekts führte sie zur Unterstützung der 7. Ephorie für Prähistorische und Klassische Altertümer vom 9.-18. 4. und 5.-9. 5. 2003 eine Notgrabung in diesem Bau in Hinblick auf die Neuverlegung der Mosaiken bis zu den Olympischen Spielen 2004 aus. Darüber hinaus setzte sie ihre Studien zu Keramik und Glas aus Lousoi und Olympia sowie zu den Dächern aus Lousoi fort. W. Gauss verfolgte seine Untersuchungen zu Stratigraphie und Chronologie des FH-III- bis SH-I-Fundmaterials aus der Grabung ÄginaKolonna. V. Mitsopoulos-LeON widmete sich inhaltlichen und organisatorischen Themen zur Grabung Lousoi und verfaßte die nötigen Berichte. Nahezu abgeschlossen ist ihr Manuskript zu den Tonstatuetten aus dem Artemisheiligtum in Lousoi, in Bearbeitung ist das Manuskript zu den Weihgaben in Metall und anderem Material aus dem Artemisheiligtum in Lousoi. Abgeschlossen ist ebenfalls die Druckvorbereitung eines Manuskriptes zu den Lampen und Webgewichten aus der Basilika in Ephesos. 


\section{Wissenschaftliche Veranstaltungen}

\section{Vorträge}

Am 7. 3. 2003 fand der Institutsabend in den Räumlichkeiten der Zweigstelle des ÖAI Athen statt. Das Programm umfaßte den öffentlichen Jahresbericht zu den Aktivitäten des Jahres 2002 von G. LADSTÄTTER sowie den Festvortrag von V. GASSNER (Institut für Klassische Archäologie der Universität Wien) mit dem Thema »Elea: Entwicklung einer großgriechischen Stadt«. Im Abschluß lud das ÖAI Athen zu einem Empfang.

Am 12. 3. 2003 hielt U. Tischler im Hause einen Vortrag zum Thema »Die perotische Gesellschaft von Istanbul im 20. Jahrhundert. Vergessene Insel des Kosmopolitismus«; organisiert wurde die Veranstaltung von der Vereinigung der Österreicher in Griechenland und dem Institut für Geschichte der philosophischen Fakultät der Universität Athen.

Am 27. 3. 2003 hielt M. Kerschner ein Hauskolloquium zum Thema »Ephesos zur Zeit der Ionischen Wanderung«.

\section{Vorträge der Institutsbediensteten}

W. Gauss, Ägina Kolonna - Materialaufarbeitung und Dokumentation. Tagung »Aufnahme, Bearbeitung und Publikation größerer Mengen an Keramikfunden aus langzeitigen Grabungsprojekten. Schwerpunkt Ägäis«, Abteilung für Klassische Archäologie der Comenius Universität in Bratislava, 28.-29. 11. 2003.

DERs., Ägina Kolonna, neue Forschungen und Ausgrabungen. Institut für Klassische Archäologie, Universität Köln, 2. 12. 2003.

Ders., Early and Middle Bronze Age pottery from Aegina Kolonna. Tagung »Arbeiten des griechischen Antikendienstes (2. Ephorie für prähistorische und klassische Altertümer) des Jahrzehnts 1994-2003《, Athen, 18. 12. 2003.

G. LADSTÄTter, Aigeira. Die Entwicklung einer antiken Stadt in Achaia/Griechenland im Spiegel der jüngeren österreichischen archäologischen Forschungen. Archäologische Gesellschaft Innsbruck, Innsbruck, 10. 4. 2003

\section{Ausstellungen, Veranstaltungen, Öffentlichkeitsarbeit}

G. LADSTÄTtER führte eine Exkursion der Universität Wien und offizielle Vertreter der Republik Österreich durch Antikenstätte in Athen und der Peloponnes.

G. Ladstätter und V. Mitsopoulos-Leon gaben Interviews für die Sendung »Forschungen am Golf von Korinth. Das Österreichische Archäologische Institut in Griechenland«, welche vom ORF Ö1 im Rahmen der Sendereihe »Dimensionen« am 15. 1. 2004 ausgestrahlt wurden.

\section{Administratives}

\section{Allgemeines}

Das Haus am Leforos Alexandras 26, welches seinerzeit auf einem vom griechischen Staat für den Bau des Österreichischen Archäologischen Instituts geschenkten Grundstück errichtet worden war, beherbergte seit der unmittelbaren Nachkriegszeit auch die österreichische Botschaft. Dieser Zustand, der anfangs als kurzfristiges Provisorium gedacht gewesen war, hatte im Lauf der Jahre zu einer immer schwieriger werdenden Situation geführt, da einerseits die gestiegenen Aktivitäten beider Institutionen zu vermehrtem Raumbedarf führten, andererseits das Sicherheitsbedürfnis der 
österreichischen diplomatischen Vertretung mit einem offenen Haus der wissenschaftlichen Kommunikation nicht in Einklang zu bringen war. 2003 ist es gelungen, dieses Problem durch die Absiedelung der österreichischen Botschaft in neue Amtsräume in der Vassilis Sofias endgültig zu lösen. Dafür gebührt den Verhandlungspartnern der zuständigen Ministerien und den freundlichen Bemühungen des Herrn Botschafters Dr. R. Pollitzer großer Dank.

D. KREIDL wurde als wissenschaftlicher Mitarbeiter und Restaurator am 1. 4. 2003 in den dauernden Ruhestand versetzt, in der Folge trat W. GAuss am 1. 10. 2003 als wissenschaftlicher Mitarbeiter seinen Dienst am ÖAI Athen an.

Am 31. 8. 2003 ging P. RiTTER als Sekretärin des Instituts in den Ruhestand, am 17. 7. 2003 trat S. KabOuRELIS in der Nachfolge ihren Dienst an.

Der Zweigstellenleiter präsentierte die Zweigstelle im Rahmen der Tagung »Eckpunkte für eine Strukturplanung/Profilierung der Archäologie in Österreich bis 2009 «, veranstaltet von der Arbeitsgruppe Profilentwicklung (bm:bwk) und vom Rat für Archäologische Forschung, Wien 17./18. 11. 2003. Darüber hinaus vertrat G. LADSTÄTTER die Zweigstelle bei Dienstleiterbesprechungen der offiziellen Vertreter der Republik Österreich in Griechenland und bei Treffen der Direktoren der ausländischen archäologischen Forschungsinstitute in Athen.

Gemeinsam mit der Sekretärin S. Kabourelis betreute G. Ladstätter die Anträge österreichischer Altertumswissenschafter für ihre Grabungen, Surveys und Forschungsvorhaben in Griechenland an das griechische Kulturministerium. Ch. SCHAUER beteiligte sich an den anfallenden Verwaltungsaufgaben des ÖAI.

2003 fanden am Institut 31 Gäste Unterkunft (309 Nächtigungen); es handelt sich um Bedienstete und Mitarbeiter des ÖAI und der Österreichischen Akademie der Wissenschaften sowie Dissertanten, Diplomanden, Mitarbeiterinnen und Mitarbeiter der Grabungen der Zweigstelle und Gäste; das Institut übernahm Hilfestellungen administrativer und wissenschaftlicher Art.

\section{Photoarchiv}

Zu den laufenden Grabungen und Forschungen des Instituts wurden die erforderlichen Photoarbeiten von K.-V. von EicKSTEDT erledigt. Dieser leistete für das Institut auch weitere allgemeine Hilfestellungen.

\section{Bibliothek}

Ch. SCHAuer erledigte die laufenden Bibliotheksarbeiten der Zweigstelle Athen. Die Bibliothek hatte im Berichtsjahr 410 Neuzugänge (422 Bände), darunter wieder zahlreiche Geschenke griechischer und in Athen ansässiger ausländischer Institutionen.

\section{Archiv}

W. Gauss konzipiert eine Neuordnung des wissenschaftlichen Archivs der Zweigstelle und erarbeitet zunächst eine Bestandsaufnahme der photographischen Hinterlassenschaft von O. WaLter. 


\section{ZWEIGSTELLE KAIRO}

$\begin{array}{ll} & \text { Personal } \\ \text { Leitung: } & \text { o. Univ.-Prof. Dr. Manfred BIETAK } \\ \text { wissenschaftliches Personal: } & \text { Dr. Irene ForStNer-MüLLER } \\ \text { Verwaltung: } & \text { Renate HasSANEIN }\end{array}$

\section{FeLdFORSCHUNGSPROJEKTE}

\section{Tell el Dabca/Avaris (Ägypten)}

Die Feldarbeiten in Tell el-Dabca wurden im Jahr 2003 vom 2. März bis 28. Mai fortgesetzt, die Herbstkampagne vom 15. September bis 11. November 2003 wurde vor allem als Studienkampagne abgehalten. Die Grabungen standen unter Leitung von M. BIETAK (stellvertretende Leitung: I. FORSTNER-MüLLER). Die ägyptische Antikenverwaltung wies im Frühjahr Ahmed Said NASAIF und Hassan Mohamed M. Soliman und im Herbst Hassan CHALIfA als Grabungsinspektoren zu.

An den Grabungen nahmen außerdem teil: als Ägyptolog(inn)en D. Aston (Keramikanalyse H/VI), P. Fuscaldo (CONICET, Argentinien, Keramikanalyse), I. HeIn (Keramikanalyse H/I, HIV, H/V), P. Janosi (Spezialprojekt H/I, H/IV) sowie N. Math, B. Toвias und Z. Toth; weiters A. Aslanidou (Freskenprojekt), N. Marinatos (University of Illinois, Chicago) und K. Palyvou (Universität Thessaloniki; beide minoische Fresken); als Archäolog(inn)en B. Nowacky, G. Philip, A. Hassler, W. Müller, F. Höflmayer und M. Aufschnarter; als Praktikant(inn)en E. Bechtold, A. Zdiarsky, H. Steiner und J. Knoll; weiters G Wiplinger (Architekt, ÖAI Wien), M. Mehofer (Metallurg), U. ThanheIser (Paläobotanikerin), J. Dorner (Geodät und Archäologe), L. W. Fliesser (Photograph), R. Seeber (Restauratorin), M. A. Negrete-Martinez (Zeichnerin), K. Grossschmidt und M. Gstettrer (Anthropologe/-in).

\section{Untersuchungen im tuthmosidischen Palastareal H/III}

In der Frühjahrskampagne 2003 wurden die Untersuchungen im tuthmosidischen Palastareal H/III an der Nordflanke des Palastes G vom Österreichischen Archäologischen Institut Kairo gemeinsam mit dem Institut für Ägyptologie der Universität Wien am Westrand des Ruinengeländes des alten Avaris wiederaufgenommen. Bei dem Areal handelt es sich um Substruktionen eines ausgedehnten Palastes (ca. $330 \times 150$ Ellen), der auf einer Plattform errichtet worden war. Basierend auf einer Eingangsrampe von 70 Ellen Länge konnte die Höhe der Substruktion der Lehmziegelmauer auf ca. 14 Ellen berechnet werden. Der Palast selbst war in der Antike bereits abgebaut worden, um Baumaterial für Projekte des späteren Neuen Reiches zu gewinnen. In dieser Saison wurde die Eingangsrampe und Landung in der Hoffnung untersucht, in gleicher Lage wie beim kleineren Palast F weitere minoische Fresken zu finden.

Die Rampenlandung fugt an die Nordost-Außenmauer des Palastes an. Rampe und Landung wurden mindestens zweimal umgebaut. Die ursprüngliche Konstruktion bestand aus einer schlammig-siltigen Mauer M 2004 von unterschiedlicher Stärke (im Süden 2,5 Ellen, sonst 2,8 Ellen), die im Kernbereich renoviert und durch eine ca. 5 Ellen breite Schlammziegelmauer M 2003 gestützt wurde. Der Bezirk war durch eine Umfassungsmauer eingefaßt. Die ursprüngliche Mauer M 2207 
(ca. 3 Ellen breit) wurde im Rahmen einer Reparatur völlig ausgerissen, der Bezirk nach Osten hin erweitert und eine neue, gleich orientierte Mauer gebaut.

Die minoischen Wandmalereien waren bislang vor allem entlang der Rampe und Landung des kleineren Palastes F und entlang eines Torwegs mit einer Portikus der Umfassungsmauer in der Nähe des Fußes der Rampe des Palastes G gefunden worden; deshalb wurde die Rampe nach weiteren Wandmalereien untersucht. Zwischen Rampenlandung und Umfassungsmauer wurde in den Verbruchschichten tatsächlich Kalkverputz gefunden, der von Decken und Böden stammte, Mattenabdrücke aufwies und ohne Bemalung war; die Fragmente werden nach gründlicher Analyse zur Rekonstruktion des oberen Stockwerks des Palastes beitragen können. Unterhalb dieser Verbruchschicht fanden sich neben vielen kleineren Verputzteilen einige aus Lehm mit Resten von Malereien von einer oder mehreren Wänden. Die Farbe war nur einen Bruchteil eines Millimeters dick. Zu erkennen waren u. a. Darstellungen eines Papyrusdickichts mit Vögeln, blaue Pflanzen mit rotem Hintergrund, Reste einer Uräus-Schlange, auf einem größeren Fragment war schemenhaft eine weibliche Figur mit reich dekoriertem Schal über dem Kopf oder die Schulterpartie mit Oberarm auszunehmen. Während die in früheren Kampagnen gefundenen Malereien auf Kalkverputz in rein minoischer Technik und Stil ausgeführt waren, zeigen die Malereien auf Lehmverputz deutlich ägyptische Motive mit minoischem Einfluß, z. B. in der Farbkonvention wie Blau für den Papyrus und andere Pflanzen oder den typisch minoischen roten Hintergrund. War Palast F mit minoischen Malereien ausgestattet, so war offensichtlich der große Palast G mit Wandmalereien in ägyptischer Technik auf Lehmputz, die jedoch deutliche minoische Einflüsse aufweisen, versehen.

Die Landung der Rampe des Palastes G erweiterte sich an ihrem Ende auf doppelte Größe. In die Außenwand der Rampe war ein Kalksteinschrein - ohne erhaltene Inschriften und Dekoration - integriert. Er war von Anfang an in die Rampenkonstruktion eingebunden; beim Umbau der Anlage blieb ein Mauerstumpf mit dem Schrein bestehen; an diesen wurde die neue Mauer angefügt. Offenbar war die Störung der Kulttätigkeit nicht erwünscht. Vor dem Schrein lag eine Steinplatte als Fundament für einen Opfertisch. Wenn auch seine Funktion nicht klar ist, ist eine Deutung als Königskultstelle wahrscheinlich.

In diesem Gebiet wurde keine frühere Bauperiode gefunden. Die Substruktionen des Palastes G ruhten auf massiven künstlichen Schüttungen aus Sand und Erde. Das 1998 im Areal H/III südlich der Grabung 2003 freigelegte Wasserleitungssystem konnte nicht weiterverfolgt werden: es änderte entweder seine Richtung, oder das Erdreich wurde in dieser Region für die Vorbereitungen zum Palastbau völlig abgegraben.

In den Schichten nach dem Verfall des Palastbezirks fanden sich abermals Spuren von Weidetätigkeit wie die Bestattungen von Ziegen, Schafen und erstmals die vollständige Bestattung eines Stieres, der in senkrechter Position in einer schmalen Grube beigesetzt worden war.

\section{Fundbearbeitung und Restaurierung}

Andere Tätigkeiten im Frühjahr 2003 umfaßten weitere Untersuchungen der minoischen Wandmalereien zur Vorbereitung der Publikation, die Untersuchung von Siegelabdrücken der vermutlichen Büros der Werkstatt W und Keramikanalysen des Palastbezirkes H/I-VI.

Die Tätigkeiten der Herbstkampagne 2003 konzentrierten sich auf die Untersuchung und Restaurierung der in den vergangenen Grabungskampagnen gewonnenen Objekte.

\section{Bronzeobjekte}

Ein Schwerpunkt dieser Kampagne lag auf der Untersuchung aller bisher ausgegrabenen Bronzeobjekte. M. Mehofer (VIAS) entnahm den einzelnen Stücken Proben zu weiteren Analysen. G. Philip (Universität Durham) konnte die Aufnahme für seinen Katalog der Bronzeobjekte von Tell el-Dabca vervollständigen und hat den betreffenden Band bereits zur Publikation vorgelegt. 
Untersuchung der minoischen Fresken von 'Ez̧bet Helmy (Grabungsareale H/I und III)

K. Aslanidou untersuchte die ornamentalen Darstellungen und rekonstruierte sie zu Friesen. Weiters stellte sie lebensgroße figürliche Darstellungen zusammen, um sie für die Restaurierung vorzubereiten. M. Negrete-Martinez - unter der Anleitung von M. Bietak - bereitete eine Computerrekonstruktion der Stierspringerfriese zur Publikation vor.

Restaurierung der ägyptischen Wandmalereien

Die im Frühling 2003 freigelegten ägyptischen Wandmalereien auf Lehmziegel wurden von R. Seeber gereinigt. Der Schwerpunkt lag auf den Darstellungen des Papyrusdickichts, der weiblichen, möglicherweise minoischen Figur und dem nb-Korb.

\section{Keramikbearbeitung}

D. Aston untersuchte die Keramik der späten Tuthmosidenzeit aus den Straten über dem tuthmosidischen Palast. P. Fuscalodo setzte ihre Untersuchung des Materials der früheren Phasen der 18. Dynastie und der Hyksoszeit in Areal H/VI fort. I. Forstner-Müller nahm mit Hilfe von A. Hassler und F. Höflmeyer das Keramikmaterial des späten Mittleren Reiches in Areal A/II auf. Zweck dieser Untersuchung war die Erforschung der Handelskontakte dieser Zeit.

Botanik

Die Paläobotanikerin U. Thanheiser (VIAS) untersuchte die organischen Reste nach Botanikproben und bereitete gemeinsam mit I. Forstner-Müller die einjährigen Samen zu ${ }^{14} \mathrm{C}$-Untersuchungen vor.

\section{Sonstige wissenschaftliche Untersuchungen}

Gemeinsam mit dem VIAS-Institut wurde ein Forschungsprojekt zum Scannen der Cheopspyramide initiiert. Aus diesem Grund erfolgte im November 2003 eine Begehung vor Ort durch I. FORSTNer-Müller und W. Neubauer.

Von 1.-5. August arbeitete M. BIETAK in den Magazinen der Grabungen auf Akrotiri/Thera, um spätkykladische Keramik zu studieren und um über die dortigen Fortschritte der Freskenrekonstruktion und Restaurierung informiert zu sein.

Anfang Oktober 2003 unternahmen M. Bietak, I. Forstner-Müller und W. MüLLER eine Studienreise nach Syrien, wobei die laufenden Grabungen in Ebla (Leiter P. MATTHIAE, Universität Rom), Qatna (Leiter P. PfäLzner, Universität Tübingen und M. LuZZiani, Universität Udine) und Aleppo (K. Kohlmeyer, Berlin) besucht wurden, um Palastmalerei, Architektur und die materielle Kultur der Mittleren Bronzezeit dieser Grabungen zu studieren sowie Kooperationen mit den Teams für das SCIEM-Projekt zu vereinbaren.

Im November 2003 unternahm I. Forstner-Müller eine Studienreise nach Luxor/Theben, mit dem Ziel, die Keramik des Mittleren Reiches und der Zweiten Zwischenzeit der Grabung des Deutschen Archäologischen Instituts in Dra' Abu-l-Naga zu untersuchen und Kooperationen mit dem Team des Deutschen Archäologischen Instituts und Kollegen des Centre Franco Egyptien des Temples du Karnak sowie des Institut français d'archéologie orientale zu vereinbaren.

\section{WissenschaftLiche Veranstaltungen}

\section{Ausstellungen, Veranstaltungen und Öffentlichkeitsarbeit}

Am 12. Mai wurde von I. ForstNer-MülLer die BBC-Dokumentation »Auf den Spuren von Moses« wissenschaftlich betreut.

Sowohl die 2nd EuroConference des SCIEM 2000 (Wien, 28. 5.-1. 6. 2003) wie auch die anschließende Konferenz »Hyksos Culture«. Kulturkontakt und Innovation - Der Einfluß der Hyksos auf das Neue Reich (Wien, 4.-8. 6. 2003) wurden unter Mitwirkung des ÖAI Kairo organisiert. 
Das ÖAI Kairo arbeitete auch 2003 eng mit dem Spezialforschungsbereich SCIEM 2000 der Österreichischen Akademie der Wissenschaften, mit dem Institut für Ägyptologie und dem Vienna Institute of Archaeological Sciences der Universität Wien (VIAS) sowie mit der ägyptischen Altertümerverwaltung zusammen; außerdem mit dem Deutschen, dem Französischen und dem Polnischen Archäologischen Institut in Kairo.

\section{Vorträge und Posterpräsentationen}

M. BiEtak, Avaris, from the Hyksos Period to the Eighteenth Dynasty. Hebräische Universität in Jerusalem.

Ders., Near Eastern Temples in Egypt. »Early Temples.« A workshop at the Netherlands-Flemish Institute of Archaeology and Arabian Studies in Cairo (gelesen von I. Forstner-Müller), 9.-10. 1. 2003.

Ders., The Minoan Paintings at Tell el-Dabca, The SCIEM 2000 Late Bronze Age Conference. Wien, Österreichische Akademie der Wissenschaften, 30. 1.-1. 2. 2003.

DERs., Ägyptologie als Beispiel eines kleinen Faches mit hohem Forschungsauftrag. Kleine Fächer an Österreichs Universitäten. Konferenz der Österreichischen Forschungsgemeinschaft in Mödling, 14.-15. 3. 2003

DERs., The Beautiful Festival of the Valley in Thebes. Ägyptische Altertümerverwaltung, Ägyptisches Museum Kairo.

DERS., Is a consensus in the Aegean Bronze Age chronology possible? 2nd EuroConference SCIEM 2000. Wien, Österreichische Akademie der Wissenschaften, 28. 5.-1. 6. 2003.

Ders., The continuation of the Hyksos craftsmenship in the New Kingdom. Konferenz »Hyksos Culture«, Wien, Österreichische Akademie der Wissenschaften, 4.-8. 6. 2003.

DERS., War Peru-nefer in Avaris? Ständige Deutsche Ägyptologenkonferenz, Universität Basel, 11.-13. 7. 2003 (inkl. Teilanahme an der Podiumsdiskussion).

Ders., Das Institut für Ägyptologie, das Österreichische Archäologische Institut in Kairo, das Vienna Institute of Archaeological Sciences. Profilbildung: Archäologie an Österreichischen Universitäten. Wien, Österreichischen Akademie der Wissenschaften., 17.-18. 11. 2003.

Ders., Neue Ausgrabungsergebnisse in Tell el-Dabca/cEzbet Helmi, Universität München.

Ders., The Egyptian Military and Naval Stronghold Peru-Nefer, was it in Avaris? WinckelmannVorlesung am Deutschen Archäologischen Institut Kairo.

I. Forstner-Müller, The Colonization/Urbanization of the Tell Area A II at Tell el-Dab a and its chronological implications. 2nd EuroConference SCIEM 2000. Wien, Österreichische Akademie der Wissenschaften, 28. 5.-1. 6. 2003.

\section{Administratives}

\section{Allgemeines}

G. WiPLINGER sanierte den Bad- und WC-Trakt im Wohntrakt des Grabungshauses. Aufgrund des gesteigerten Bedarfs wurde ein Arbeitsraum zu einem Computerraum umfunktioniert. Die Solaranlage und das Dach der Garage wurden repariert, der Balkon für die minoischen Fresken neu gestrichen.

Der Schwerpunkt der Tätigkeiten am Institut in Kairo lag auf der Erneuerung der EDV-Ausrüstung. Die Computerausrüstung konnte auf vier PC für das Institutspersonal und wissenschaftliche Mitarbeiter aufgestockt werden; das System wurde vereinheitlicht, von W. MüLLER wurde ein Netzwerk aufgebaut.

2003 wurden die Sanierungsarbeiten für die Jubiläumsfeier 2004 begonnen: Adaptierungen in vier Räumen wurden vorgenommen, die alte Wasserpumpe konnte endlich durch eine neue ersetzt werden. 
Durch die zunehmenden wissenschaftlichen und organisatorischen Tätigkeiten des Instituts wurde eine zusätzliche Mitarbeiterin zur Abwicklung der Organisation notwendig: S. MAHMOUD erledigt aufgrund ihrer Sprachkenntnisse die arabische Korrespondenz, insbesondere mit den Behörden.

\section{Bibliothek}

In der Bibliothek der Zweigstelle waren dringende, lange anstehende Arbeiten notwendig: Eine Bestandsaufnahme der Bibliothek, die in früheren Jahren stark vernachlässigt worden war, wurde begonnen. Für die Eingabe der Daten konnte D. SHANOurBI gewonnen werden.

Um Kosten für die knapp budgetierte Bibliothek im Rahmen zu halten, vereinbarte das ÖAI einen Büchertausch mit dem IFAO (Institut français d'archéologie orientale) und dem ARCE (American Research Center in Egypt). 


\section{BiBLIOGRAPHIE 2003}

Die Bibliographie umfaßt die im Jahr 2003 erschienenen Publikationen von Institutsangehörigen und Projektmitarbeiterinnen und -mitarbeitern sowie Berichte über Untersuchungen, welche mit finanzieller Unterstützung des ÖAI stattfanden.

\section{Im Verlag des ÖAI erschienen}

A. Kaltenberger, Mittelalterliche bis frühneuzeitliche Keramik aus Mautern an der Donau, 4. ErgÖJh (2003).

\section{In Zusammenarbeit mit dem Verlag des ÖAI erschienen}

H. Bender - G. Moosbauer, unter Mitarbeit von U. Brandl und E. Herzog, Das römische Donaukastell Schlögen in Oberösterreich. Die Funde aus den Grabungen 1957-1959, 1984 und die Altfunde, Passauer Universitätsschriften zur Archäologie 8 (2003).

\section{In Zusammenarbeit mit dem Verlag der ÖAW erschienen}

Jahreshefte des Österreichischen Archäologischen Institutes in Wien 72, 2003 (erschienen im April 2004).

C. Lang-Auinger (Hrsg.), Hanghaus 1 in Ephesos. Funde und Ausstattung, FiE VIII 4 (2003).

M. DAwID, Die Elfenbeinplastiken aus dem Hanghaus 2 in Ephesos. Räume SR 18 und SR 28, FIE VIII 5 (2003).

\section{Herausgegeben von Mitarbeiter(inne)n des ÖAI}

M. BietaK - H. Hunger (Hrsg.), Contributions to the Chronology of the Eastern Mediterranean. The Synchronisation of Civilisations in the Eastern Mediterranean in the Second Millennium BC, II. Proceedings of the SCIEM 2000-Euro Conference, Haindorf, 2.-7. May 2001, IV (2003).

M. Šašel Kos - P. Scherrer (Hrsg.), The Autonomous Towns in Noricum and Pannonia - Die autonomen Städte in Noricum und Pannonien, II: Pannonia, Situla 41 (2003).

E. Weber - P. Scherrer - G. Fitz (Hrsg.), RÖ 25, 2002.

\section{Bruckneudorf (Burgenland)}

H. ZABEHLICKY, Bruckneudorf, FÖ 41, 2002 (2003) 637 f.

\section{Carnuntum (Niederösterreich)}

M. Kandler (gemeinsam mit F. Humer), Carnuntum, AÖ 14/1, 2003, 4-27.

Ders. (gemeinsam mit U. Zimmermann), Petronell, Auxiliarkastell 2002, FÖ 41, 2002 (2003) 661 f.

Ders., Carnuntum, castellum, in: Zs. Visy (Hrsg.), The Roman Army in Pannonia (2003) 58-60.

P. SCHERrer, Carnuntum, in: Ch. Trümpler (Hrsg.), Flug in die Vergangenheit (Ausstellungskat. Ruhrlandmuseum Essen 2003) 55.

\section{Flavia Solva (Steiermark)}

St. Groh, KG Seggauberg, FÖ 41, 2002 (2003) 683-684.

Ders. - H. Sedlmayer, Die Grabungen 2003 im Tempelbezirk des Frauenberges bei Leibnitz, Sprechende Steine. MblFlavSolv 1/2003, 10-17.

\section{St. Pölten (Niederösterreich)}

A. Pedit-Bodvay - R. Risy - P. Scherrer, Die Römer in St. Pölten. Eine Zukunft für die Vergangenheit. Mit Beiträgen von Marianne Kudlich, Michael Walder \& Tobias Zucali, Doris Zichtl, Kata Oberleitner, anna/cello.designers, Johanna Doerfel und Monika Rycerz, CarnuntumJb 2002, 99-130.

R. RisY, Guts- und Bauernhöfe im westlichen Niederösterreich, in: St. Traxler, Römische Guts- und Bauernhöfe in Oberösterreich, Passauer Universitätsschriften zur Archäologie 9 (2003) 203-209.

DERS., Die archäologische Erforschung im ehemaligen Chorherrenstift, dem heutigen Bistumsgebäude. Ein Überblick, in: St. Pölten. Landeshauptstadt und Zentralraum, Denkmalpflege in Niederösterreich 30, 2003, 13-14. 
Ders., SG St. Pölten, KG St. Pölten, FÖ 41, 2002 (2003) 665-666.

Ders., SG St. Pölten, KG St. Pölten, FÖ 41, 2002 (2003) 714.

P. Scherrer, St. Pölten, FÖ 41, 2002 (2003) 663-665.

Ders., Rathaus auf römischem Boden, in: 500 Jahre Rathaus St. Pölten, Kulturjahrbuch St. Pölten (2003) 5-9.

\section{Zwentendorf (Niederösterreich)}

M. Doneus - W. Neubauer - St. Groh - K. Löcker - S. Seren, Prospecting the Roman military camp of Zwentendorf, Austria, Archaeologia Polona 41, 2003, 143-146.

\section{Tell el-Dabca (Ägypten)}

M. Bietak, Temple or 'Bêt Marzeah'?, in: W. G. Dever - S. Gitin (Hrsg.), Symbiosis, Symbolism and the Power of the Past: Canaan, Ancient Israel and their Neughbors, From the Late Bronze Age through Roman Palestine. The W. F. Albright Institute of Archaeological Research and the American Schools of Oriental Research Centennial Symposium, Israel Museum, Jerusalem, May 29-31, 2000 (2003) 155-168.

Ders., Two Ancient Near Eastern Temples with Bent Axis in the Eastern Nile Delta, AegLev 13, 2003, 13-38.

Ders., Israelites found in Egypt, Biblical Archaeology Review 19/5, 2003, 40-42. 82-83.

Ders., Science versus Archaeology: Problems and Consequences of High Aegean Chronology, in: M. Bietak - H. Hunger (Hrsg.), Contributions to the Chronology of the Eastern Mediterranean. The Synchronisation of Civilisations in the Eastern Mediterranean in the Second Millennium BC, II. Proceedings of the SCIEM 2000-Euro Conference, Haindorf, 2.-7. May 2001, IV (2003) 23-33.

Ders. - I. Forstner-MülLer, Ausgrabungen im Palastbezirk von Avaris, Vorbericht Tell el-Dabca/cEzbet Helmi 2003, AegLev 13, 2003, 39-50.

Ders. - N. Marinatos, The Minoan Paintings of Avaris, in: B. Manley (Hrsg.), The Seventy Great Mysteries of Ancient Egypt (2003) 166-169.

I. ForstNer-Müller, Review of H. Willems (Hrsg.), Social Aspects of Funerary Culture in the Egyptian Old and Middle Kingdoms, OLZ 98, 2003, 606-612.

Dies., Gräber und Grabkult des späten Mittleren Reiches und der Zweiten Zwischenzeit im Ostdelta. Proceedings of the congress »Totenreligion im Niltal und im Vorderen Orient«, Berlin, AOF 12, 2003, 140-170.

Dies., Continuity and Discontinuity- Attempting to establish the Beginning of the Hyksos Period at Tell el-Dabca, in: M. Bietak - H. Hunger (Hrsg.), Contributions to the Chronology of the Eastern Mediterranean. The Synchronisation of Civilisations in the Eastern Mediterranean in the Second Millennium BC, II. Proceedings of the SCIEM 2000-Euro Conference, Haindorf, 2.-7. May 2001, IV (2003) 163-174.

\section{Ephesos (Türkei)}

M. Aurenhammer, Skulpturen aus Stein und Bronze, in: C. Lang-Auinger (Hrsg.), Hanghaus 1 in Ephesos. Funde und Ausstattung, FiE VIII 4 (2003) 153-208.

J. Auinger, Ein Büstenkronenfragment aus Ephesos, in: B. Asamer - W. Wohlmayr (Hrsg.), Akten des 9. Österreichischen Archäologentages, Salzburg 2001 (2003) 15-20.

DIEs., Eine spätantike Togabüste aus Balçova, ÖJh 72, 2003, 15-28.

D. Boulasikis, Das sogenannte Freudenhaus zu Ephesos, ÖJh 72, 2003, 29-40.

M. BüYÜKKolAnCI - E. TrinkL, Ein Marmorrelief mit der Darstellung einer Säge, Forum Archaeologiae 26/III/2003 (http://farch.net).

A. Giuliani, Die hellenistischen Tonlampen der Tetragonos-Agora in Ephesos. Forum Archaeologiae 26/III/2003 (http://farch.net).

St. GroH, Integrated prospection in the Upper Town of Ephesus, Turkey - a case study, Archaeologia Polona 41, 2003, 185.

Ders., Auxiliarkastell Mautern-Favianis (hhtp://www.dieuniversitaet-online.at; Ausgabe vom 9. 9. 2003).

Ders. - W. Neubauer, Einsatz eines terrestrischen 3-D-Laser-Scanners in Ephesos, ÖJh 72, 2003, 111-122.

R. Hanslmayr, Zum Bedeutungswandel des griechischen Hermenmals in römischer Zeit am Beispiel Ephesos, Forum Archaeologiae 29/XII/2003 (http:// farch.net).

Dies., Der spätantike Hermenzaun vom Nymphäum Traiani - eine Planetenbalustrade?, in: B. Asamer - W. Wohlmayr (Hrsg.), Akten des 9. Österreichischen Archäologentages, Salzburg 2001 (2003) 63-68.

M. Heinz, Rezension zu J. Stroszeck, Löwensarkophage, ASR VI 1 (1998), AnzAW 56, 2003, 248 ff.

St. KARiwiese, Liste der Fundmünzen aus den Grabungen im Hanghaus 1 von Ephesos 1960 bis 1998, in: C. Lang-Auinger (Hrsg.), Hanghaus 1 in Ephesos. Funde und Ausstattung, FiE VIII 4 (2003) 340-355.

M. Kerschner, Stratifizierte Fundkomplexe der geometrischen und subgeometrischen Epoche aus Ephesos, in: B. Rückert - F. Kolb (Hrsg.), Probleme der Keramikchronologie des südlichen und westlichen Kleinasiens in geometrischer und archaischer Zeit. Internationales Colloquium Tübingen 24. 3.-26. 3. 1998, Antiquitas Reihe 3, Bd. 44 (2003) 43-59 Abb. 1-9. 
Ders., Zum Kult im früheisenzeitlichen Ephesos. Interpretation eines protogeometrischen Fundkomplexes aus dem Artemisheiligtum, in: B. Schmaltz - M. Söldner (Hrsg.), Griechische Keramik im kulturellen Kontext, Akten des Internationalen Vasen-Symposions in Kiel 24.-28. 9. 2001 (2003) 246-250.

G. KLEBInder-Gauss, Zu Bronzewerkstätten im früharchaischen Artemision von Ephesos, Forum Archaeologiae 27/VI/ 2003 (http://farch.net).

Dies., Zwei bronzene Doppeläxte aus dem Artemision von Ephesos, ÖJh 72, 2003, 133-140.

St. KLoTZ, Photogrammetry in Ephesos - Recording Basic Spatial Data, in: O. Altan (Hrsg.), Proceedings of the XIXth International Symposium CIPA 2003 - New Perspcetives to Save Cultural Heritage, Antalya (Turkey) 30. 9-4. 10. 2003 (2003) 656-659.

Ders., Ephesos. Auswertung und Anwendung von Geodaten, in: B. Asamer - W. Wohlmayr (Hrsg.), Akten des 9. Österreichischen Archäologentages, Salzburg 2001 (2003) 103-105.

F. Krinzinger, Ausgrabung Ephesos. Forschungsbericht 2001, in: XXIV. Kazı Sonuçlar1 Toplantıs1 II (2003) 491-508.

G. Plattiner, Korinthische Kapitelle der frühen und mittleren Kaiserzeit aus Ephesos, in: B. Asamer - W. Wohlmayr (Hrsg.), Akten des 9. Österreichischen Archäologentages, Salzburg 2001 (2003) 157-160.

A. M. PüLZ, Zu den Goldappliken aus dem Artemision von Ephesos und ihrer Verwendung, Forum Archaeologiae 28/ IX/2003 (http://farch.net).

Ch. Rogl, Hellenistische Keramik aus den Grabungen auf der Tetragonos-Agora. Ein mittelhellenistischer Fundkomplex, in: B. Asamer - W. Wohlmayr (Hrsg.), Akten des 9. Österreichischen Archäologentages, Salzburg 2001 (2003) 175-182.

DiEs., Späthellenistische Applikenkeramik und Verwandtes aus Ephesos. Lokale Produktion - Einflüsse - Importe, ÖJh 72, 2003, 187-206.

M. STESKAL, Bemerkungen zur Funktion der Palästren in den ephesischen Bad-Gymnasium-Komplexen, ÖJh 72, 2003, $227-239$

Ders. - K. Grossschmidt - M. Heinz - F. Kanz - H. Taeuber, Die Damianosstoa in Ephesos. Bericht über die Ausgrabung 2002 im Abschnitt Kathodos III, ÖJh 72, 2003, 227-239.

E. TrinkL, Artefakte für die Textilverarbeitung aus den Hanghäusern in Ephesos. Überlegungen zur gesellschaftlichen Stellung kleinasiatischer Frauen, Forum Archaeologiae 29/XII/2003 (http://farch.net).

Dies., Schwarzfirniskeramik klassischer Zeit aus Ephesos. Ein Einblick in eine lokale Produktion, in: B. Asamer - W. Wohlmayr (Hrsg.), Akten des 9. Österreichischen Archäologentages, Salzburg 2001 (2003) 227-230.

DiEs., Griechische Töpfer in Kleinasien in klassischer Zeit - Die ephesische Evidenz, in: B. Schmaltz - M. Söldner (Hrsg.), Griechische Keramik im kulturellen Kontext. Akten des Internationalen Vasen-Symposions in Kiel vom 24.-28. 9. 2001 (2003) 74-76.

P. Turnovsky, Glaslampen aus der Marienkirche in Ephesos, in: B. Asamer - W. Wohlmayr (Hrsg.), Akten des 9. Österreichischen Archäologentages, Salzburg 2001 (2003) 237-241.

M. WeIssL, Altäre im Artemision von Ephesos, Forum Archaeologiae 29/XII/2003 (http:// farch.net).

G. Wiplinger, Die Wasserver- und -entsorgung in Wohneinheit 1 und 2 des Hanghauses 2 in Ephesos, in: Ch. Ohlig u. a. (Hrsg.), Cura Aquarum in Israel (2003) 155-166.

\section{Limyra (Türkei)}

Th. MArksteiner, Limyra 2002, Anadolu Akdenizi Arkeoloji Haberleri 2003/1, 20-22.

Ders., Das Territorium der ostlykischen Polis Limyra, in: F. Kolb (Hrsg.), Chora und Polis: Methoden und Ergebnisse der historischen Landeskunde, Kolloquium des Historischen Kollegs in München (2003) 271-290.

\section{Varia}

P. Donat - S. Sakl-Oberthaler - H. Sedlmayer, Die Werkstätten der canabae legionis von Vindobona. Befunde und Funde der Grabungen Wien 1, Michaelerplatz (1990/1991) - Teil 1, FWien 6, 2003, 4-57.

K. Herold, Jupiter-Dolichenus Tafel, KHM, Forum Archaeologiae 26/III/2003 (http://farch.net).

M. KAndLeR, Die Kavallerie im Heer der römischen Kaiserzeit. Mit dem Pferd bis an den Limes (Ausstellungskat. Steirische Landesausstellung »Mythos Pferd«, Piber 2003) 84-93.

Ders., Emil Reisch, Neue Deutsche Biographie 21, 2003, 383 f.

DERs., Wagen und Spuren - Zur Geschichte der Geleisestraßen, in: H. Lachmayer - P. Plica (Hrsg.), Über die Schwelle (2003) 55-68.

St. KARWIESE, NOCHMALS PEION, Forum archaeologiae 28/IX/2003 (http:// farch.net).

Ders., Numismatik als antiquarische Fundgrube: Kleroi, Äpfel oder Preisgelder, in: B. Asamer - W. Wohlmayr (Hrsg.), Akten des 9. Österreichischen Archäologentages, Salzburg 2001 (2003) 97-101.

Ders., SG Salzburg, KG Salzburg, Klosterbezirk St. Peter, Grabung 2001, FÖ 41, 2002 (2003) 671-675.

Ders., Numismatischer Kalender 3000 Jahre OLYMPIA (gemeinsam mit W. Szaivert).

F. KRINZINGER, In memoriam Bernhard Neutsch, ÖJh 72, 2003, 13 f.

H. NoedL - E. TrinkL, The Austrian Electronic Journal 'Forum Archaeologiae' (http//farch.net) - Using New Media for the Presentation of Archaeological Content, in: E. Riedling (Hrsg.), VIEWDET 2002. Vienna International Working Conference - eLearning and eCulture, 4.-6. Dec. 2002 (2003) 125-129. 
P. Pingrtzer, Die Jupiter-Dolichenus Tafel von Traismauer, Niederösterreich. Konservierung - Technologie - Rekonstruktion, Forum Archaeologiae 26/III/2003 (http:// farch.net).

G. A. Plattiner, Ost und West. Römische Architekturen in Kleinasien, Forum Archaeologiae 29/XII/2003 (http:// farch.net).

Ch. Schauer, Fundgruppen archaischer und klassischer Zeit aus dem Bereich des Prytaneion, in: H. Kyrieleis, XII. Bericht über die Ausgrabungen in Olympia (2003) 156-206 Taf. 1-23.

P. Scherrer, Savaria, in: M. Šašel Kos - P. Scherrer (Hrsg.), The Autonomous Towns in Noricum and Pannonia - Die autonomen Städte in Noricum und Pannonien, II: Pannonia, Situla 41 (2003) 53-80.

H. Sedlmayer, Vasellame bronzeo nel territorio di Virunum, in: G. Cuscito - M. Verzár-Bass (Hrsg.), Bronzi di età romana in Cisalpina. Novità e riletture. Atti della XXXII Settimana di Studi Aquileiesi, 28-30 maggio 2001, Antichità Altoadriatiche 51 (2002) 363-378.

DiEs., Keramik aus einer frühneuzeitlichen Verfüllung und aus einem biedermeierzeitlichen Malerwerkplatz, in: P. Donat, Von einem biedermeierzeitlichen Malerwerkplatz zu den möglichen Hinterlassenschaften einer römischen Keramikwerkstatt am Wiener Michaelerplatz, FWien 6, 2003, 71-73.

U. Sinn - Ch. Leypold - Ch. Schauer, Olympia - eine Spitzenstellung nicht nur im Sport. Eine neuentdeckte Badeanlage der hellenistischen Zeit, AW 6, 2003, 617-623.

M. WeIssL, Griechische Torgottheiten, in: B. Asamer - W. Wohlmayr (Hrsg.), Akten des 9. Österreichischen Archäologentages, Salzburg 2001 (2003) 243-247.

H. Zabehlicky (gemeinsam mit W. VetTers), Der lange Winter der Römer, in: Terra Nostra. Schriften der Alfred-WegenerStiftung 2003/6, 453-455. 


